University of Rhode Island

DigitalCommons@URI

Open Access Master's Theses

1969

\title{
The Development and Implementation of a Central Hospital Transportaion System
}

\author{
William Andrews \\ University of Rhode Island
}

Follow this and additional works at: https://digitalcommons.uri.edu/theses

\section{Recommended Citation}

Andrews, William, "The Development and Implementation of a Central Hospital Transportaion System" (1969). Open Access Master's Theses. Paper 1345.

https://digitalcommons.uri.edu/theses/1345

This Thesis is brought to you for free and open access by DigitalCommons@URI. It has been accepted for inclusion in Open Access Master's Theses by an authorized administrator of DigitalCommons@URI. For more information, please contact digitalcommons-group@uri.edu. 


\title{
RA976 \\ A 63
}

\section{THE DEVELOPMENT AND IMPLEMENTATION OF A}

CENTRAI HOS PITAL TRANS PORTATION SYSTEM

$$
\text { by }
$$

William Andrews

\begin{abstract}
A THESIS SUBMITTED IN PARTIAL FULFILLMENT OF THE REQUIREMENTS FOR THE DEGREE OF MASTER OF SCIENCE IN INDUSTRIAL ENG INEER ING
\end{abstract}


MASTER OF SCIENCE THESIS

OF

WILLIAM RUSSELL ANDREWS

Approved:

Thesis Committee:

Chairman

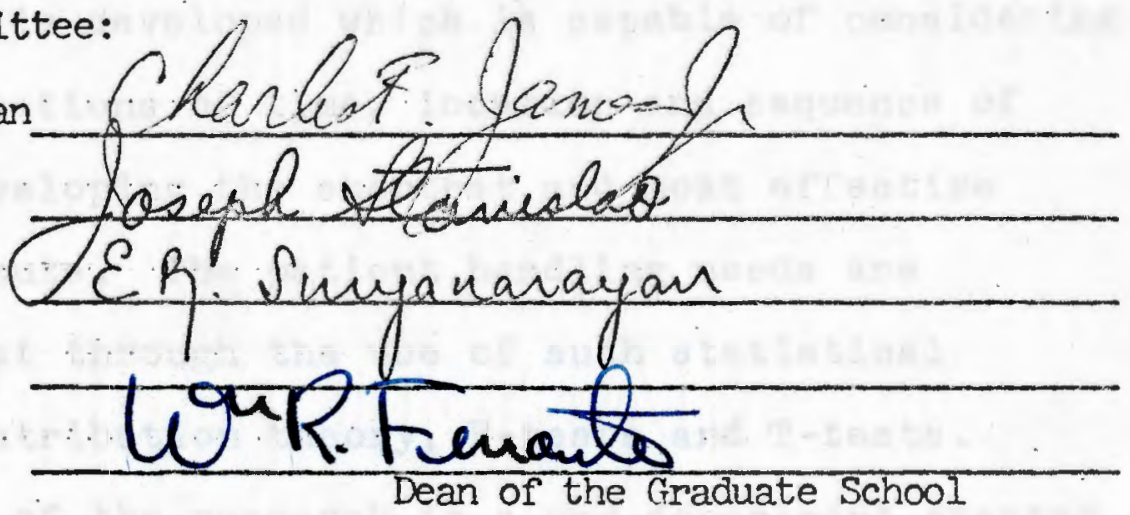

UNIVERSITY OF RHODE ISLAND

1969 
THESIS ABSTRACT

The problem involved in the thesis is the design, development and implementation of a hospital central transportation system. The system as developed must meet the following requirements:

I) It must be centrally located and transport paper, products and patients within the hospital.

2) It must be able to meet the scheduling and routing requirements of the hospital departments.

3) It must be an improvement on the present system both economically and functionally.

The major disciplines followed for the solution to the problem are systems analys is and operations research. A computer program is developed which is capable of considering the various Iimitations of time, location and sequence of operation; in developing the shortest and most effective transportation route. The patient handing needs are determined and met through the use of such statistical techniques as distribution theory, F-tests and T-tests.

The results of the research is a new department created at the Memorial Hospital of Pawtucket, Rhode Island, capable of satisfying the transport demands of the hospital. The computer program is flexible enough to have wide application in any hospital or any industrial situation with similar circumstances. 


\section{A CKNOW'LEDGMENT}

The results of this research are made possible through the generous financial assistance of the Memorial Hospital of Pawtucket, Rhode Island, and the technical assistance and encouragement of the Computer Science Department and Industrial Engineering Departments of the University of Rhode Island. The development of the program was made possible through the dedicated effort of Mrs. Barbara Randall, whose outstanding work is greatly appreciated. 


\section{TABLE OF CONTENTS}

,PAGE

List of Tables

List of Illustrations

Introduction

4

Objective

CHA PTER

I Problem defined

II Requirements of a computer program

III Development of the computer program

IV Results of the computer program

V Projected functions

VI Patient handling problem defined

VII Requirements of patient handling

41

VIII Theory application and results

43

IX Economic analysis of the delivery system

54

A.PPENDIX

COMPUTER PROGRAM

DATA

FLOW DIAGRAMS 


\section{LIS I OF TABLES}

TABLE

PAGE

1. Computed Route

2. Computed Route (con't).

3. Computed Route (con't)

4. Computed Route (con't)

5. Central Transportation Operation

6. Central Transportation Schedule 8:15 A.M. Route

7. Central Transportation Schedule 11:00 A.M. Route 64

8. Central Transportation Schedule 2:30 P.M. Route 65

9. Number of Patients Served in X-Ray NovemberDecember 1967

10. Number of Patients Served in $X$-Ray JanuaryFebruary 1968

11. Number of Patients Admitted and Discharged by Month

12. Number of Patients $\$$ dmitted and Discharged by Unit

13. Number of Patients Sasved by Physical Therapy 70

14. Number of Patients Served in X-Ray October 196771 
15. Calculation of Standerd Deviation for 9-10, 10-11, and 11-12 Hour Intervals

16. Calculation of Standard Deviation for 12-1

Hour Interval

17. Calculation of Standard Deviation for $1-2$ and 2-3 Hour Intervals

18. $x$ Square test for the $9-10,10-11$ and $14-12$ Hour Intervals

19. Square Test for the 12-1 Hour Interval 76

20. 7 Square Test for the $1-2$ and $2-3$ Hour Intervals 77

21. $x$ Square Significance Test 78

22. X-Ray Move Time 79

23. Physical Therapy Move Time 80

24. Admitting Move Time 81

25. Discharge Move Tine 82

26. Average Times for Each Hour Interval 83

27. Manpower Requirenents 84

28. Transportation Cost Breakdown 85

29. Transportation Cost Breakdown (con't) 86

30. Transportation Cost Breakdown (con't) 87

31. Manpower Potential 88 


\section{LIST OF IILUSTRATIONS}

FIGURE

PAGE

1. Memorial Hospital of Pawtucket

2. Transportation Receipt 90

3. Hourly Breakdown of Patient Noves 91

4. Frequency Distribution for 9-10, 10-11 and 11-12 Hour Intervals 92

5. Frequency Distribution for 12-1 Hour Interval 93

6. Frequency Distribution for $1-2$ and $2-3$ Hour Intervals $\quad 94$

7. Calculation of Standard Deviations 95

8. Square Tests on Hour Intervals 96

9. F-Test and T-Test Between Discharge-Admitting 97 


\section{INTRODUCTION}

The application of industrial principles and techniques to those situations which are not completely analogous to production systems, but which nevertheless require the use of efficient and economical means in order to function to their optimum peak, has opened an affluent realm to the Industrial Engineer.

The economic situation that exists at a hospital is one which is quite the reverse of that of industry. Instead of being positively motivated towards profits, the hospital instead is established in a framework of cost reduction. Few if any hospitals show a profit, but rather attempt to achieve a minimum operating cost.

In particular, within the last four years, hospltals have been a prime consumer of industrial engineering services. Hospital systems have developed from the Alms House and have been plagued to the present decade by untrained and many cases inexperienced doctor-administrators, whose primary function was the care of patients and secondary, administrating effectively to the physical problems of the hospital itself.

An important factor to be considered, however, is that hospitals provide a service which often means life 
or death to the consumer. The industrial concern on the other hand deals with an inert object whose product quality is usually less critical. Arbitrary decisions are more easily made and the result of a poor decision is measured in terms of money. Hospital staffs have as their major goal the attempt to save or prolong all human life with less regard for costs. Should hospltals make decisions to cut back on spending impairing the services they provide? No, all departments and systems within a hospital should make a concentrated effort to use effectively and efficiently physical and monetary resource available to them, thus reducing or holding the line on operating costs while maintaining or advancing the present quality standards.

Good hospital care and efficient and economical hospital procedures go hand in hand; rising costs, and new medical methods and equipment have emphasized this fact.

It is in this sense that the Memorial Hospital of Pawtucket has financed a joint project with the University of Rhode Island, the purpose being the improvement of systems and procedures at the hospital. 
OB JECT IVE

The proposed research is the design, development and implementation of a central transportation system for the Memorial Hospital of Pawtucket.

A central transportation system is a centrally located department, the function of which is to provide the means of transport for anything that requires movement from one department or unit to another. Basically, such a department will have a department head, whose primary function and responsibility will be the proper and smooth running of the transportation system; a dispatcher, who will recelve and log all in-coming calls and assign such orders to the messengers as is necessary to fulfill the transporting demands of the various departments and units.

The central transportation system shall be required to provide all intra and inter-hospital transportation. Not only shall the primary purpose of this project be the design and development of such a system, but also the smooth implementation that is so important for the study to be a success. This will require on the spot changes as well as anticipation of future problems.

It is also the purpose herein to evaluate the system as to its capabilities of handling the present hospital 
demands as well as any future demands resulting from change or innovation.

The final phase is a financlal judgement on the effectiveness of the system and the importance of its role in the hospital framework. 


\section{PROBLEM DEFINED}

Initially, there existed no type of central transportation system at the Memorial Hospital of Pawtucket. Transport services were provided internally by the departments. Usually there was no particular person whose function was to transport articles from his or her own department to others. This was true within the business and administration departments. The person who was least busy or was traveling in the proper direction made the delivery.

of course, there were exceptions, a green aide provided transportation service to the nursing units and closely related departments. She made three trips daily; one in the morning, one in the late morning and early afternoon, and one in the late afternoon. These three rounds handed a large portion of the transportation, but was quite limited. Time sheets, pay checks, medical information and lab reports were given close attention and were delivered promptly and regularly.

Whth such departments as Central Supply, Laundry, Addressograph, and Equipment Room, delivery is an integral part of their function. In sorne of these cases, a certain knowledge or skill is necessary in order to effectively transport. The Central Supply and Laundry Transporters must be familiar with nursing unit inventories. The 
Equipment Room attendant must accompany his equipment in order that it may be set up properly, being the only one available with this knowledge. Thus, it is necessary in these departments that they maintain some form of control over the delivery of their product.

The transporting of patients is done by orderlies, green aides, volunteers and nurses. Orderlies are not assigned a particular floor, but are dispatched frorn a central area in the nursing administration department. The services of the "floaters" may be obtained by phoning nursing administration. Permanent orderlies are assigned to the operating room and the accident room.

Patient transporting will be discussed later in more detail. This will, however, serve as a very brief picture of the transporting network presently in operation.

From the previous discussion, it is obvious that the transporting needs of the hospital can be broken down to three general categories: patients, products, and papers. Included in the categories are:

1) patients-persons either dead or allve moving to or from the nursing units or other servicing departments.

2) products-articles such as laundry, central supply items, storeroom supplies, drugs, lab specimens, and large volumes or bulk amounts of paper. 
3) papers - Include intra-hospital communications, mail, medical and lab reports and any other administrative, nursing or service department business papers.

The transporting needs of the hospital are divided in this manner for a most obvious reason. Each of the categories and the articles included in them require different types of transporting.

Examination of survey data Indicated that much of the paper transporting was done dally by the same departments or units and at approximately the same time of the day. This was particularly true of the nursing units. They all had the same material to be transported at the same time to the same place.

Some of the problems attributed to the lack of a formal hospital wide paper delivery system were:

1) loss of secretarial time within the administrative and business departments.

2) Ineffective scheduling of computer time within data processing.

3) articles desired by departments being held up in the storeroom due to slow delivery of purchase involces.

4) medical information and lab reports slow in reaching the nursing units.

The development. of a daily pick-up and delivery route 
seemed to be a tentative solution. This in itself presents problems:

1) path of routes.

2) frequency of pick-up and deliveries.

3) order of the various departments in the delivery route.

4) time necessary to complete the route.

5) the handing of emergency deliveries.

6) the equipment necessary to handle the volume of papers.

7) determining which articles will be handled on the route and which will not.

8) determining the staffing requirements such that the route may be run efficiently.

The delivery of products presented a problem which could at least partially be handled by a route. Many of the small items, particularly from the nursing units, could quite easily be handled by a delivery route. Laundry and central supply items would be difficult to handle with a delivery route. Drugs, addressograph material, central supply items returning from the nursing units and others could possibly be scheduled to be done at certain times of the day. Some specific problems that are commonly encountered are:

1) delay of regular duties to perform product transporting. 
2) need for more help throughout the hospital to handle all the necessary product transporting.

Some of the more general problems to be considered before a central transportation system can handle product movement are:

1) determining which are transport tasks and which are department tasks.

2) determining whether enough transporting is done to warrant the specialization of two separate jobs.

3) determing how many people are needed to handle the transporting of products for the hospital.

The transporting of patients is a third entirely different phase of the hospital transportation problem. Patients usually do not move at any regularly scheduled times. The demand on patient transportation is quite random. This type of transporting could probably be most easily handled by a dispatcher. Some of the specific problems of patient moving are:

1) lack of immediately available help, resulting in the patient waiting.

2) irregularity of patient delivery makes the scheduling of the X-Ray, E.E.G., and E.K.G. activities very difficult.

3) nurses are often required to move patients resulting in a decrease of available nursing time. 
4) patient discomfort due to long delays.

The use of a dispatcher and messengers as possible solutions present such problems as:

1) determining the special needs of the operating room and the accident room.

2) determining the volume of patient transporting that is done in the hospital.

3) determining the number of messengers necessary to handle the volume of work without any patient walting.

4) determining what transporting equipment is needed, what is avaliable, and where it is to be stored. The Memorial Hospital of Pawtucket is approximately a three hundred bed installation. It is by no means a new hospital, having been established at the turn of the twentieth century. It's early design and construction thus leaves something to be desired, although a modern bullding program is well underway. Presently, much of the hospital consists of one or two-story structures connected by tunnels or passageways. There are eight major sections of the hospital. Richardson, Administration, Out-patient building, and MacColl all have two floors. Read, Sayles. North; and Sayles South have a single floor. Wood building is the newest and most modern section of the hospital; it has six floors. The hospital is served by four banks of elevators, of which three are single 
elevators and the fourth a set of three. Figure 1. shows the floor plan of the hospital and the location of the elevator banks and the stairwells. All the elevators are of the self-service type. At each floor there are call buttons. If an elevator is called, it will come immediately if it is not in use or if it is in use and is moving toward the floor calling it. Otherwise there is a delay until it is not being used.

In addition to elevators, swinging doors and ramps are quite numerous throughout the hospital. In particular they are both commonly encountered when going from one buliding to another.

The Wood building is equipped with a pneumatic tube system. The nursing units on the sixth, fifth, fourth and second floors have terminals. There is also a terminal in the dietary department. This system can carry only small paper communications between these departments. It is, therefore limited and is not used extensively.

The discussion of the above facilities is presented because of the possible effect on any transporting system. 


\section{REQUIREMENTS OF A COMPUTER PROGRAM}

The use of a computer program to develop a delivery route must have as its major goal the optimization of any such system, optimization in the sense that all primary demands on the system by the various hospital departments and units must be successfully met.

The demands on the system can be broken down into two general categories: those of the servicing department and those of the department to be served. The servicing department has the following requirements. The route must be one which covers the least possible distance and in turn takes the shortest time to attend all of the departments requiring service. The route must be easy to operate in that the physical demands upon the employees and equipment not be excessive. One of the most important criteria to be met is that the system be flexible. It must have the quality of easy adaptation to meet the changing physical set of the hospital, or the changing demands of the departments being served.

The departments being served have the following route demands. The system must be able to meet the time requirements. Meeting the time requirements means that the pick-up of material, as well as the delivery to other departments, must be made at the proper time. Also, the 
various departments must be visited in the correct sequence. In many cases there are priorities to be met. In order for one department to carry on it's work, papers and memos from other departments must first be received. Thus, in many situations there are various critical subsequences that must be followed closely.

The successful operation of the computer program depends on the data available. Precision and thoroughness of data determine how well the results fit the actual situation.

Time, of course, plays an important role in meeting the requirement that pick-up and delivery be made at the proper time. In order to allow for the maximum flexibility in choosing the various departments to build into the system, it was at first necessary to calculate the amount of time needed to travel from one department to another. This system being new, it was impossible to obtain any indication of the actual delivery times by direct observation. It became necessary to simulate these times as best as possible. The simulation was broken in three parts: First, the pushing of a hand cart through the hospital corridors. Second, the time spent riding the elevators to the different hospital floors. Third, the time spent at the various stops picking-up and delivering the materials.

The times for the hand cart movement were obtained 
by moving through the hospital at different times of the day, through doors, up and down ramps, and along corridors measurIng the distance traveled and time taken. An average distance covered per minute was calculated.

The elevator situation was quite different. Within the hospital are four banks of elevators as shown in Figure 1 . The elevators move at different speeds and handle various amounts of traffic at different times of the day. It was thus necessary to obtain an average elevator time for each bank. This was obtained by riding the elevators to various floors at different times of the day. The times were noted and the average was calculated. No consideration was given to the distance that the elevator traveled. The observations indicated there was little difference due to this factor; the amount of traffic played a dominant role.

The amount of time spent at each stop was a difficult figure to estimate. Such factors as the amount of material at a particular stop, who the messenger is, and whether or not the material is ready to be picked up, all play a role. Much of the time was spent sorting the material and placing it in its proper slot on the hand cart. A similar activity of having people sort and put in order a number of lettered cards results in an average time which could be associated with the activity of the messenger at each stop. Consultation with persons familiar with the situa- 
tion agreed that the figures calculated were applicable and an overall al lowance of a minute at each stop was adequate.

Even with these times available, associating a time with the distance between two points or departments is not easy. The number of route choices increases rapidly as the distance between source and destination increases. It is necessary that all the possible routes be considered. The quickest or the shortest route may not meet the demands of the department served.

All the distances between departmonts can now be calculated in terms of time. The corridor distance in feet was taken from a floor plan and multiplied by the average time necessary to cover one foot. The elevators used were listed and their average times were added to the above figure. Finally, the stopping allowance for each department was added. These times were calculated for every possible permutation of two using all of the departments to be included in the route. With this information it is possible to calculate the time at any point during the route or the total elapsed time.

The next piece of information is that concerning the time requirements of each department. These times are limitations or restrictions on the system. Interviews with each department head resulted in a list of times whon a pick-up was needed. In all cases it was desired that the pick-up be made exactly on time or a little late, but 
never earlier than the requested time. In all Iikelihood the material to be picked up would not be ready early but more probably a little late. Thus a fifteen to thirty minute time allowance was made on the late side of the established pick-up times.

Throrgh the interviews it was possible to obtain a list of the departments that must be visited before a particular department is visited. The departments that must be visited first are referred to as priority departments.

In order to facilitate the listing of the departments and units, each department has a number assigned to it. This number is used in all the data tabulation operations. Thus far enough information is available to satisfy the requirements of the departments being served.

In many cases it is desirable to service all those departments or units having the same functions at the same time, or as reasonably.close as possible. With this in mind, an additional bit of information was needed. Each department is assigned a similarity number. Two departments with the same similarity number are exactly the same and, therefore, have the same function. An attempt is made to serve these departments consecutively because the demands of these departments are exactly alike and satisfying the demands of one will satisfy the demands of the other departments with the same similarity number. Given the situation that exists at the Memorial Hospital of Pawtucket, this applies only to the nursing 
units.

Another block of information that is necessary is that of the group numbers. The various nursing units and departments of the hospital are lumped together to form groups. Each group is assigned a group number. The size and number of the groups was determined by past experience and the location of the particular departments. There are seventeen groups varying in size from two to five departments. The departments are quite close to one another and a stop at one warrants a stop at the other departments in the group. The theory behind the group numbers is that once a messenger is in a group area an attempt should be made to stop at the remaining departments, thus developing the shortest route in both distance and time.

Also, included in the data banks is a preference listing. Each group is taken individually and the best group to go to from the group being considered, is listed, then the second. best and so on all the way down to the least desirable group to go to. The basis for this choice is again the proximity of the groups to one another. 


\section{DEVELOPMENT OF THE COMPUTER PROGRAM}

The program developed is one which meets the demands of the departments being served as a primary goal, and those of the serving department as a secondary goal.

There are eight parts to the program, one main program and seven sub-routines. The basis of the program is the development of arrays of departments and then choosing from the arrays the proper sequence of departments. Not all the departments are put in the arrays being considered. There are first two large categories that the various departments are divided into, those with a time requirement and those with no time requirement. A running time check is maintained by the sub-routine TIMECAL. The first test the program performs is determing if there are any departments that are to be put in the system at this time or a time that has already elapsed. If there are departments to be put in at this time, they are grouped together and referred to as hour departments. These hour departments are further divided. If there are any departments with the same similarity number, these hour departments are separated and grouped together. Thus, it is possible to have two groups of hour departments, those with the same similarity number and those with different similarity numbers. All of the priority 
departments of the hour departments and the priorities of the priority departments are grouped together. This function is accomplished by the sub-routine PRIOR. The priorities are then listed under their respective hour departments, forming an array. Only one array is worked with at a time. Sub-routine ORDER is then brought in and puts the hour departments which are also priority departments in the proper order in which they are to be considered and eliminates any which are repeated in the array. ORDER sets these hour departments into sub-arrays, or sub-subarrays as the case may be. The purpose of this step is that certain hour departments must be put in the system before other hour departments because the initial hour departments are priority departments.

The preference listings are used to determine the positions of the departments. The starting point department's group number is listed and that group's preference listing is followed. This function is performed by the HOUR sub-routine.

The same process is repeated for the group of hour departments with the same similarity number.

It is quite possible that there are no particular departments to be put in the system at the time when the time check is made. In this case, an array is developed with the departments which have no time restriction. Their priorities are listed and an array 


\section{RESULTS OF THE COMPUTER PROGRAM}

Application of the program resulted in the delivery system as shown in Tables 1 through 4. This particular route is one that meets the morning demands of the Memorial Hospital of Pawtucket. The data used was that pertaining exclusively to the morning hours. The system, at least on the surface, seemed to meet the demands of the hospital. However, as was expected there were a considerable number of implementation problems. There were three very pressing and crucial questions that required attention:

1) How many times a day should this route be run and how radically will the runs differ from one another?

2) What shall be handled by this route?

3) How many people are necessary for the operation of the route and what will be the departmental organization?

The number of times the pick-up and delivery routes were to be run was a question that could be answered by the people who were to be served by the system. As a result interviews were held with the department heads. It was obvious that a morning route would be required 
and would be the most complicated and heavily used. This route should start at the earliest possible time in the norning. It would be the most difficult to run, because all departments in the hospital need at least one stop in the morning and many of them have priority departments or time requirements. It was also felt that a run be made as close to the closing time of as many departments as possible. This run would be able to handle all the end of the day out-going mail and memos requiring attention the following day at the various departments. The morning delivery would not be able to handle these deliveries. Many of the larger departments required a run in the middle of the day. This was necessary for those departments whose function required an almost constant flow of material to and from other departments. The initial run through of the program indicated a running time of approximately two hours. Thus, the total route running time for an entire day would be close to six hours. The department head interviews suggested that the major hours of operation should be between eight o'clock in the morning to five o'clock in the afternoon, a time span of nine hours. Ideally, the first route should begin at elght o'clock in the morning and end at ten o'clock. The second route should begin at eleven $0^{\prime} c l o c k$, end the first part at twelve noon, start the second half at one o'clock in the after- 
noon and finish at two o'clock. The third route should begin at three o'clock and end at five o'clock. The break in the second route is for lunch. Tables 5 through 8 give the actual routes and their starting times. The first route starts fifteen minutes later than planned, because it is necessary for the messenger to prepare for the day's activities. The last route ends fifteen minutes early to provide some necessary close-down time. As a result the starting and ending times of the routes are juggled accordingly, but yet coincide quite well with the theoretical situation.

Tables 5 through 8 also indicate the changes necessary to accommodate the various departments. Even the original morning route is not exactly as ordered by the program. However, the changes in the morning route are not extensive because the route meets the major demands of the departments being served. The changes instead are ones made by the serving department to facilitate easier handing for the messengers. These few changes in no way reduce the offectiveness of the route and do not interfere with the demands of the other departments. The other two routes at first glance may seem quite different. A closer examination reveals, however, that the basic system remains and that blocks or groups of departments are shifted in position. These shifts were made to satisfy the needs of a few main departments, whose operation required it. The 
changes were easily made because the last two routes are not critical, that is, there are many departments indifferent as to when they are visited. In many cases the single or possibly the double delivery is all that is required by a certain department.

The pick-up and delivery route itself handles only papers and small products. This is due to the fact that the means of transporting is a small hand cart. This hand cart has slots for each particular department and a small area underneath for articles. The volume and bulk of the materials handled is quite limited. In spite of this, the route was found to be able to handle the transporting needs of the administrative departments and most of the service departments. Such areas as pharmacy, central supply and the nursing units found the route to be lacking, the reason being that these departments sent very large volumes of bulk articles to other parts of the hospital. These other problems will be discussed under other duties and functions which should be performed by the Central Transportation department.

Emergency or stat deliveries, although not handled by the delivery route, did require attention by the Central Transportation department. Also, included within this grouping were items to be delivered before the scheduled delivery system would normally function. In order to handle these-situations, a dispatcher is required 
who, upon receiving a phone call requesting messenger service, would dispatch a messenger to personally deliver the itern. It was necessary to encourage the departments to have their items ready for delivery and not to depend on the individual messenger service. This problem was partially solved by careful examination of the dispatch records, noting the frequency and type of delivery for a particular department, and informing the head of that department of any abuse. Another problem confronting tho Central Transportation department was that of staffing and departmental organization. The success of this project depended a great deal on the person or persons handling deliveries. A certain amount of knowledge and familiarity with the hospital layout and operation was necessary. Fortunately, a girl was available who had been performing a similar function but on a much smaller scale. A department head was hired to coordinate the activities of central Transportation and at least temporarily serve as dispatcher. Two more girls were hired to fill the positions.

The equipment needed for initial operation was limited. A home area with office facilities, a waiting area for the nessengers, and various types of hand carts were among the nost important. The first days of operation pointed out the need for training. The physical drain on one individual was excessive. This plus the coverage needed for sick days and vacations required that there be at least one 
other and perhaps two people familiar with the routes. This was put underway immediately.

As the project moved along, many small problems were encountered. In order to fully use the system it became necessary that some type of time-table be developed. Many of the departments were not aware as to when or how long it would take to deliver the item they were sending, or even when the messenger would be at their department for a pick-up. The result was an increased use of the dispatch service and material not arriving at its destination on time. A schedule was published listing the order of dopartments and the expected time of arrival. Although sometimes the scheduled arrival time was not met exactly, a routine was soon developed and the departments easily fell into 1t. It was also necessary to accustom the senders as to what articles the system could handle. It was important that this be approached in as objective and positive manner as possible. Discontent with the system at this point could mean rejection and fallure. In order to provide the eight o'clock to five o'clock coverage, messengers had to remain late. Rather than put this in as overtime, two of the messengers' hours were ohanged. Two came in at elght-thirty and left at five, while one messenger came in at eight and left at fourthirty.

Another problem "was that of IN-OUT boxes. Many, if 
not most, of the people in any department were unaware of the transportation service. Thus, instead of using the service, people continued to deliver their own materials. When a messenger arrived at a department, no one was familiar as to what was to be sent or even where it was. The IN-OUT boxes provided an easy pick-up and delivery point and also encouraged the use of the system by the departmental employees.

Initially it was quite common for material to be delivered to the wrong department or not at all. In most cases it was the lack of properly identifying the destination of the material being sent. In order to avoid any arbitrary decision by the messenger, as to the destination of any item, all material being sent had to be clearly labeled as to where it was being sent. If many small items were involved, they could be put in an envelope and labeled. Even with this, it was still a problem with departmental people dropping a form, involee, or notice in the INmOUT box and expecting it to make it to 1ts proper destination. The Central Transportation department also ran into the problem of lost material. In most cases it was the department receiving the material who called. A call to the sender resulted in a strong assertion that the material had been sent. A further check usually showed that the article never made the IN-OUT box. 
These incidents signaled the need for some type of check, necessary to avoid lost material. A registered delivery idea was put into practice. It was used in the handling of medical records. These records were patient histories and required close attention. The transporting of drugs also required the use of the registered delivery. This was used to avold the loss or theft of drugs while they are in transit. The registered delivery system consists of a slip of paper listing the article being sent. The sender signs and dates the slip. The receiver upon delivery of the material, checks the slip against the shipment and then signs acknowledging the delivery. If any material is lost, it can be pinned down to a time either before or after the delivery and not during. The slip is shown in Figure 2 .

There were a few problems that could be classified as arrangement trouble. With slight. shifting or elimination a comprehensive system could be worked out. A few of these problems need to be detalled in order that the difficulty of programming all the possibilities into the computer program be pointed out.

After a short time of operation, it was found that some departments required only two or possibly only one delivery a day. Determining which departments these 
were was simple, but re-arranging was the challenging part. The pick-up of the mall made it necessary that a large amount of sorting and filing be done by the messenger. The result was a considerable loss of time, possibly fifteen minutes or more, delaying the route. A similar situation existed in the lab, where a large number of lab reports were sent out. The combination of these two could, and often did, throw the system fifteen to thirty minutes off schedule. The lab problem was partially solved by having the lab people do a pre-sorting; the mail problem is still present.

One of the most difficult problems was also found in the lab. The lab ran tests on specimens all day long until four o'clock in the afternoon. After this bour no lab report would be completed for a specimen sent in. The lab required delivery of all lab reports at eleven $o^{\prime}$ clock in the morning and four $0^{\prime} \mathrm{clock}$ in the afternoon. The nursing units on the other hand, wanted the route to come to them before four. in order that their late specimens would be in on time for lab reports to be completed on them before four. This required a major revision in the late afternoon route. To solve the problem, the nursing units were visited just before four and right after the lab stop had been made. This double coverage was able to satisfy the demands of both areas. 


\section{PROJECTED FUNCTIONS}

Once the operation had proven successful, an immediate thought was to branch out and attempt to take over functions which were closely allied with transportation. Included in this group, were those activities of transporting which were originally thought to be too closely bound to the function of certain departments throughout the hospital to be successfully separated. The expansion possibilities are:

1) Metering and sorting of all incoming and outgoing mail.

2) Delivery of ice to various nursing units.

3) Moving of film projectors.

4) Pick-up and delivery of the pharmacy drug baskets.

5) Delivery and return of sterile supplies and equipment to the nursing units.

6) Photocopying and addressograph department.

7) The take over of the outside delivery truck service.

One of the most natural take overs, was the mail. The Central Transportation department handles all the mail to and from the departments both incoming and outgoing. Rather than have all outgoing mail to be metered sent to 
the switchboard, it could be brought back to the central Transportation department metered there and then sent out all at once at the end of the day. As far as delivering incoming mail, it would certainly be easier and save tine if it was brought to Central Transportation and sorted and filed on the cart before the route began, rather than stopping at Mr. Dietz's office and Iosing time on the route by sorting there.

The delivery of ice to the nursing units and the moving of film projectors are two odd jobs that have fallen to the Housekeeping department. The reason was that there was no other department particularly setup to handle this function. Both of these could quite easily be handled by the Central Transportation department. The demand for projector moving is random and very limited. Ice delivery, however, is done twice a day: once in the morning and once in the afternoon and requires approximately an hour and one-half each time.

The outside delivery system should obviously be handled by the Central Transportation department. This consists of one man and a panel truck who is available to the various departments when the need arises for an errand to be run outside of the hospital.

The Pharmacy department runs a small delivery route of its own. It consists of going around to all the nursing units and picking up baskets in which drug orders are 
placed. The baskets are brought back to the pharmacy, the orders are made up and the baskets are filled. The baskets are then brought around on a cart and returned to the nursing units. This activity takes place between nine forty-five and ten forty-five in the morning. The need for someone to handle this has put a strain on the available working time in the pharmacy. This delivery function could easily be taken over by Central Transportation.

A similar function is performed by the nursing units. Each unit is assigned a certain amount of sterile supplies and equipment each day which must be either returned that day or replenished. At approximately two o'clock in the afternoon each day, every nursing unit returns its used sterile equipment and restocks its supplies on the return trip. Again it seems that the Central Transportation department could provide this service provided the personnel were available.

A final area that could be added to the Central Transportation department is that of the Addressograph department. A large amount of the time spent by the two people in this department is in the delivery of the work done by them for other departments. As it is now, the messenger brings the forms and paper work to this department and delivers the finished product if it is neoded in a hurry. The messengers are also called on 
sometimes to do photocopying. Many departments request that when material is sent down, that it be returned right away thus charging the central Transportation department with the responsibility to see that it is completed and returned right away. If this responsibility is to be taken by central Transportation, it seems only right that it have some control over the performance of the addressograph duties. 


\section{PATIENT HANDLING PROBIEM DEFINED}

The problem of transporting patients is one which is quite different from the development of a pick-up and delivery route. The most obvious difference is that the system is now handling humans rather than inert objects. It becomes essential to meet a balance between patient comfort and convenience and the requirements of the patient servicing department involved. Also, very l1ttle routine or scheduled patient transporting takes place. This section will be concerned with determining the optimum number of messengers necessary to provide the amount of manpower to transport a patient from point of origin, which shall be the department or unit requesting a messenger, to the point of destination, which shall be the department or unit receiving the patient. This shall be referred to as one-patient move.

The assumptions and limitations of this system are imposed in order to establish a framework which will in turn give a starting point. Let it be understood that said assumptions and limitations are by no means binding, but only temporarily simplify a situation which is most complicated. Once the basic system has been established, the easing of Iimitations and generalizing the situation 
WII allow for a system which will be quite flexible and serviceable.

The following assumptions and limitations shall be Imposed:

1) The messenger will be used only to supply the manpower to move the patient from point of origin to point of destination.

2) The patient will be ready to be transported when the messenger arrives, and, once the point of destination is reached, will be free to perform further duties as shall be assigned by the C.T.S. dispatcher.

3) Only one messenger is required on all transporting cases.

4) All transporting equipment shall remain at the point of origin and if necessary must be returned.

5) For patient comfort and convenience, all requests for messengers will be handled immediately; enough messengers will be on hand to fulfill this requirement.

6) Only week day service will be considered; the week ends will have an understandably reduced load. The system will be able to be expanded quite easily to handle the week end requirements. 
7) Temporarily, messenger service shall be available from the hours of 8 A.M. to 5 P.M., holidays and weekends exempted.

8) Both male and female messengers who are relatively young and strong will be required to staff the system.

There are three types of situations where a messenger is required.

1) A patient in a wheelchair, transported between units or departments.

2) A patient on a stretcher requiring transporting between units or departments.

3) A patient who is admitted and is able to walk but must be accompanied to his room.

In situations 1 and 2 the patient involved must usually be transported twice. However, there are situations where only one move is required:

1) Body to morgue, either from a nursing unit or D.O.A.

2) Patient to be discharged.

3) Patient admitted requiring a wheelchair.

4) Transfer of patients from one unit to another.

5) Patient admitted requiring immediate service and then to unit.

The preceeding exceptions represent a small fraction of the transporting, and will, therefore, be considered 
the exception rather than the rule.

Situation 3 are those cases which are entirely one

way.

In the light of this discussion, the data concerning the number of patients admitted and discharged, which include deaths in units, will be considered as one-way trips. All other data from the departments on number of patients served will be considered double trips.

The most important factor to be considered in developIng the patient transport system is the source of demand. The source of demand will not only indicate the amount of transporting needed, but the time required for a move and the type of transporting situation to be expected.

The sources of patient transporting at the Pawtucket Memorial Hospital vary and are spread over a wide area. Naturally, those departments considered were those of the highest volume and those presenting a situation where a centrally located messenger is both feasible and recommended.

Surveying the entire hospital, the following departments were considered and either accepted fully, partially, or not at all for various reasons which shall be discussed. The listed departments were chosen because they have a function directly involving the patient:
A) X-Ray
B) E.E.G.
E) $A C D . R m$.
C) E.K.G.
F) Admitting
D) $O . R$.
G) Physical Therapy
H) All Nursing Units
I) Isotope Lab. 


\section{REQUIREMENTS OF PATIENT HANDIING}

of the nine previously mentioned E. E. G., E. K. G., and the Isotope Lab. were eliminated immediately. E. K. G. deals with the patient directly in his room and handies only outside patients in its own department area. E. E. G. handles house patients in its department area at an average of about two patients per day. Deletion was deemed justified because of the difficulty in obtaining data and the insignificant amount of activity involved. The Isotope Lab. handles even fewer patients than E. E. G. and was also eliminated.

The circumstances surrounding the accident room and the operating room indicate the need for a transporting service, but the very activities of these departments make it extremely difficult for them to actively use any but their own transporting services.

Any Operating Room messenger must, due to the sterile conditions necessary in the 0 . R. wear the proper cap, mask, and tunic while handling any patient, as well as have some knowledge of $0 . R$. procedures. These restrictions thus make it very difficult to have an $0 . R$. orderly externally located within the central pransportation department. 
The patients requiring transporting from the accident room are those to be admitted to the hospital or those requiring emergency service at the various hospital departments. The very expedience necessary in transporting any of these emergency cases eliminates the use of a central messenger. Instead, accident room orderlies handle the emergency transporting. Only a patient admitted through the accident room will be considered.

The pertinent data to be used were obtained from the X-Ray department, Physical Therapy department, and the Admitting department. These figures show the number of house patients serviced at the X-Ray and Physical Therapy departments. The data was avaliable on a daily basis and each potient represents a double trip. The Admitting department figures show the total number of patients admitted and discharged daliy, including deaths in the hospital. Each patient in this case represents a single trip.

No data was collected from the various nursing units. Any figures from the units would be a duplication of the data collected from the servicing departments. All the patient moves considered, will require the use of a stretcher or a wheel chair, the only exception being those patients who are admitted and are able to make it to their respective rooms under their own power. 


\section{THEORY APPLICATION AND RESULTS}

The theory used in determining the optimum number of messengers conforms very well to the conditions, assumptions, and limitations of the situation. The theory of distribution and laws of probability will allow the determination with a given level of confidence of how many patient moves may be expected for a given hour interval, and this in turn, how many messengers will be needed for that hour interval.

The first step is to form a frequency distribution of the number of single patient moves throughout the hospital for a given hour interval. These frequency distributions were calculated by polling the various departments concerned, that is, those discussed previously. The departments figures for each hour can then be pooled and form a certain frequency distribution. It then becomes necessary to determine what types of distribution each hour interval is. Once this has been ascertained, it is of very little difficulty to assign a certain probability and then determine the maximum number of patient moves that is associated with the given probability level. With a calculated time per move, the number of messengers needed for each hour interval can be figured. 
The exact data for the frequency distribution were not avaliable. Instead, each department concerned had a breakdown of the number of patients moved on a daily basis. The distribution on the other hand required a breakdown concerning the number of patients moved per hour.

The conclusion was reached that it could be assumed, without departing greatly from reality, that the number of patients moved by each particular department was evenly distributed over the period of operation. Indeed, a previous study indicated this assumption to be valid. Figure 3 shows the results of this two-week study. All departments and units within the hospital were asked to log everything that was moved to or from their department by people within their own department. Everything moved was broken down into three general categories: papers, products, and patients. The papers category contained any communications, reports, requisitions, or slips that were to be sent or picked up. The products group consisted of any lab specimens, laundry, medications, etc., that were handled. The patient classification naturally included only patients or bodies picked up or moved. As can be seen, the table indicates a quite consistent number of patient moves over the hours of operation.

Tables 9 thru 13 list the data from the particular departments. A breakdown of departments of the number of patients handled in $X$-Ray on each day for the month of 
october is shown in Table 14. Tables 9 and 10 tabulate the results in the $\mathrm{X}$-Ray department for the months of November, December, January and February, respectively. The in-patient column is the one of concern. These figures are multiplied by 2 and divided by 6 , in order to arrive at an average hourly figure. Each in-house patient served in $X-R a y$ must be moved twice, from the unit to $X-R a y$ and back again. Thus, each patient served is considered twopatient moves. The 6 is used as a denominator because clearly the majority of the $\mathrm{X}$-Ray transporting is done between the hours of 9 A.M. and 3 P.M., or six hours, as is shown in Figure 13 .

Table 13 indicates the number of in-patients served on the given days by the Physical Therapy department. These, as was the case in the $\mathrm{X}-\mathrm{R}$ ay department, represent double patient moves, from the unit to physical therapy and back again. To establish the average number of patient moves per hour for physical therapy, the number of patients served is multiplied by 2 and divided by 3 . The 3 is used as a denominator because the bulk of the servicing takes place between 9 A.M. and 12 P.M., as is indicated by Figure 3 . Tables 11 and 12 list the adritting and discharge flgures, including deaths, for the months of october through February inclusive. Unlike the previous figures, each patient served is considered as only one patient move, either from the unit to admitting, or from the admitting 
area to the unit. No direct information was available to determine the major hours of discharge and admitting. These figures are mixed with those of other departments in the nursing unit figures on patient moves. Consultation with the admitting office, and the various nursing units indicated that both the discharge and admitting of patients, other than emergency cases, were fairly evenly distributed over the hours of 9 A.M. and 12 A.M. for discharge and I P.M. and 3 P.M. for admitting.

As previously stated in the assumptions and Iimitations, the transporting service shall be initially restricted to week days between the hours of 8 A.M. and 5 P.M. As a result, the frequency distribution shall also be confined to hour intervals within this span of time. For the hour Intervals of 8 A.M. - 9 A.M., 3 P.M. - 4 P.M., and 4 P.M. 5 P.M., very few patient moves were recorded. This, however, does not completely exempt any available service at this time, and indeed there will obviously be some patient transporting at this time. However, the small amount done during these slack periods, should be easily handled by one man. These slack intervals should be expected due to the fact that their time periods are at the beginning and end of the day's activities. The 9 A.M. - 10 A.M., 10 A.M. - 11 A.M., and 11 A.M. - 12 A.M. hour intervals all are made up of ontrles from the figures of $X$-Ray, Discharge, and Physical Therapy. The 12 A.M. - I P.M. hour interval contains observations from X-Ray only, while the I P.M. - 2 P.M. 
and 2 P.M. - 3 P.M. frequency distribution contains readings from the X-Ray and Admitting department.

The frequency distribution charts were constructed by totaling the patient moves of the particular departments in the desired hour interval. The result of this tabulation were three distinct distributions. The 9 A.M. - 10 A. M., 10 A.M. - 11 A.M., and 11 A.M. - 12 A.M. hour intervals are exactly the same and thus have the same frequency distribution. This is shown in Figure 4. The hour interval 12 A.M. - 1 P.M. frequency distribution is shown in Figure 5. The hour intervals of 1 P.M. -2 P.M. and 2 P.M. 3 P.M., are exactly alike and they too have the same frequency distribution, which is shown in Figure 6. The distributions thus give the total number of patient moves for a particular hour interval over the week days of a fivemonth period, holidays exempted.

observation of the frequency distributions of. 9 A.M. 12 A.M., and 12 P.M. - I P.M., respectively, discloses the possibility of a normal distribution, while the I P.M. 3 P.M. distribution shows a distinct inclination towards a Poisson distribution.

A Chi-Square goodness-of-fit test was used to determine how closely each sample distribution fit the hypothesized population distribution. Tables 15,16 and 17, and Figure 7 are the preliminary calculations of the sample standard deviation of each respective frequency distribution, which are necessary for the Chi-square test. 
The chi-square total is associated with the probability of arriving at a value of this size due to chance causes only. Various probabilities are expected for different degrees of freedom. The higher the probability, the better is the fit of the sample distribution to the hypothesized distribution. The chi-square calculations for the 9 A.M. 10 A.M., 10 A.M. - 11 A.M., and 11 A.M. - 12 A.M. distributions are shown in Table 18 and Figure 8 .

The Chi-square total is 4.5644 , with 8 degrees of freedom. This value falls between the 80 and 90 percent levels. The assumption of a normal distribution for this sample is concluded to be a valid one.

Table 21 is a comparison of the chi-square values with that of the expected chi-square values at the 5 percent significance level, for the three distributions.

The first column shows no significant difference betwoen

a normal distribution and the 9 A.M. - 10 A.M., 10 A.M. 11 A.M., and 11 A.M. - 12 P.M. distribution.

Table 19 and Figure 8 show the Chi-square value for the 12 P.M. - 1 P.M. distribution to be 3.4705. The probability associated with this total and 5 degrees of freedom is between the 70 and 50 percent levels.

Although this may not be as good a fit as desired, the comparison of this value with that of the expected value at the 5 percent elgnificance level and with 5 degrees of freedom, shows no significant deviation from the normal distribution. 
Table 20 and Figure 8 show the Chi-square test figures on the 1 P.M. - 2 P.M., and 2 P.M. - 3 P.M. distribution. The calculated value is 5.784 and is associated with a probability between 90 and 80 percent for 10 degrees of freedom. Again, the chi-square value at the 5 per cent significance level with 10 degrees of freedom is well above the calculated value, further strengthening our conclusion of a Poisson distribution for this sample.

With the aid of these test results it is now possible to make the following conclusions.

1. 9 A.M. - 12 P.M. (Inclusive) distribution is a sample from a normal population.

2. 12 P.M. - I P.M. distribution is a sample from a normal population.

3. 1 P.M. - 3 P.M. (inclusive) distribution is a sample from a Poisson distribution.

The problem of determining the average time necessary for a single patient move, has threebasic difficulties:

1. Data collected from the various nursing units were quite insufficient.

2. The limited number of entries made reflected readings which included the time to help a patient on to or off a stretcher or wheel chair, and possibie loitering on the job.

3. It is almost impossible to come up with a single representative time for a patient move anywhere in the hospital. 
Observations of the actual patient moving would normally give a good predictor value; however, the restrictions and limitations originally assumed differ greatly enough from the actual situation to warrant the discarding of this idea.

The normal times previously calculated serve as a sound basis. The times themselves proved to be quite accurate and representative of the situation existing under the desired restrictions and limitations.

Instead of using a single timo value for the entire hospital, three different values are calculated, an X-Ray time, \& Physical Therapy time, and an AdmittingDischarge time. The fact that the distance from the various nursing units to the three service areas is so varied made it impossible to obtain one representative time for the whole hospital for all patient moves. Another possible problem was a distribution of patient move times from the various nursing units to the particular service area involved. This would make it impossible to assign one single time to a particular service area, that was representative of the time to move a patient to this service area from the nursing units. This is opposed to the assumption of an even distribution. A T-test was used to test the hypothesis that the assumption of an even distribution was a valid one. A distribution of actual times was calculated for X-Ray, 
Physical Therapy, Discharge, and Admitting.

The distributions are the number of patient moves between the servicing areas and the departments served. These are single, one-way trips only.

The samples were taken over a period of three to four weeks, excluding weekends. Tables 22 and 23 show the results for $\mathrm{X}$-Ray and Physical Therapy, respectively. The straight average time is the figure arrived at by assuming equal trips to and from all departments, or an even distribution. The weighted average time is arrived at by taking into account the frequency of trips to and from each floor, or assuming some type of a distribution. The assumption of an even distribution is shown to be valid due to the fact of no significant difference between the straight average and the weighted average.

The possibility of a distribution of patient moving times is disregarded. The admissions and discharge observations, on the other hand, indicate a significant difference between the straight average and weighted average times as shown in Tables 24 and 25 .

The assumption of an even distribution is not valid and the result is a distribution of patient move times. A pooled $T$-test was run to determine if there existed any significant difference between the admitting and discharge weighted average times. Figure 9 shows the results to be insignificant. It is thus possible to 
arrive at a pooled average figure, also shown in Figure 9. In spite of the fact that the straight average and weighted average for both Admitting and Discharge prove to be significant, the average pooled time will be used for two reasons:

1. The pooled figure was obtained by using the actual data from both Admitting and Discharge.

2. In spite of the fact that the time calculations are carried out to four decimal places the significant difference will not actually affect the calculations because of the quite large margin of error allowed.

We now have the times necessary to calculate the number of people to satisfy the patient moving demands of the hospital.

A weighting factor is again necessary to take into consideration the effect of the contributing service departments within a given hour interval.

Table 26 shows the weights assigned and the average times calculated for each hour interval. The daily observations of all three departments for the month of January, excluding holidays and weekends, were used as the weighting factor. The 9 A.M. - 12 P.M. intervals contain all three departments and the. times are weighted accordingly. The 12 P.M. - I P.M. interval contains only X-Ray, and the I. P.M. - 3 P.M. intervals contain 
the X-Ray and Admitting departments.

Discussions with the hospital administration and poople in the field indicated that a 90 per cent confidence interval would be the optimum level to work with. That is, it is desired that the system be able to handle all demands on the service 90 per cent of the time, without any delay at all.

Table 27 indicates the number of trips or fewer that can be expected 90 per cent of the time for all of the hour intervals concerned. The product of trips and average time is the amount of transporting time needed to be done within that particular hour interval. This total time divided by the number of minutes in an hour is the number of people necessary to fulfill the patient transporting needs. 


\section{ECONOMIC ANALYSIS OF THE DELIVERY SYSTEM}

The success of an operation is at least partially measured by an economic analysis. It was not primarily economics that initiated this project at the Memorial Hospital of Pawtucket. It was instead the inconvenience and loss of time by the hospital departments that precipitatod this study. It was felt at the time that the transporting was done by many individuals in many departments, and, by drawing these individuals together and consolidating their activities, a smooth hospital operation would result.

With this in mind, one of the first stipulations placed upon the project was that it would generate no new expense. That is, job functions would be rearranged in such a manner that people would be free to work strictly as messengers in the Central Transportation department.

The first step was to determine those departments Which do a considerable arnount of transporting. A survey was made of the entire hospital. Each department or unit was asked to log all trips where something required transportation. This activity was carried out for two weeks. The data recorded on each trip consisted of the person's position or job, what was transported, 
where it was transported to, the time the person left and and the time he or she returned.

studying the information, gave an idea of the amount of transporting done, which particular positions did most of it, what was transported by the departments, and the amount of time spent transporting. It was obvious that a great deal of transporting, between three and four hours a day, was done by the nursing units. The people who performed most of these transporting duties were the green-aides. The figures for each unit or department are shown in Tables 28 and 29 . These are averages over the logging period and each is a daily average figure. Most of the logg1ng was carried out in the eight o'clock to five o'clock time period. Thus in many cases the efforts of some departments were very poor. It can safely be concluded that many of these figures are on the low side.

The green-aides and the orderlies became the first Immediate source of manpower for the Central Transportation department. The administrative and service departments did have transporting time. It would be difficult to consolidate the efforts of these departments and then draw manpower away from them. However, through the use of the Central Transporting department, a considerable amount of working time was made available. 
Naturally, a numerical figure was desired on the amount of savings picked up by the new system. An average hourly cost for each department was calculated. Each of the hourly wage rates for the jobs involved were obtained. Each department $l o g$ was gone over and the number of trips by each type of particular job was noted. This total number of trips for each type of job was multiplied by the wage rate for that job. A total was taken and an average hourly wage rate was calculated for each department. The average hourly wage rate was in turn multiplied by the average number of hours spent in daily transporting. The final product was an average daily transporting cost for each particular department. These figures are shown in Tables 28 and 29. The grand total of transporting cost was $\$ 150.20$ per day. However, the inadequacy of the logging warranted a further study. Careful consideration of the departments involved and the volume of transporting done by these units suggest a possible daily transporting cost of approximately $\$ 160$ to $\$ 170$ per day.

Either of these figures, of course, are possible theoretical savings. In many cases, the people involved In the transporting could not be consolidated, thus glving no immediate savings. However, it should be quite possible to recognize an increase in work performed by these people, increased efficiency, and less lost time. The result is indirect savings which would be difficult to calculate. 
Assuming an average hourly wage rate of the messenger to be $\$ 1.70$ per hour, Table 30 shows that as many as eleven people could be hired at this hourly rate at no additional cost. Again, these savings will not be immediately obvious. Where it is possible to eliminate job positions; it is necessary that it be done over a long period of time through voluntary terminations and retirement. 


\section{THE \\ STATION IS 17}

GTART IIME-IS - 8.15000

FINAL TIME IS__ 8.52121

$2323435 \quad 3640 \quad 4130 \quad 39 \quad 3 \quad c$

STAOT TIME IS 8.52121
QROER OE OEPTS. FOR THIS PERIOO FINAL TIME IS 8.59653
8

START TIME IS 8.53653 FINAL TIME IS 8.55316 TER UE REPTS. FCR THIS PEFIOD

Ab

START TIYE IS 8.55316

CADER OF OFPTS. FOR THIS PERIOO

FINAL TIME IS 8.57576

47

STAMT TTME IS $=8.57576$

GADER OF DEPTS. FOR THIS PERIOD

FINAL TIME IS 8.58706

$3+5$

SITRT TIME IS 8.58706

TRDER OF OEPTS. FOR THIS_PERIOTO

FINAL TMEE ES ?.0R:75

6

START TIME IS 9.01175

ORDER OF DEPTS. FOR THIS PERIOD

FINA: EMME IS S.12948

17.22 182031

in

$i=$

START TIME IS 9.12948

30 OF OEPTS. FOR THIS PER TCO

FINAL TIME IS 9.14774

START_IME IS

ORCER OF OEP 9.14774

FINAL TIME IS 2.16428

- oRer OF DEPTS. FOR THIS PEPIOO 
TABLE-2

START TINE TS 9.16698

ORDER OF DEPTS. FOR THIS RERIOD

FINAL TIME IS 9.18557

SIART IIVE $15 \quad-2.18557$

FINAL TIME IS 9.20219

GRDER OF DEPTS. FOR THIS PERIOD

$2 T$

OQDER OE OEPTS. POR. THIS PERIOD

FINAL TIME IS 9.22062

sthiture Is 9.22062

Anter OF DEPTS. FOR THIS PERIOO

ETAL IUKE IS 9.24237

20

START TIME IS 9.24737

OROER OR DEOSS FOR THIS PERIOD

FINAL TIME IS 9.27243

42

s

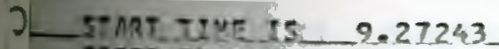

oxDEA DF DEPTS, FOR THIS PERIOD

FINAL TIME IS 9.29013

3

START TIME IS 9.29013

16 OAPR OE DEPIS. FOR THES PEREOC

\section{FINAL TIME IS 9.31839}

2

START_TME IS $\quad 2.31830$

ORQER OF DEPTS. FOR THIS PER 100

FINAL TIME IS 9.33627

START TINE TS 9.33697

F UNAL TIME IS $\$ .36783$


TABLE-3

OROER DF OEPTS. FOR THIS PERIOO

is

FHoT THE IS 9.36783

FINAL TIME IS 9.39114

ST DRT TIUE IS _ 9.39114

FINAL IIME IS 9.40745

ORDER OF DEPTS. FCR THIS PERIOD

3)

Maz true is 9.40745

ONDER OF DEPTS. EOR THIS PERIOD

FINAL TIME IS 9.43804

3

S1ART TUME IS 9.43804

DRDER OF DEPTS. FDR THIS PERIOD

FINAL ITME IS Q 94860

START TIME IS 9.46860

QROES OF DEPJS. FOR THIS PERTOD

FINAL TIME IS 9.49110

2

T=

1 START TIME IS 9.49110 OSTMAL TIME IS_. 2.92228

OROER OF DEPTS. FOR THIS PERIOD

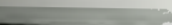

START TIME IS 9.51238

OROER OF OEPTS. FOR THIS PER IOD

FINAL TIME IS 9.52714

START TIME_IS_ 9.52714

OROER OF DEPTS. FOR THRS PER IOD

FINAL TIME IS 9.34560 
TABLE-4

TIME TS 9.54560

OOEERLE DEPTS. FOR TMIS_PERIOD

FINAL TIME IS .9 .58394

START TIME IS 9.59394 TIS PER IOD

FINAL TLME IS 10.01948

10

CTNT TTKE $15 \quad 10.01948$

GNOER OR DECTS. FOR THIS RER IOD

FINAL TIME IS 10.03644

Stantutus is 10.0 .3644

EINAL TME IS 10.05279

EROET OF DEPTS. FOR THIS PERIOD

12

10.05274

FINAL TIME IS 10.06888

QNoER DE DERTS . FOR THIS PERIOD

管

START_tIME is 10.06888

FIMAL TIME IS 20.09453

is

J

CRDER OF DEPTS. FOR THIS PERIOO

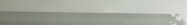

START TIME IS 10.08453

ORORR_OF OEPTS. FOR THIS PERIOD

FINAL TIME IS 10.10177

43 


\section{CENTRAL TRANS PURTATION OPERATION:}

This is a revioed schedule of the Central Iransportation delivery route that is run three times a day, from the hours of 8:00 A.M. to 5:00 P.M.. Monday through Friday, excepting holidays. It supersedes all other schedules.

The schedule indicates when the messenger will be at the designated departments. It is requested that you check the arrival time for your department and, whenever possible, use the routine delivery service. If special messenger service is required, call Central Transportation and a messenger will be placed at your disposal.

In order to expedite the delivery of any papers or small articles they should be clearly marked as to theix destination. Aloo, please have an IN-OUI box available at the point of delivery in your department.

As Central Transportation expands their facilities, you will be advised as to bow they may better serve you.

The extension for Central Transportation is 237.

Thask you.

$2 / 26 / 68$ 


\section{First pick up and delivery $--\infty 8: 15 \mathrm{A.M}$.}

Dept.

$\begin{aligned} 45 & \text { Mr. Fawcett } \\ 17 & \text { Nursing Office } \\ 15 & \text { I.C.U. } \\ 21 & \text { Accident Room } \\ 25 & \text { s-ray } \\ 32 & \text { Wood } 2 \\ 34 & \text { Wood } 4 \\ 35 & \text { Wood } 5 \\ 36 & \text { Wood } 6 \\ 41 & \text { Sayles North } \\ 40 & \text { Read Building } \\ 38 & \text { R I } \\ 39 & \text { R II } \\ 3 & \text { Out-Patient Dept. } \\ 6 & \text { Pharmacy } \\ 9 & \text { Central Supply } \\ 8 & \text { Maintenance } \\ 30 & \text { Uperating Room } \\ 31 & \text { Lab \& Bl.Bank } \\ 24 & \text { Medical Staff Sec. } \\ 17 & \text { Nursing Office } \\ 22 & \text { Admitting Office } \\ 18 & \text { Billing Office } \\ 20 & \text { Credit Office } \\ 23 & \text { Information Desk } \\ 4 & \text { Niedical Records } \\ 7 & \text { Addressograph } \\ 10 & \text { Storeroom } \\ 11 & \text { Purchasing } \\ 43 & \text { Photography } \\ 12 & \text { Health Office } \\ 13 & \text { I.B.iv. } \\ 14 & \text { E. 2.G. } \\ & \\ & \end{aligned}$

Estimated

Arrival Time

$8: 15$

$8: 19$

$8: 21$

$8: 23$

$8: 25$

$8: 28$

$8: 32$

$8: 35$

$8: 39$

$8: 43$

$8: 45$

$8: 47$

$8: 49$

$8: 53$

8:57

8: 59

9:01

9:03

9:05

9:07

9:09

$9: 12$

$9: 14$

$9: 16$

$9: 18$

$9: 21$

9:23

9:26

9:27

$9: 29$

$9: 31$

$9: 32$

$9: 34$
Estimated Arrival Time

9:36

9: 38

$9: 40$

$9: 42$

$9: 45$

$9: 47$

$9: 49$

9:51

$\begin{array}{lll}37 & \text { Volunteer Uffice } & 9: 52 \\ 46 & \text { Miss McGinn-Payroll } & 9: 55\end{array}$

1 Physiotherapy $9: 58$

2 Housekeeping 10:00

44 Laundry 10:03

48 Equipment Rm. 10:05

47 Nursing Educ. 10:09

5 Dietary Office 10:13.

* A.M. 6top only if delivery is to be made. 


\section{TABLE - 7}

Second Pick-up and Delivery - 11:00 A.M.

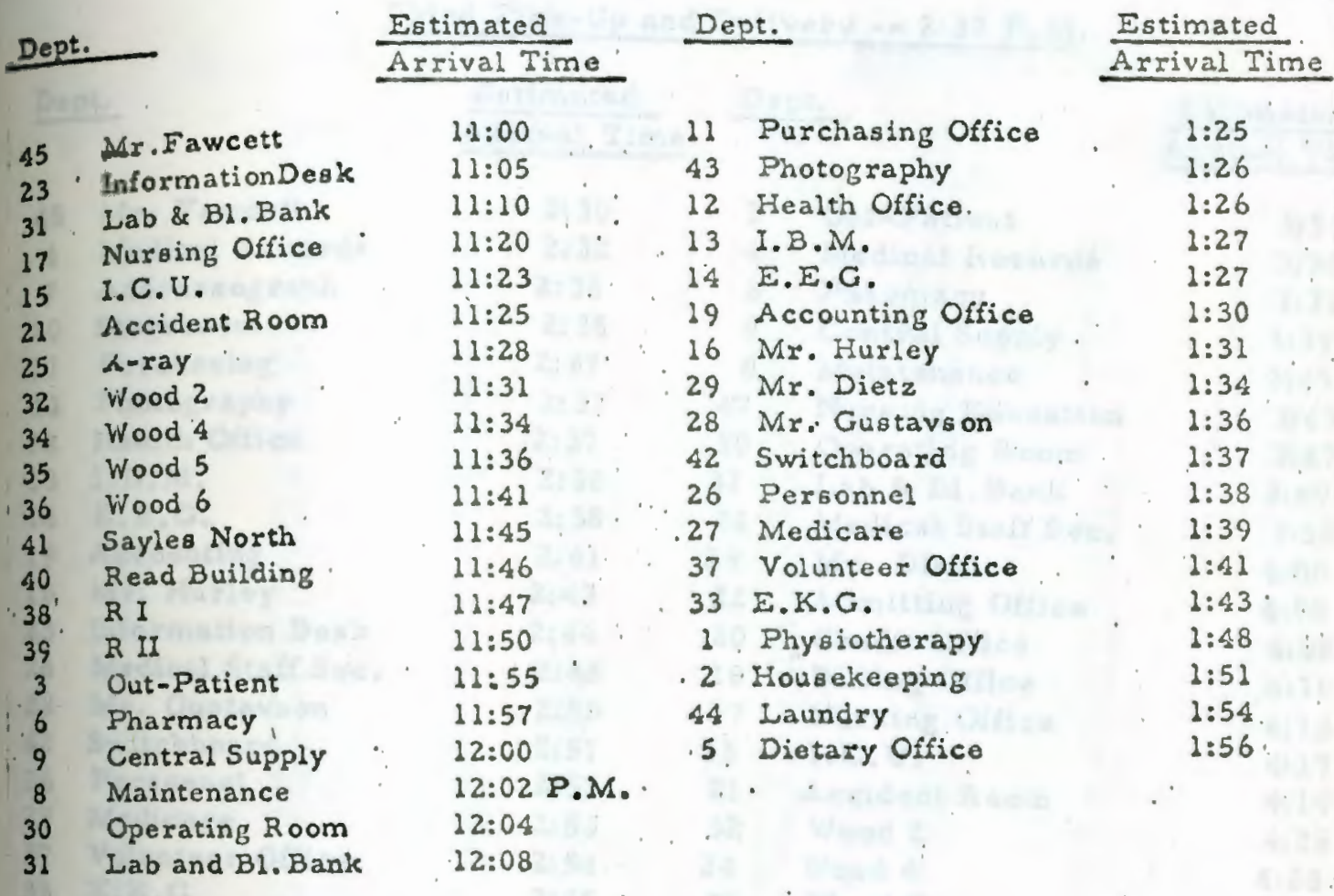

Under present operation route service will be interrupted for personnel lunch break but apecial mes sengex service will be available.

$\begin{array}{rlr}\text { 24. Medical Staff Sec. } & 1: 10 \\ 17 & \text { Nursing Office } & 1: 12 \\ 22 & \text { Admitting Office } & 1: 14 \\ 18 & \text { Billing Office } & 1: 16 \\ 20 & \text { Credit Office } & 1: 17 \\ 4 & \text { Medical Records } & 1: 20 \\ 7 & \text { Addressograph } & 1: 22 \\ 10 & \text { Storeroom } & 1: 24\end{array}$


Third Pick-Up and Delivery - 2:30 P.M.

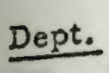

$\begin{aligned} & 45 \text { Mr. Fawcett } \\ & 4 . \text { Medical Records } \\ & 7 \text { Addressograph } \\ & 10 \text { Storeroom } \\ & 11 \text { Purchasing } \\ & 43 \text { Photography } \\ & 12 \text { Health Office } \\ & 13 \text { I. B.M. } \\ & 14 \text { E.E.G. } \\ & 19 \text { Accounting } \\ & 16 \text { Mr. Hurley } \\ & 23 \text { Information Desk } \\ & 24 \text { Medical Staff Sec. } \\ & 28 \text { Mr. Gubtavson } \\ & 42 \text { Switchboard } \\ & 26 \text { Personnel } \\ & 27 \text { Medicare } \\ & 37 \text { Volunteer Office } \\ & 33 \text { E. K. G. } \\ & 1 \text { Physiotherapy } \\ & 2 \text { Housekeeping } \\ & 5 \text { Dietary Office } \\ & 17 \text { Nurging Office } \\ & 15 \text { I.C.U. } \\ & 21 \text { Accident Room } \\ & 25 \text { X-ray } \\ & 32 \text { Wood } 2 \\ & 34 \text { Wood } 4 \\ & 35 \text { Wood } 5 \\ & 36 \text { Wood } 6 \\ & 41 \text { Sayles North } \\ &-40 \text { Read Building } \\ & 38 \text { RI } \\ & 39 \text { R II } \\ & \\ & 13\end{aligned}$

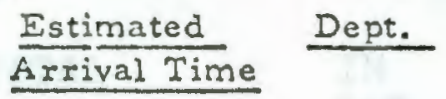

2: 30

2: 32

2: 34

$2: 35$

2: 37

2: 37

2: 37

2: 38

2:38

2:41

2: 43

2: 44

2: 48

. $2: 50$

2:5i

2:52

2:53

2: 54

2:55

2:58

3:02

3:04

3:06

3:08

3:10

3:11

3:14

3:16

3:19

3:21

$3: 23$

$3: 25$

$3: 26$

$3: 27$ $\frac{\text { Estimated }}{\text { Arrival Time }}$

$3: 33$

$3: 35$

$3: 37$

$3: 39$

3:40

$3: 43$

$3: 47$

$3: 49$

3:55

4:00

4:05

4:08

$4: 10$

$4: 13$

4:17

4:19

$4: 25$

$4: 28$

4: 32

4: 34

$4: 37$

4: 38

$4: 39$

4:21

4:41

$4: 45$ 
NUMBER OF PATIENTS SERVED IN $X-R A Y$

NOVEMBER-1967

$\begin{array}{lll}\text { DATE } & \text { IN } & \text { OUT } \\ & \text { PAT. } & \text { PAT. }\end{array}$

$\frac{1}{2}$

329

$4 \quad 17$

512

630

$724_{t}$

829

925

$10 \quad 31$

$11 \quad 19$

129

$13 \quad 37$

1420

1519

$16 \quad 29$

1724

$18 \quad 24$

198

2041

$21 \quad 32$

$22 \quad 25$

239

$24 \quad 46$

2520

263

2739

$28 \quad 21$

$29 \quad 32$

$30 \quad 23$

31

TOTAL $737 \quad 1714 \quad 21451$
DECEMBER-2967

$\begin{array}{lll}\text { IN } & \text { OUT } & \text { TOTAL } \\ \text { PAT. } & \text { PAT. } & \end{array}$

$\begin{array}{ll}22 & 54 \\ 28 & 42\end{array}$

$12 \quad 23$

41

28

38

23

30

25

10

37

32

31

28

17

10

42

32

30

28

31

30

12

II

37

32

30

37

32
13

835
65

57

49

62

24

24

62

60

63

54

52

43

37
67

67

49

60

50

51

28

27

62

66

70

57

74
48

$1636 \quad 2471$

IN PAT.-In house patients

OUT PAT.-out private patients 
NUMBER OF PATIENTS SERVED IN X-RAY

JANUARY- 1968

$\begin{array}{lll}\text { DATE IN } & \text { OUT } \\ & \text { PAT. TOTAL } & \text { PAT. }\end{array}$

$\begin{array}{llll}1 & 10 & 43 & 53 \\ 2 & 42 & 62 & 104 \\ 3 & 39 & 65 & 104 \\ 4 & 40 & 75 & 115 \\ 5 & 37 & 77 & 114\end{array}$

$\begin{array}{llll}4 & 37 & 77 & 114\end{array}$

$\begin{array}{llll}6 & 29 & 62 & 91 \\ 7 & 8 & 25 & 33\end{array}$

$\begin{array}{llll}7 & 46 & 57 & 103\end{array}$

$\begin{array}{llll}9 & 27 & 73 & 102\end{array}$

$10,21 \quad 90 \quad 111$

$11 \quad 34 \quad 73 \quad 107$

$\begin{array}{llll}12 & 31 & 73 & 104\end{array}$

1325

1411

$15 \quad 45$

1725

Is 28

$19 \quad 29$

2023

216

$22 \quad 52$

2327

2431

$25 \quad 32$

$26 \quad 37$

$27 \quad 22$

2811

2943

3040

$31 \quad 31$

TOTAL 912

86

32

72

57

68

73

61

55

26

68

81

55

65

75

55

33
60

54

43
717
85

93

101

90

78

32

120

108

86

97

112

77

44

103

94

18892801

IN PAT.-in house pationts

OUT PAT.-out private patients 
NUMBER OF PATIENTS ADMITTED AND DISCHARGED

$\begin{array}{llllll}\text { DATE } & \text { OCT }-67 & \text { NOV }-67 & \text { DEC }-67 & \text { JAN }-68 & \text { FEB-68 } \\ \text { ad ds } & \text { ad ds } & \text { ad ds } & \text { ad ds } & \text { ad ds }\end{array}$

$\begin{array}{lllllllllll}1 & 20 & 25 & 15 & 29 & 23 & 19 & 18 & 23 & 30 & 17\end{array}$

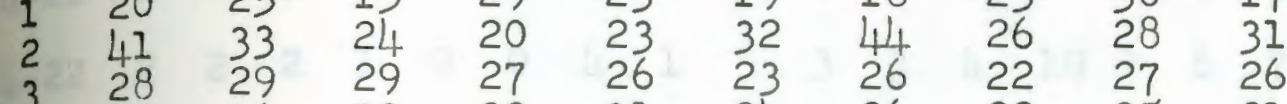

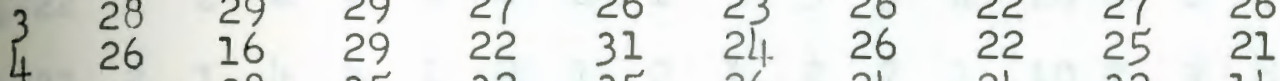

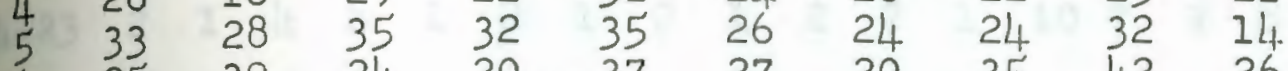

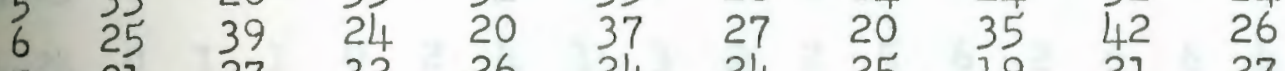

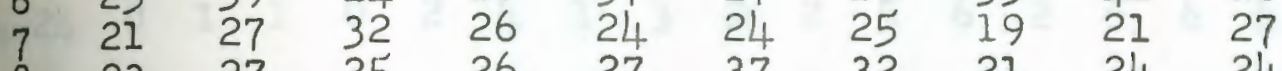

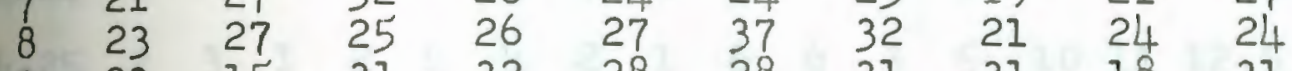

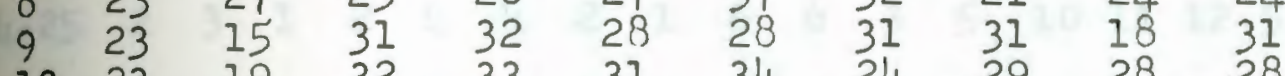

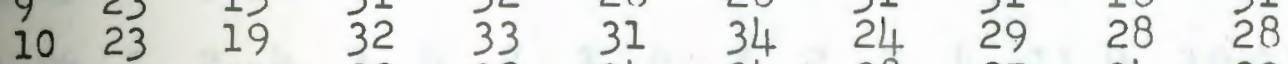

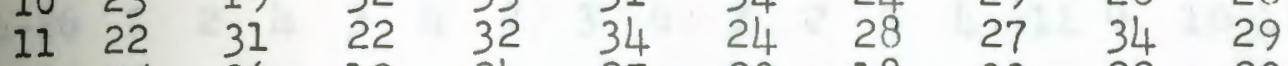

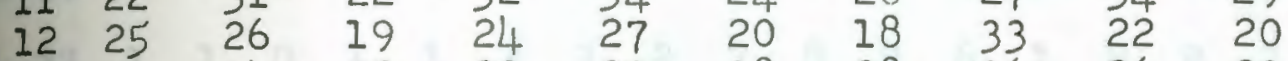

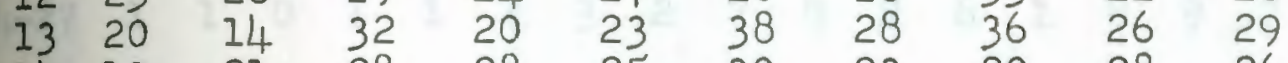

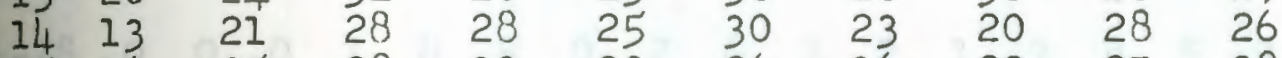

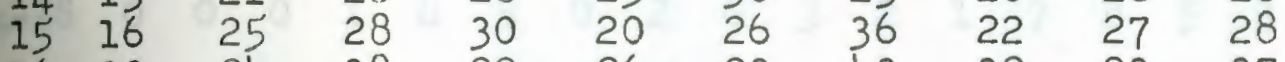

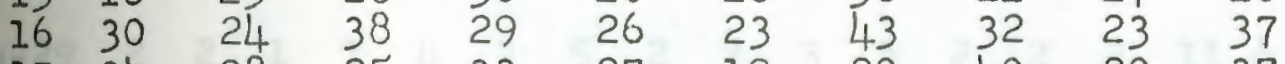

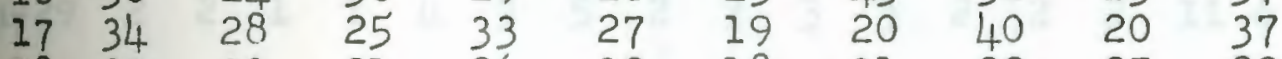
$\begin{array}{lllllllllll}18 & 23 & 30 & 21 & 26 & 32 & 18 & 31 & 22 & 27 & 29\end{array}$

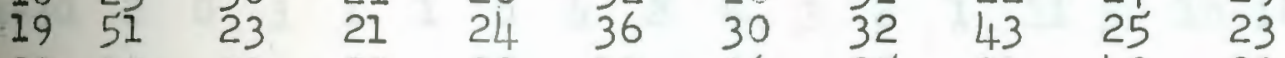

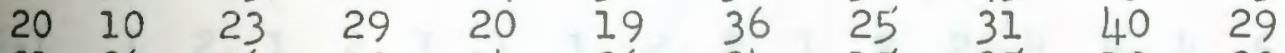

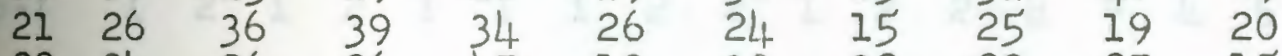

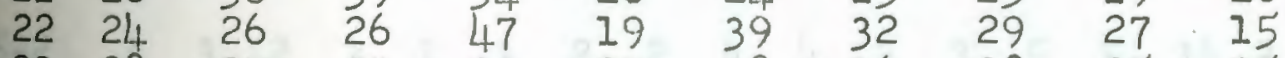

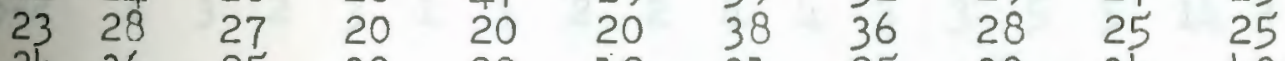

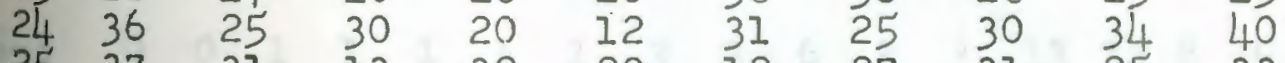

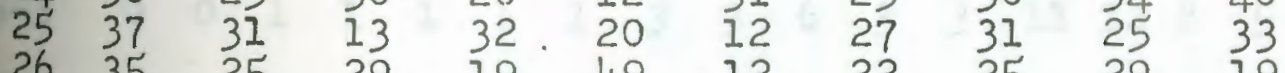

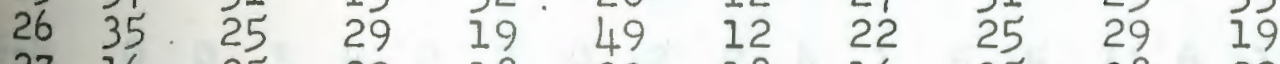

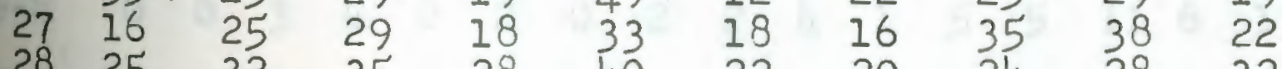

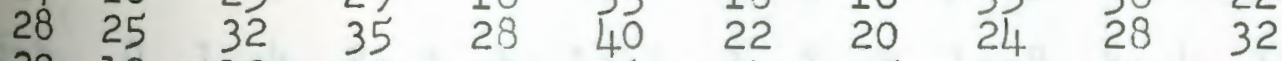

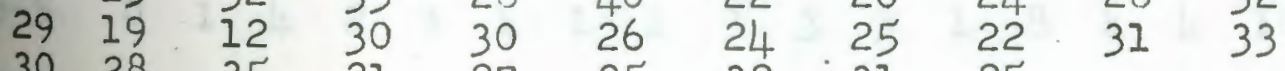
$\begin{array}{llllllllll}30 & 28 & 35 & 21 & 27 & 25 & 32 & 31 & 25 & \\ 31 & 33 & 18 & & & 23 & 35 & 18 & 25 & \end{array}$ $\begin{array}{llllllllll}814 & 795 & 817 & 803 & 844 & 832 & 823 & 858 & 814 & 773\end{array}$ 


\section{TABLE - 12}

NUMBER OF PATIENTS DISCHARGED AND ADMITTED

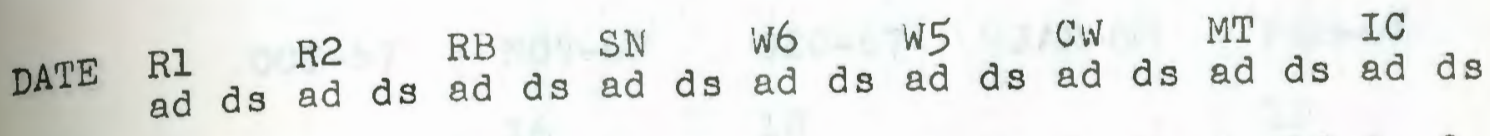
$\begin{array}{lllllllllllllllllll}4-21 & 0 & 1 & 3 & 4 & 2 & 3 & 4 & 5 & 5 & 6 & 1 & 3 & 5 & 3 & 3 & 12 & 3 & 0\end{array}$ $\begin{array}{lllllllllllllllllll}4-22 & 2 & 2 & 2 & 1 & 0 & 0 & 4 & 1 & 5 & 3 & 3 & 4 & 10 & 9 & 6 & 7 & 1 & 0\end{array}$ $\begin{array}{lllllllllllllllllll}4-23 & 2 & 1 & 4 & 4 & 1 & 2 & 1 & 0 & 1 & 2 & 2 & 1 & 10 & 7 & 9 & 8 & 0 & 0\end{array}$

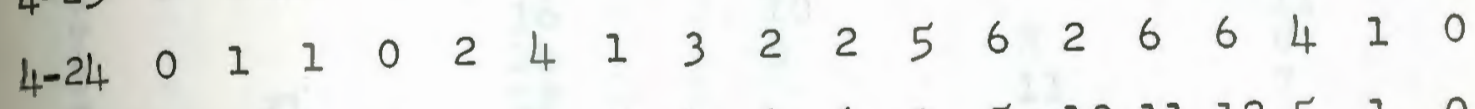
$\begin{array}{lllllllllllllllllll}4-25 & 2 & 3 & 1 & 2 & 4 & 4 & 2 & 1 & 6 & 6 & 3 & 5 & 10 & 11 & 12 & 5 & 1 & 0\end{array}$ $\begin{array}{lllllllllllllllllll}4-26 & 1 & 2 & 4 & 3 & 4 & 2 & 3 & 6 & 2 & 2 & 3 & 4 & 11 & 9 & 10 & 11 & 0 & 0\end{array}$ $\begin{array}{lllllllllllllllllll}4-27 & 1 & 1 & 0 & 1 & 1 & 2 & 3 & 2 & 7 & 8 & 2 & 6 & 1 & 8 & 9 & 7 & 0 & 1\end{array}$

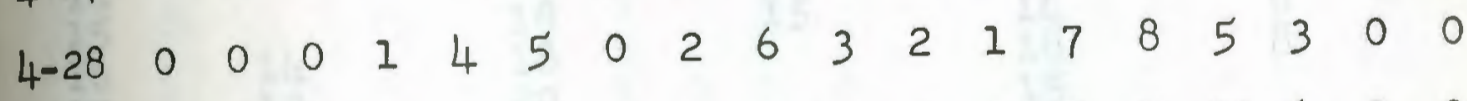
$\begin{array}{ccccccccccccccccccc}4-29 & 2 & 2 & 1 & 1 & 4 & 3 & 5 & 2 & 3 & 3 & 3 & 2 & 2 & 2 & 11 & 6 & 0 & 0\end{array}$ $\begin{array}{lllllllllllllllllll}4-30 & 2 & 0 & 3 & 1 & 1 & 0 & 4 & 2 & 4 & 3 & 2 & 1 & 11 & 5 & 10 & 18 & 0 & 0\end{array}$ $\begin{array}{ccccccccccccccccccc}5-1 & 1 & 2 & 1 & 2 & 1 & 1 & 1 & 2 & 2 & 1 & 2 & 2 & 4 & 9 & 4 & 5 & 0 & 0\end{array}$

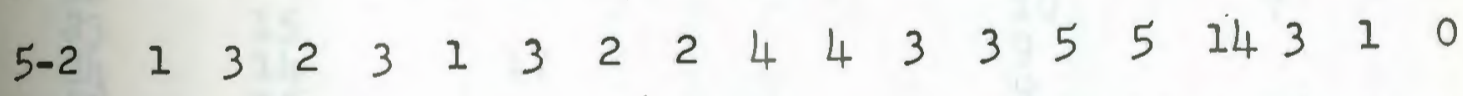
$\begin{array}{ccccccccccccccccccc}5-3 & 0 & 0 & 1 & 1 & 1 & 1 & 1 & 3 & 3 & 6 & 3 & 3 & 11 & 12 & 8 & 5 & 1 & 0\end{array}$ $\begin{array}{ccccccccccccccccccc}5-4 & 0 & 0 & 3 & 4 & 0 & 2 & 0 & 2 & 2 & 4 & 1 & 5 & 5 & 11 & 6 & 13 & 1 & 0\end{array}$ $\begin{array}{lllllllllllllllllll}5-5 & 0 & 1 & 4 & 2 & 3 & 1 & 1 & 1 & 3 & 3 & 3 & 1 & 8 & 4 & 4 & 10 & 2 & 0\end{array}$ 5-6 $4 \begin{array}{llllllllllllllllll} & 4 & 0 & 0 & 0 & 1 & 1 & 1 & 3 & 4 & 2 & 2 & 7 & 2 & 8 & 7 & 1 & 0\end{array}$ $\begin{array}{ccccccccccccccccccc}5-7 & 2 & 2 & 2 & 4 & 2 & 4 & 1 & 5 & 3 & 4 & 0 & 2 & 9 & 5 & 9 & 7 & 0 & 1\end{array}$ $\begin{array}{ccccccccccccccccccc}5-8 & 4 & 3 & 1 & 0 & 0 & 0 & 0 & 0 & 2 & 2 & 4 & 3 & 5 & 9 & 11 & 3 & 2 & 1\end{array}$ $\begin{array}{lllllllllllllllllll}5-9 & 0 & 1 & 2 & 3 & 2 & 4 & 4 & 5 & 1 & 3 & 2 & 2 & 8 & 4 & 9 & 6 & 1 & 0\end{array}$ TOTAL 2429353733,42384564694656131129154141153 * ad-admitted ds-discharged 


\section{TABIE -13}

NUMBER OF PATIENTS SERVED BY PHYSICAL THERAPY

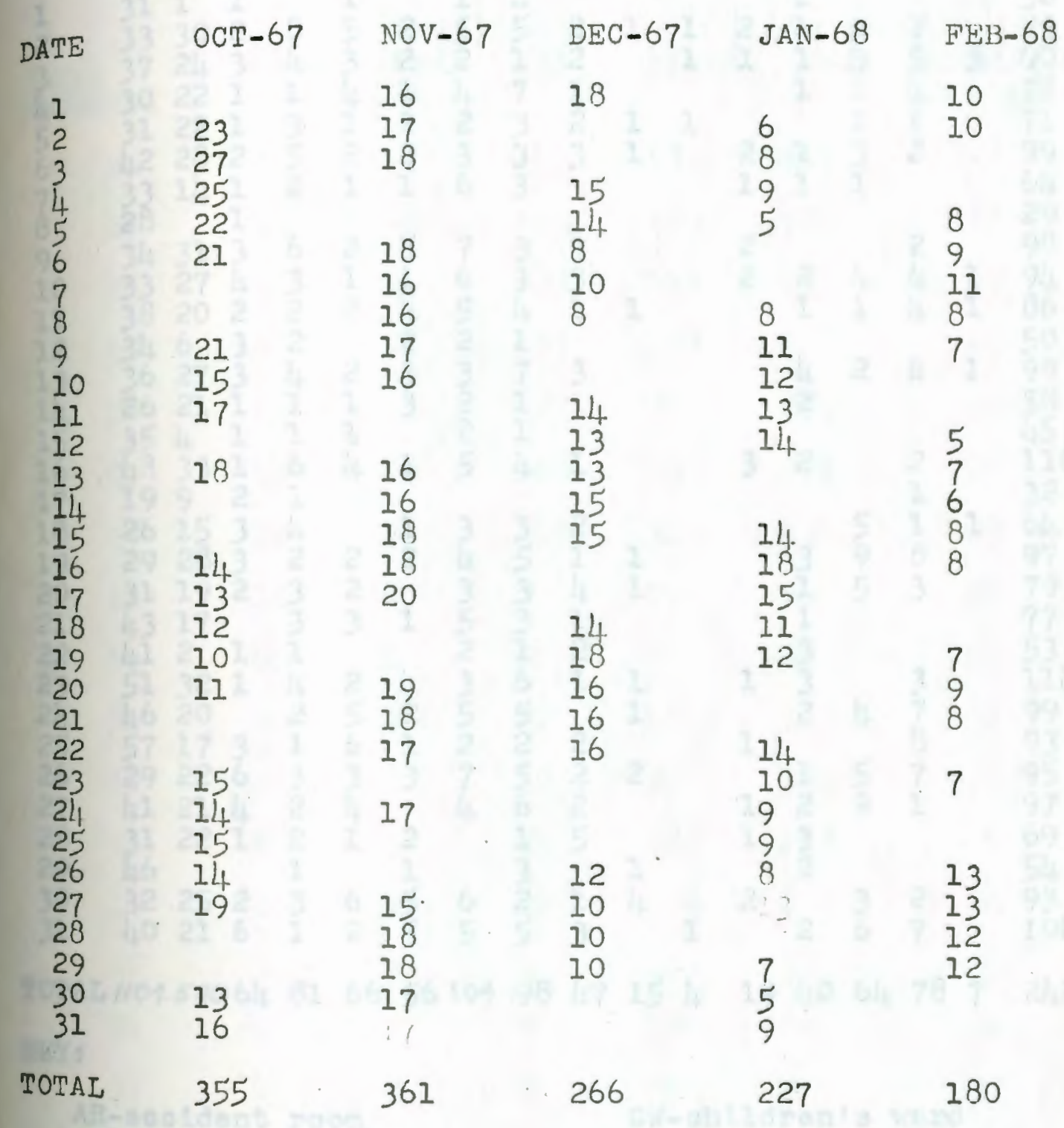


NUMBER OF PATIENTS SERVED IN X-RAY OCTOBER 1967

DATE AR PP RB RI R2 SN W6 W5 CW MT DR NR IC HC OP OR TOTAL

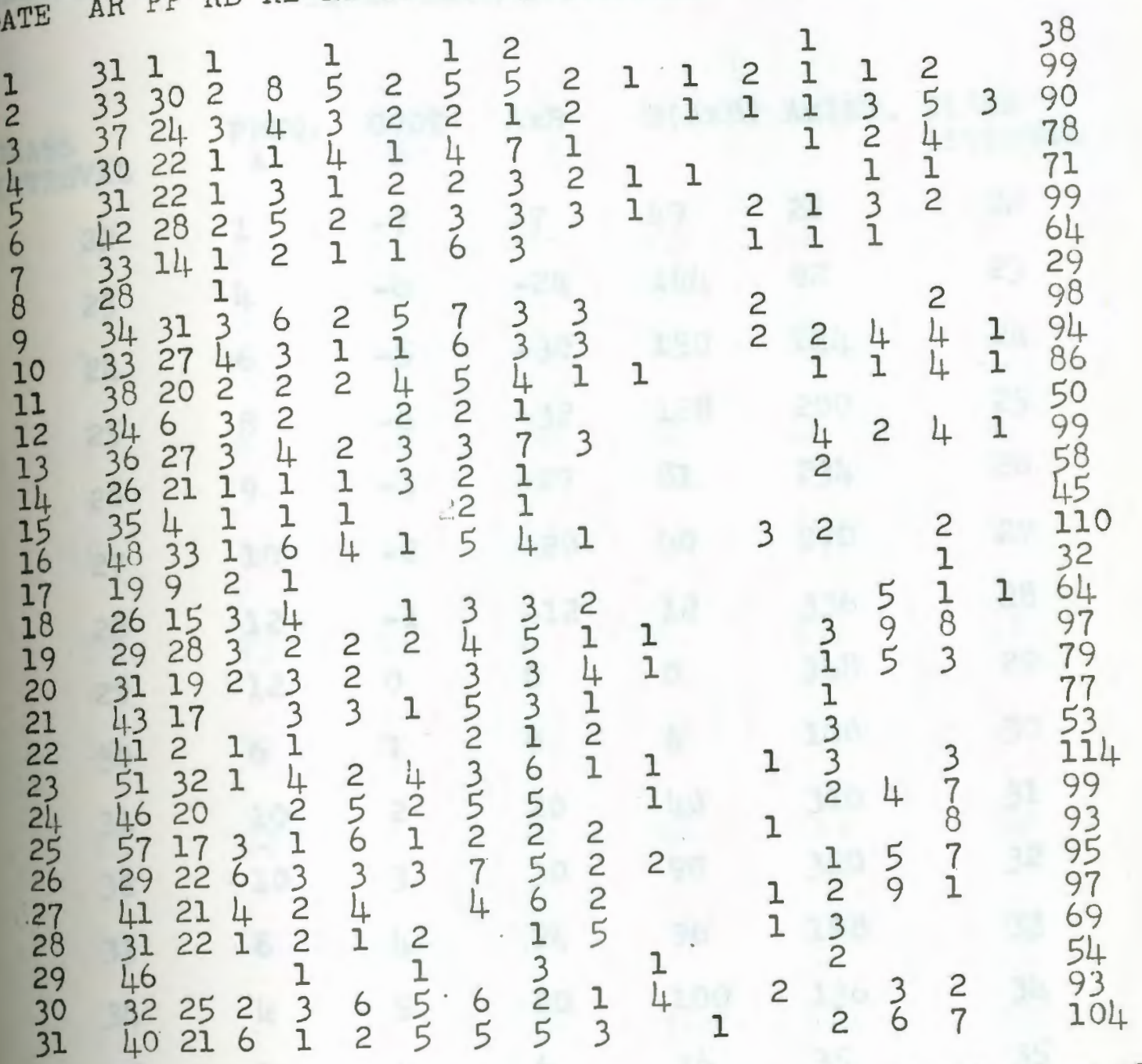

TOTAL $11045806481665610498 \quad 47.154 \quad 194064787 \quad 2428$ KEY:

AR-accident room

PP-private patients

RB-read building

Rl-richardson first floor

R2-richardson second floor

$\mathrm{SN}$-sayles north

W6-wood sixth floor

W5- wood fifth floor
CW-children's ward

MT-maternity

OR-operating room

NR-nursing

IC-intensive care unit

HC-health clinic

op-out patient department

DR-delivery room 


\section{TABLE - 25}

CALCULATION OF STANDARD DEVIATION FOR $9-10,10-11$ and
$11-12$ HOUR INTERVALS

CLASS

$\begin{array}{ccccc}\text { EREQ. } & \text { CODE } \\ \text { A } & B & A \times B & B(A \times B) A X I N T & \text { CLASS } \\ \text { INTERVAL }\end{array}$

$\begin{array}{lllllll}22 & 1 & -7 & -7 & 49 & 22 & 22 \\ 23 & 4 & -6 & -24 & 144 & 92 & 23 \\ 24 & 6 & -5 & -30 & 150 & 144 & 24 \\ 25 & 8 & -4 & -32 & 128 & 200 & 25 \\ 26 & 9 & -3 & -27 & 81 & 234 & 26 \\ 27 & 10 & -2 & -20 & 40 & 270 & 27 \\ 28 & 12 & -1 & -12 & 12 & 336 & 28 \\ 29 & 12 & 0 & 0 & 0 & 348 & 29 \\ 30 & 6 & 1 & 6 & 6 & 180 & 30 \\ 31 & 10 & 2 & 20 & 40 & 310 & 31 \\ 32 & 10 & 3 & 30 & 90 & 320 & 32 \\ 33 & 6 & 4 & 21 & 96 & 198 & 33 \\ 34 & 4 & 5 & 20 & 100 & 136 & 34 \\ 35 & 1 & 6 & 6 & 36 & 35 & 35 \\ 36 & 1 & 7 & 7 & 49 & 36 & 36 \\ 37 & 1 & 8 & 8 & 64 & 37 & 37 \\ 38 & 2 & 9 & 18 & 162 & 76 & 38 \\ & & & & & & 36\end{array}$

TOTAL

103

$13 \quad 1247 \quad 2974$ 


\section{TABLE - 26}

CALCULATION OF STANDARD DEVIATION FOR 12-1 HOUR INTERVAL

CLASS

INTERVAL

\begin{tabular}{|c|c|c|c|c|c|c|}
\hline 6 & 2 & -4 & -8 & 32 & 12 & 6 \\
\hline 7 & 4 & -3 & -12 & 36 & 28 & 7 \\
\hline 8 & 8 & -2 & -16 & 32 & 64 & 8 \\
\hline 9 & 12 & -1 & -12 & 12 & 108 & 9 \\
\hline 10 & 23 & 0 & 0 & 0 & 230 & 10 \\
\hline 11 & 16 & 1 & 16 & 16 & 176 & 11 \\
\hline 12 & 12 & 2 & 24 & 48 & 144 & 12 \\
\hline 13 & 10 & 3 & 30 & 90. & 130 & 13 \\
\hline 14 & 7 & 4 & 28 & 112 & 198 & 14 \\
\hline 15 & 5 & 5 & 25 & 125 & 75 & 15 \\
\hline & 99 & & 75 & 503 & 1065 & \\
\hline
\end{tabular}

INTERVAL

B

AxB

CLASS

FREQ. CODE AXB B(AXB) AXINT. 
CALCULATION OF STANDARD DEVIATION FOR $1-2$ and $2-3$ HOUR INTERVALS

$\begin{array}{lllllll}\text { CLASS } & \text { FREQ. } & \text { CODE } & \text { AxB } & \text { B }(A \times B) & \text { AXINT. } & \text { CLASS } \\ \text { INTERVAL } & \text { A } & B & & & & \\ 15 & 1 & -11 & -11 & 121 & 15 & 15 \\ 16 & 0 & -10 & 0 & 0 & 0 & 16 \\ 17 & 0 & -7 & 0 & 0 & 0 & 17 \\ 18 & 3 & -8 & -24 & 192 & 54 & 18 \\ 19 & 6 & -7 & -42 & 294 & 114 & 19 \\ 20 & 10 & -6 & -60 & 360 & 200 & 20 \\ 21 & 6 & -5 & -30 & 150 & 126 & 21 \\ 22 & 6 & -4 & -24 & 96 & 132 & 22 \\ 23 & 9 & -3 & -27 & 81 & 207 & 23 \\ 24 & 8 & -2 & -16 & 32 & 192 & 24 \\ 25 & 6 & -1 & -6 & 6 & 150 & 25 \\ 26 & 12 & 0 & 0 & 0 & 312 & 26 \\ 27 & 5 & 1 & 5 & 5 & 135 & 27 \\ 28 & 4 & 2 & 8 & 16 & 112 & 28 \\ 29 & 6 & 3 & 18 & 54 & 174 & 29 \\ 30 & 4 & 4 & 16 & 64 & 120 & 30 \\ 31 & 6 & 5 & 30 & 150 & 186 & 31 \\ 32 & 2 & 6 & 12 & 72 & 64 & 32 \\ 33 & 4 & 7 & 28 & 196 & 132 & 33 \\ 34 & 1 & 8 & 8 & 64 & 34 & 34 \\ 35 & 1 & 9 & 9 & 81 & 35 & 35 \\ 36 & 2 & 10 & 20 & 200 & 72 & 36 \\ 37 & 1 & 11 & 11 & 121 & 37 & 37 \\ 38 & 0 & 12 & 0 & 0 & 0 & 38 \\ 39 & 1 & 13 & 13 & 169 & 39 & 39 \\ & & & & & & \\ \text { TOTAL } & 104 & & -82 & 2524 & 2642 & \\ & & & & & & \end{array}$




\section{TABLE - 18}

WQUARE TEST FOR THE 9-10, 10-11, and 11-12 HOUR INTERVALS

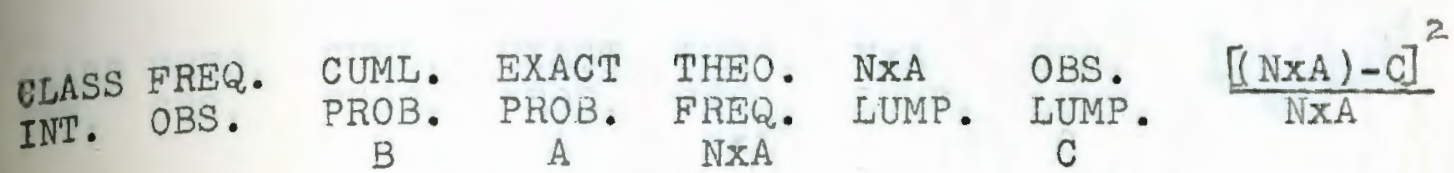

$\begin{array}{llllllll}22 & 1 & .0322 & .0322 & 3.30 & & & \\ 23 & 4 & .0606 & .0288 & 2.96 & 10.90 & 11 & .0010 \\ 24 & 6 & .1056 & .0450 & 4.64 & & & \\ 25 & 8 & .1711 & .0655 & 6.75 & 6.75 & 8 & .2310 \\ 26 & 9 & .2578 & .0876 & 8.94 & 8.94 & 9 & .0004 \\ 27 & 10 & .3632 & .1054 & 10.85 & 10.85 & 10 & .0690 \\ 28 & 12 & .4801 & .1169 & 12.05 & 12.05 & 12 & .0002 \\ 29 & 12 & .5987 & .1176 & 12.10 & 12.10 & 12 & .0008 \\ 30 & 6 & .7088 & .1101 & 11.41 & 11.41 & 6 & 2.5500 \\ 31 & 10 & .8023 & .0935 & 9.64 & 9.64 & 10 & .0135 \\ 32 & 10 & .0749 & .0726 & 7.47 & 7.47 & 10 & .08600 \\ 33 & 6 & .9265 & .0516 & 5.31 & 5.31 & 6 & .0885 \\ 34 & 4 & .9599 & .0334 & 3.44 & & & \\ 35 & 1 & .9798 & .0199 & 2.05 & & & \\ 36 & 1 & .9906 & .0108 & 1.11 & 7.56 & 9 & .7500 \\ 37 & 1 & .9960 & .0054 & .55 & & & \\ 38 & 2 & 1.0000 & .0040 & .41 & & & \end{array}$

TOTAL

4.5644 
X SQUARE TEST FOR THE 12-1 HOUR INTERVAL

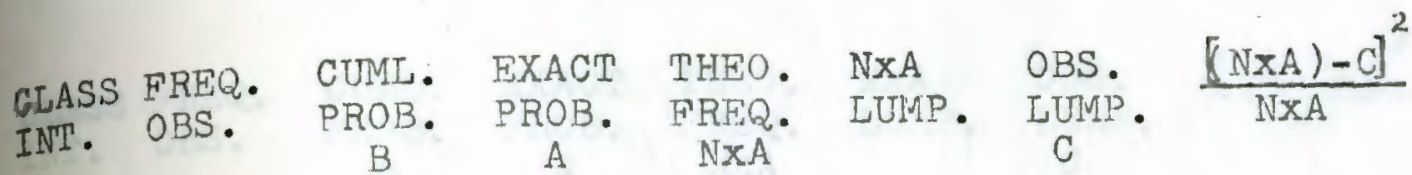

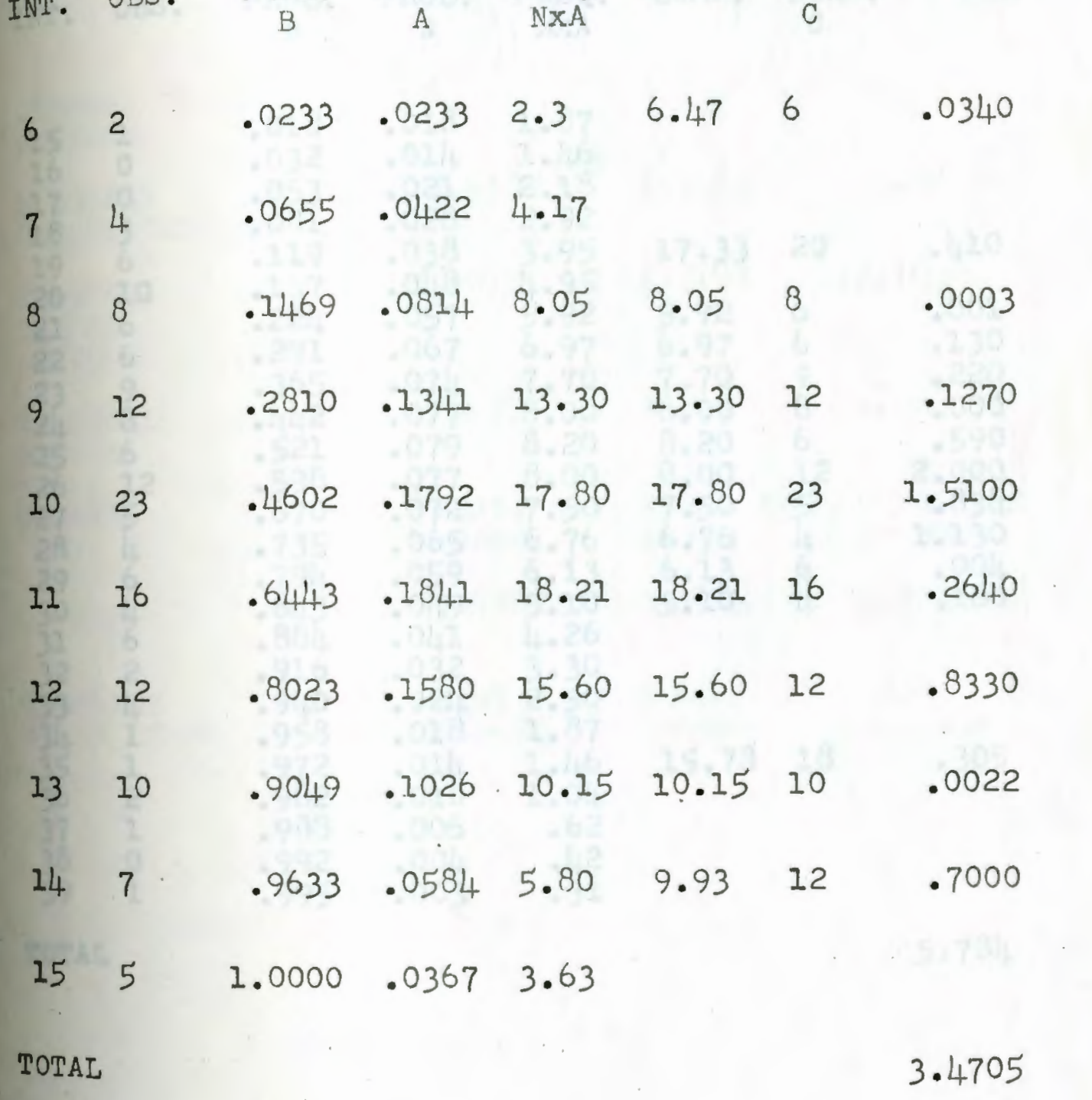


$x$ SQUARE TEST FOR THE $1-2$ and $2-3$ HOUR INTERVALS

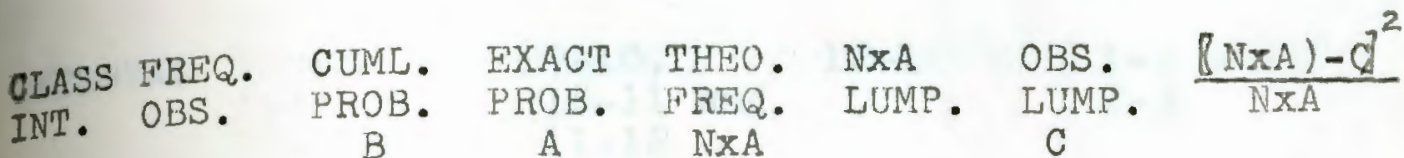

$\begin{array}{llllllll}15 & 1 & .018 & .018 & 1.87 & & & \\ 16 & 0 & .032 & .014 & 1.146 & & & \\ 17 & 0 & .053 & .021 & 2.18 & & & \\ 18 & 3 & .081 & .028 & 2.92 & & & \\ 19 & 6 & .019 & .038 & 3.95 & 17.33 & 20 & .410 \\ 20 & 10 & .167 & .048 & 4.95 & & & \\ 21 & 6 & .024 & .057 & 5.92 & 5.92 & 6 & .001 \\ 22 & 6 & .091 & .067 & 6.97 & 6.97 & 6 & .130 \\ 23 & 9 & .365 & .074 & 7.70 & 7.70 & 9 & .220 \\ 24 & 8 & .142 & .077 & 8.00 & 8.00 & 8 & .000 \\ 25 & 6 & .521 & .079 & 8.20 & 8.20 & 6 & .590 \\ 26 & 12 & .598 & .077 & 8.00 & 8.00 & 12 & 2.000 \\ 27 & 5 & .070 & .072 & 7.50 & 7.50 & 5 & .834 \\ 28 & 4 & .735 & .065 & 6.76 & 6.76 & 4 & 1.130 \\ 29 & 6 & .094 & .059 & 6.13 & 6.13 & 6 & .004 \\ 30 & 4 & .043 & .049 & 5.10 & 5.10 & 4 & .160 \\ 31 & 6 & .084 & .041 & 4.26 & & & \\ 32 & 2 & .916 & .032 & 3.30 & & & \\ 33 & 4 & .940 & .024 & 2.50 & & & \\ 34 & 1 & .958 & .018 & 1.87 & & & \\ 35 & 1 & .972 & .014 & 1.46 & 15.78 & 18 & .305 \\ 36 & 2 & .982 & .010 & 1.04 & . & & \\ 37 & 1 & .988 & .006 & .62 & & & \\ 38 & 0 & .992 & .004 & .42 & & & \\ 39 & 1 & .995 & .003 & .31 & & & \end{array}$

TOTAL 


\section{TABLE - 21}

X SQUARE SIGNIFICANCE TEST

IMWERVAL

$9-10,12-1$ and $1-2$ and
$10-11$ and
$11-12$

8

5

10

FREEDOM

SQUARE

3.14705

$4 \cdot 5644$

5.7840

CALCULATED

X SQUARE

11.0705

15.5073

18.3070

TABIES

$=.05$

CRITICAL

REGION

$x_{c}^{2}>x_{T}^{2}$

$x_{c}^{2}>x_{T}^{2}$

$x_{c}^{2}>x_{T}^{2}$

ASSUME

Dist. not Dist. not Dist. not nornal normal

poisson

$3.4705<x_{T}^{2} \quad 4.5644<X_{T}^{2} \quad 5.7840<X_{T}^{2}$

CONCLITDE

AT 5\% LEVEL

Dist.

normal
Dist. normal
Dist.

poisson 


$\begin{array}{llllll}\text { UNIT } & \begin{array}{l}\text { ROUND } \\ \text { TRIP IN } \\ \text { MINUTES }\end{array} & \text { FREQUENCY FREQXTIME WA-SA } & (\text { DIF })^{2} \\ \text { RI } & 6.2286 & 81 & 504.5166 & .0427 & .0018 \\ \text { R2 } & 7.8436 & 66 & 517.6776 & 1.5723 & 2.4721 \\ \text { RB } & 5.5764 & 64 & 356.8896 & .6946 & .4 .825 \\ \text { SN } & 4.9566 & 56 & 277.5696 & 1.3147 & 1.7284 \\ \text { WOOD } & 6.3714 & 286 & 1822.2204 & .1001 & .0100 \\ \text { IC } & 6.0004 & 40 & 240.0160 & .2709 & .0734 \\ \text { TOTAL } & 56.0912 & 593 & 3718.8898 & & \end{array}$

$S A=\frac{56.0912}{9}$

$S A=6.2323$

$W A=\frac{3718.8898}{593}$

$W A=6.2713$

$\sum(D I F)^{2} F R E Q=296.7708$

$r^{2}=\frac{296.7708}{592}$

$\sigma^{2}=.5013$

$$
\begin{aligned}
& \text { HYP.: SA=WA } \quad \alpha=.01 \\
& \text { ALT. HYP.: SA } \begin{array}{ll}
C R A & C R T C T_{T} \\
T_{T}=2.62
\end{array} \\
& T=\frac{\bar{X}_{1}-\bar{X}_{2}}{\sqrt{N}} \\
& T c=\frac{.0490}{.708} \\
& T_{c}<T_{r} \\
& \text { Accept HYP. } \\
& \text { Conclude } S A=W A \\
& T_{c}=1.6817
\end{aligned}
$$




\section{TABIE - 23}

PHYSICAL THERAPY MOVE TIME

UNIT

ROUND
TRIP IN

FREQUENCY FREQXTIME WA-SA

$(D I F)^{2}$

MINUTESS

RI

$5.2672 \quad 33$

R2

$5.2672 \quad 45$

$\mathrm{RB}$

$6.0498 \quad 34$

SN

$6.5716 \quad 28$

WOOD

$10.4116 \quad 75$

215

1581.4096

HYP. $S A=W A$

$\mathrm{SA}=\frac{43.9790}{6}$

$S A=7 \cdot 3298$

$N A=\frac{1581 \cdot 4.096}{215}$

$W_{A}=7.3553$

$\begin{array}{lll}173.8176 & 2.0881 \quad 4.3601\end{array}$

$273.0240 \quad 2.0881 \quad 4.3601$

$205.6932 \quad 1.3055 \quad 1.7043$

$184.0048 \quad .7837 \quad .6141$

$780.8700 \quad 3.0563 \quad 9.3409$

$\sum(D I F)^{2} F R E Q=1115.7963 \quad T_{c}=.1442$

$\sigma^{2}=\frac{1115 \cdot 7963}{214}$

$r^{2}=5.214$ 


\section{TABLE - 24}

\section{ADMITTING MOVE TIME}

UNIT

ROUND

TRIP IN

MINUTES

FREQUENCY FREQXTIME WA-SA

$(D I F)^{2}$

$\begin{array}{lrlrrr}\text { RI } & 7.3538 & 24 & 176.4912 & .2700 & .0738 \\ \text { R2 } & 8.9688 & 35 & 313.9080 & 1.8850 & 3.3332 \\ \text { RB } & 6.6688 & 33 & 220.0704 & .4150 & .1724 \\ \text { SN } & 5.9514 & 38 & 226.0832 & 1.1324 & 1.2824 \\ \text { W5 } & 7.1132 & 46 & 327.2072 & .0294 ! & .0009 \\ \text { W6 } & 7.1132 & 64 & 455.2448 & .0294 & .0009 \\ \text { W4 } & 7.1132 & 131 & 931.8292 & .0294 & .0009 \\ \text { W2 } & 7.1132 & 154 & 1095.4328 & .0294 & .0009 \\ \text { IC } & 5.1360 & 14 & 71.9040 & 1.9468 & 3.7730 \\ \text { TOTAL } & 62.5316 & 539 & 3818.2408 & & \end{array}$

$S A=\frac{62.5316}{9}$

$S A=6.9479$

$W_{A}=\frac{3818.2408}{539}$

$W A=7.0839$

$\sum(D I F)^{2} F R E Q=233.9616$

$r^{2}=\frac{33.9616}{538}$

$\sigma^{2}=.4340$
HYP.: $S A=W A \quad \alpha=.01$

ALT. HYP.: SAFWA $C R=T_{C}>T_{T}$

$\mathrm{T}_{c}=\frac{\bar{X}_{1}-\bar{X}_{2}}{\sqrt{N}}$

$\mathrm{T}_{c}=\frac{.136}{.0284}$

$T_{c}=4.7887$
Don't Accopt HYP. Conclude $S A \neq W A$ 


\section{TABLE - 25}

DISCHARGE MOVE TIME

$\begin{array}{llllll}\text { UNIT } & \begin{array}{l}\text { ROUND } \\ \text { TRIP IN } \\ \text { MINUTIS }\end{array} & \text { FREQUENCY FREQXTIME WA-SA } & {\text { (DIF })^{2}}^{2} \\ \text { RI } & 7.3538 & 29 & 213.2602 & .2428 & .0688 \\ \text { R2 } & 8.9688 & 37 & 331.8456 & 1.8578 & 3.4516 \\ \text { RB } & 6.6688 & 42 & 280.0896 & .4422 & .1556 \\ \text { SN } & 5.9514 & 45 & 267.8130 & 1.1596 & 1.3448 \\ \text { W5 } & 7.1132 & 56 & 398.3392 & .0022 & .0001 \\ \text { W6 } & 7.1132 & 69 & 490.8108 & .0022 & .0001 \\ \text { W4 } & 7.1132 & 129 & 914.6028 & .0022 & .0001 \\ \text { W2 } & 7.1132 & 182 & 1294.6024 & .0022 & .0001 \\ \text { IC } & 5.1360 & 3 & 15.4080 & 1.9750 & 3.9008 \\ \text { TOTAL } & 62.5316 & 592 & 4209.7716 & & \end{array}$

\begin{tabular}{|c|c|c|}
\hline$S A=\frac{62.5316}{9}$ & $\begin{aligned} \text { HYP. : } & \text { SA=WA } \\
\text { AIT.HYP.: } & \text { SA WA }\end{aligned}$ & $\begin{array}{l}\alpha=.01 \\
\mathrm{CR} T_{C}>T_{T}\end{array}$ \\
\hline$S A=6.9478$ & $T_{c}=\bar{X}_{1}-\bar{X}_{2}$ & $I=2.02$ \\
\hline$W A=\frac{4209 \cdot 7716}{592}$ & $\sqrt{N}$ & $\begin{array}{l}\text { Don't Accept HYP. } \\
\text { Conclude SA=WA }\end{array}$ \\
\hline & $\mathrm{T}_{c}=\frac{.1632}{.0243}$ & \\
\hline$\Sigma(D I F)^{2} F R E Q=210.0224$ & $T_{c}=6.857$ & \\
\hline$\sigma^{2}=\frac{210.0224}{591}$ & & \\
\hline$\sigma^{2}=.3547$ & & \\
\hline
\end{tabular}




\section{TABLE -26}

AVERAGE TIMES FOR EACH HOUR INTERVAL $9-10,10-11$, and $11-12$ hour intervals

$\begin{array}{lllll}\text { DEPT. } & \begin{array}{l}\text { NUMBER OF } \\ \text { TRIPS }\end{array} & \begin{array}{l}\text { AVG. TIMF } \\ \text { PER TRIP }\end{array} & \begin{array}{l}\text { TOTAL } \\ \text { TIME }\end{array} & \begin{array}{l}\text { AVG. } \\ \text { TIME }\end{array} \\ \text { X-RAY } & 252 & 6.2323 & 1570.5396 & \\ \text { PHY.THY. } & 149 & 7.3298 & 1092.1402 & \frac{4288.1447}{630} \\ \text { DISCH. } & 229 & 7.0981 & 1625.14649 & \\ \text { TOTAL } & 630 & & 4288.1447 & 6.80 \mathrm{~min} .\end{array}$

12-I hour interval

$\begin{array}{lllll}\text { DEPT. } & \begin{array}{l}\text { NUNBER OF } \\ \text { TRIPS }\end{array} & \begin{array}{l}\text { AVG. TIME } \\ \text { PER TRIP }\end{array} & \text { TOTAL } & \text { AVG } \\ \text { TIMT } & \text { TTME } \\ \text { X-RAY } & 252 & 6.2323 & 1570.5396 & \frac{1570.5396}{252} \\ \text { TOTAL } & 252 & & 1570.5396 & 6.23 \mathrm{~min} .\end{array}$

1-2, and 2-3 hour intervals

$\begin{array}{lllll}\text { DEPT. } & \text { NUMBER OF } & \text { AVG. TIME } & \text { TOTAL } & \text { AVG. } \\ & \text { TRIPS } & \text { PER TRIP } & \text { TIMT } & \text { TIME } \\ \text { X-RAY } & 252 & 6.2323 & 1570.5396 & \frac{3880.6373}{569} \\ \text { ADMTT. } & 317 & 7.0981 & 2250.0977 & \\ \text { TOTAL } & 569 & & 3820.6373 & 6.71 \mathrm{~min} .\end{array}$

Sample includes the month of January, weekdays only 


\section{TABLE -27}

MANPOWER REQUIREMENTS

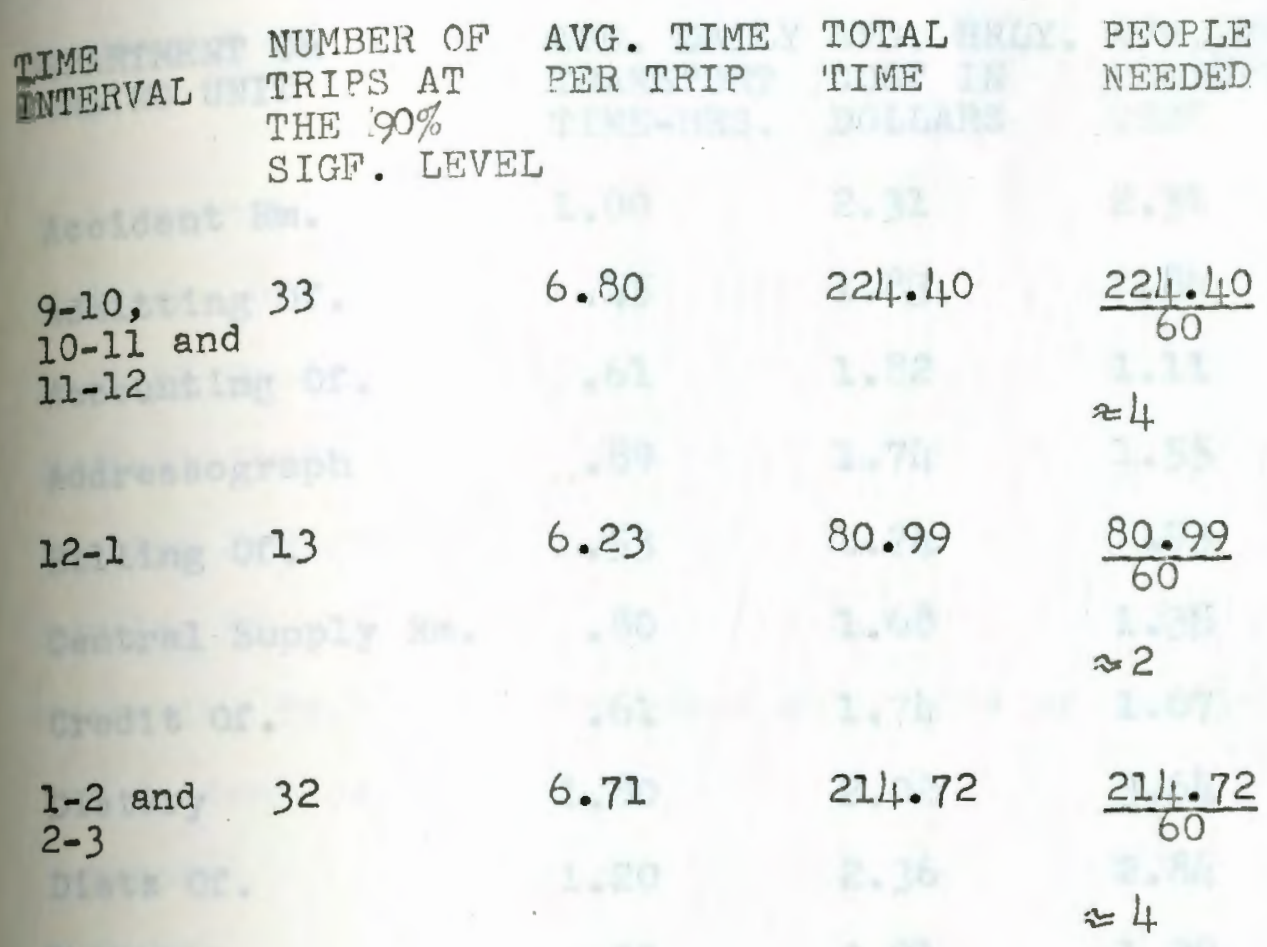




\section{TABLE - 28}

TRANSPORTATION COST BREAK DOWN

DEPARTMENT OR

WURSING UNIT

Accldent Rm.
Admitting of.
Accounting of.
Addressograph
Billing of.
Central Supply Rm.
Credit of.
Dietary
Dietz Of.
E.E.C.
E.K.G.

Plant Eng. Of'.

Gustavson of.

Health of.

Housekeeping

Hurley of.

I.B.M.

I.C.U.

Information Desk

Lab.

Laund ry
AVG. DAILY AVG. HRLY. AVG. DAILY

TRANSPORT COST IN

TIME-HRS. DOLLARS

TRANSPORT

$\cos T$

1.00

2.31

2.31

.45

1.83

.84

.61

1.82

1.11

.89

1.74

1.55

.53

1.74

.93

.80

1.68

1.35

.61

1.74

1.07

1.80

2.02

$3.6 \%$

1.20

2.36

2.84

.33

3.91

1.29

$.71 t$

1.82

1.35

no data avaliablo

.66

2.26

1.49

.89

3.28

2.92

2.69

1.70

4.58

.66

1.74

1.15

1.33

2.10

2.80

2.10

1.68

3.53

1.18

1.82

2.15

1.06

1.90

2.02

no data avaliable 


\section{TABLS - 29}

TRANSPORTATION COST BREAK DOWN

DEPARTMENT OR

NURSING UNIT

Maintenance

Medicare of.

Medical Recd.

Medical Staff Sec.

Nursing Ser. Del1v.

Nursing of.

operating Rm.

Out Patient Dopt.

Personnel

Pharmacy

Physical Therapy

Purchasing of.

Read

Richardson I

Richardson 2

Sayles

Store Rm.

Volunteer of.

Wood 2

Wood 4

Wood 5
AVG. DAILY AVG. HRLY. AVG. DAILY TRANSPORT COST IN TRANSPORT

TIME-HRS. DOLLARS COST

$\begin{array}{lll}.70 & 2.99 & 2.09\end{array}$

$\begin{array}{lll}.60 & 1.82 & 1.10\end{array}$

$3.45 \quad 1.77 \quad 6.11$

$\begin{array}{lll}.40 & 1.90 \quad .76\end{array}$

5.00

$1.74_{4}$

8.70

.34

1.90

.65

included with nursing service delivery

$\begin{array}{lll}2.03 & 1.68 & 3.41\end{array}$

$\begin{array}{lll}.94 & 1.94 & 1.82\end{array}$

$4.10 \quad 1.91 \quad 1.82$

$\begin{array}{lll}2.66 & 1.85 & 4.92\end{array}$

$\begin{array}{lll}.83 & 1.90 & 1.58\end{array}$

$\begin{array}{lll}3.41 & 1.80 & 6.13\end{array}$

$\begin{array}{lll}3.32 & 1.85 & 6.14\end{array}$

$\begin{array}{lll}3.10 & 1.32 & 5.62\end{array}$

$3.21 \cdots 1.80 \quad 5.77$

$\begin{array}{lll}1.43 & 2.11 & 3.02\end{array}$

$\begin{array}{lll}.86 & 2.26 & 1.94\end{array}$

$3.31 \quad 1.72 \quad 5.70$

$\begin{array}{lll}3.50 & 2.13 & 7.46\end{array}$

3.140

2.05

6.97 
TRANSPORTATION COST BREAK DOWN

DEPARTMENT OR

NURS ING UNIT

Wood 6

$\mathrm{X}$-Ray

Payroli of.

photography

Equipinent Rm.

Nursing Ed. Of.

*it

Estimate
AVG. DAILY AVG. HRLY. AVG. DAILY TRANSPORT COST IN TRANSPOR'

TIME-HRS . DOLLARS COST

$\begin{array}{lll}3.33 & 1.91 & 6.36\end{array}$

5.46

1.83

10.00

no data available

no data available

no data available

no data available

$4.00 \quad 1.80 \quad 7.20$

AVERAGE TOTAL COST \#150.20 PER DAY

*

Estimate for those departments with no data available 
MANPOWER POTENTIAL

* ESTIMATEd tRansportation SAVINGS

$\$ 150.20$

HOURLY WAGE RATE FOR TRANSPORTERS

$\$ 1.70$

NUMBER OF WORKING HOURS THAT CAN BE PAYED 88

NUMBER OF TRANSPORTERS THAT CAN BE HIRED

11

"Minimum estimate
Rate is .10 above minimum wage 
FIGURE - 1

MEMORIAL HOSPITAL OF PAWTUCKET
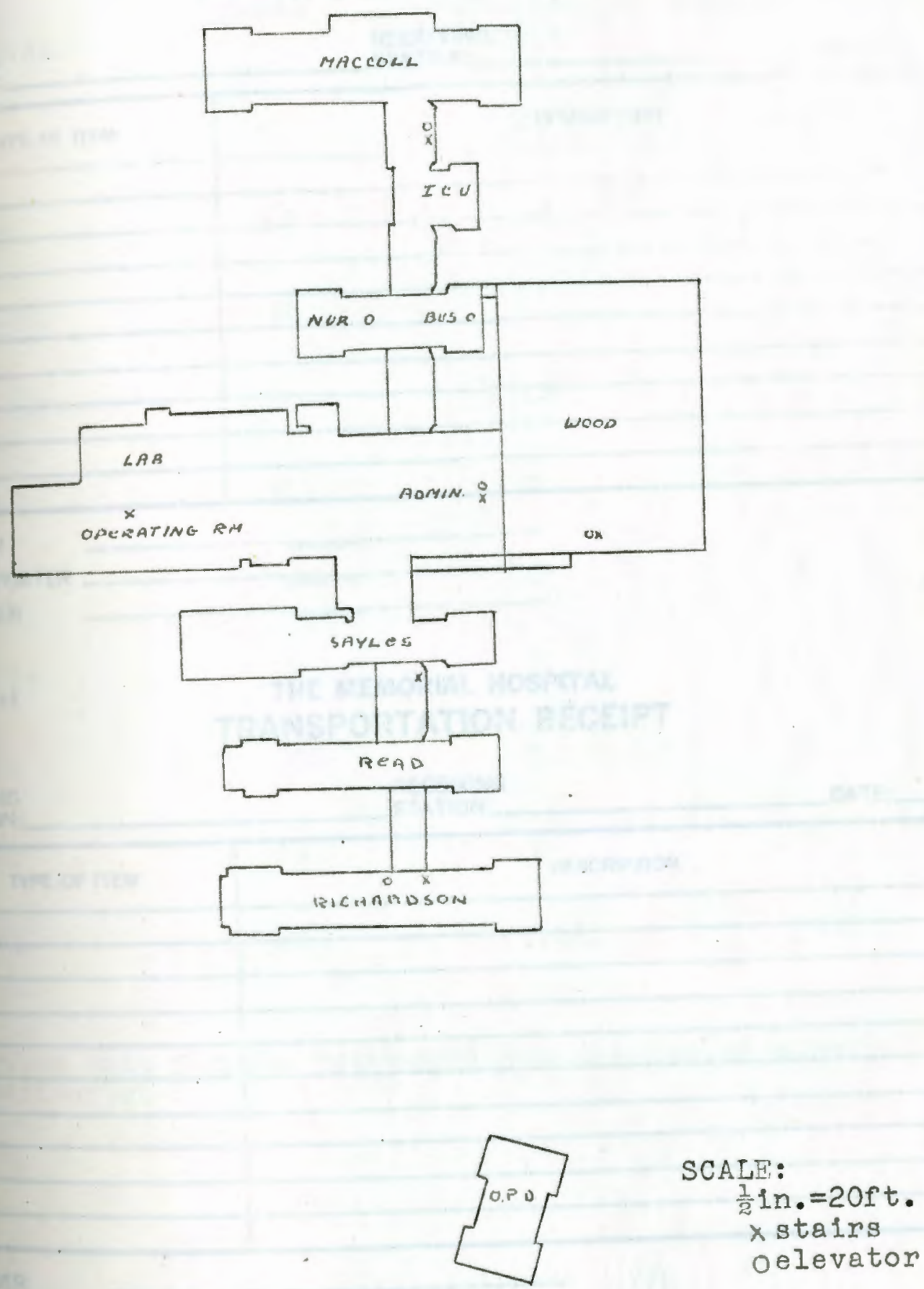
form CTS :

THE MEMORIML HOSPITAL

TRANSPORTATHON RECEIPT

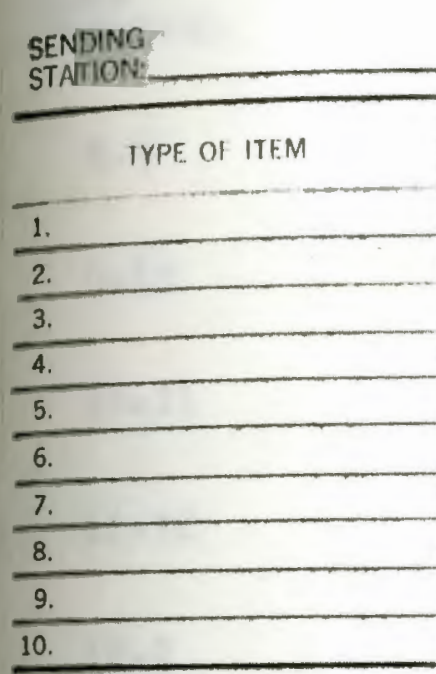

RECIEIVING

STA:TION:

MAl

SENDER

IRANSPORTER

RECEIVER

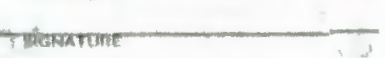

form cis I

THE MEMORIAL HOSPITAL TRANSPORTATION RECEIPT

SENDING

STATION

RECEIVING

STATION:

DATE:

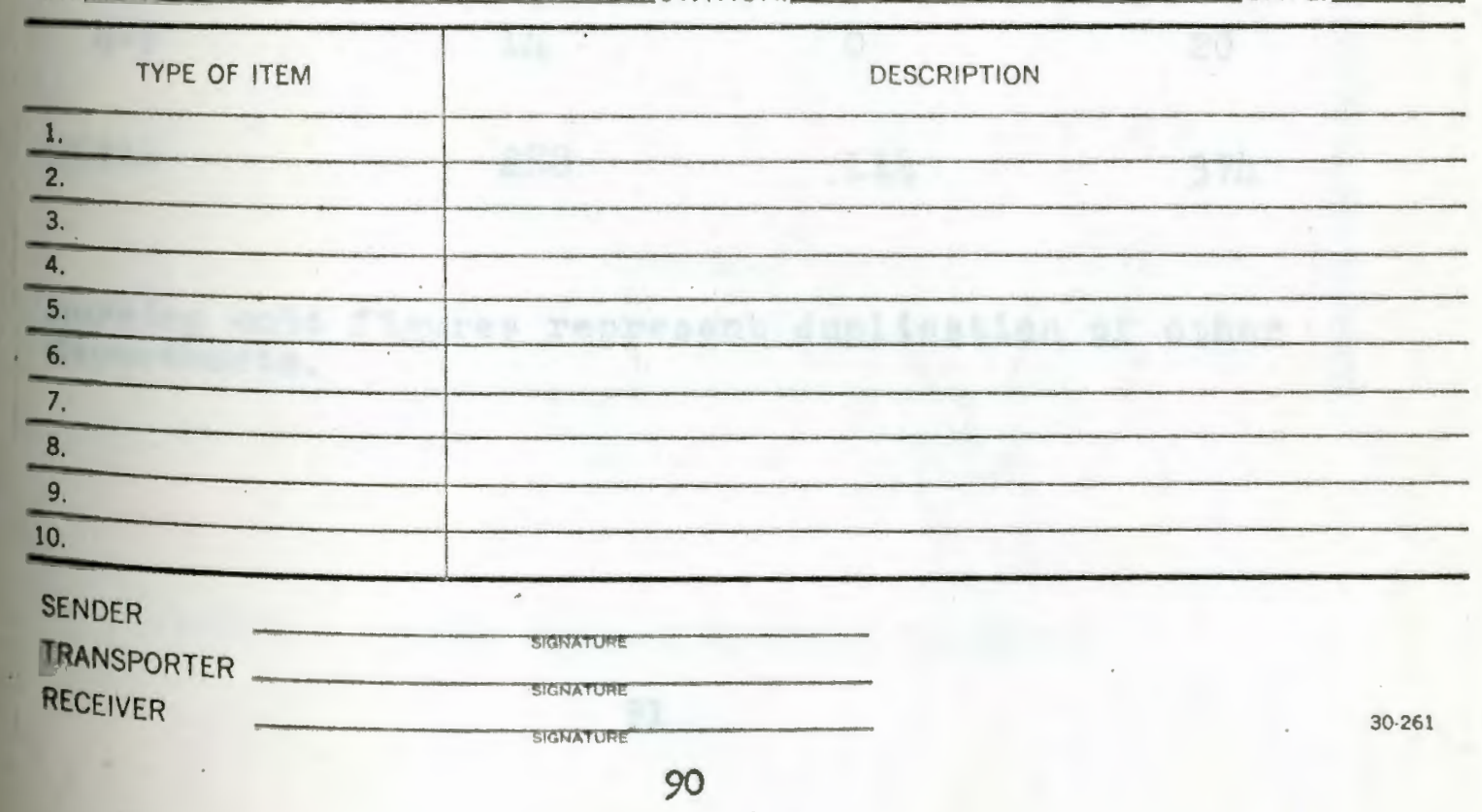


Flgure - 3

HOURLY BREAKDOWN OF PATIENTS MOVES FOR ONE WEEK

HOUR

INTERVAL

$$
8-9
$$

$9-10$

10-11

$11-12$

$12-1$

$1-2$

$2-3$

$3-4$

4-5

TOTAL

$$
\mathrm{X}-\mathrm{RAY}
$$

6

50

46

42

34

32

44

20

14

288
PHYSICAL THERAPY

2

32

48

16

0

31

36

33

20

20

0

114

37

37

80

80

6

7

3

(

374

nursing unit figures represent duplication of other departments. 
FIQURS - 4

FREQUENCY DISTRIBUTION FOR 9-10, 10-11 and 11-12 HOUR INTERVALS

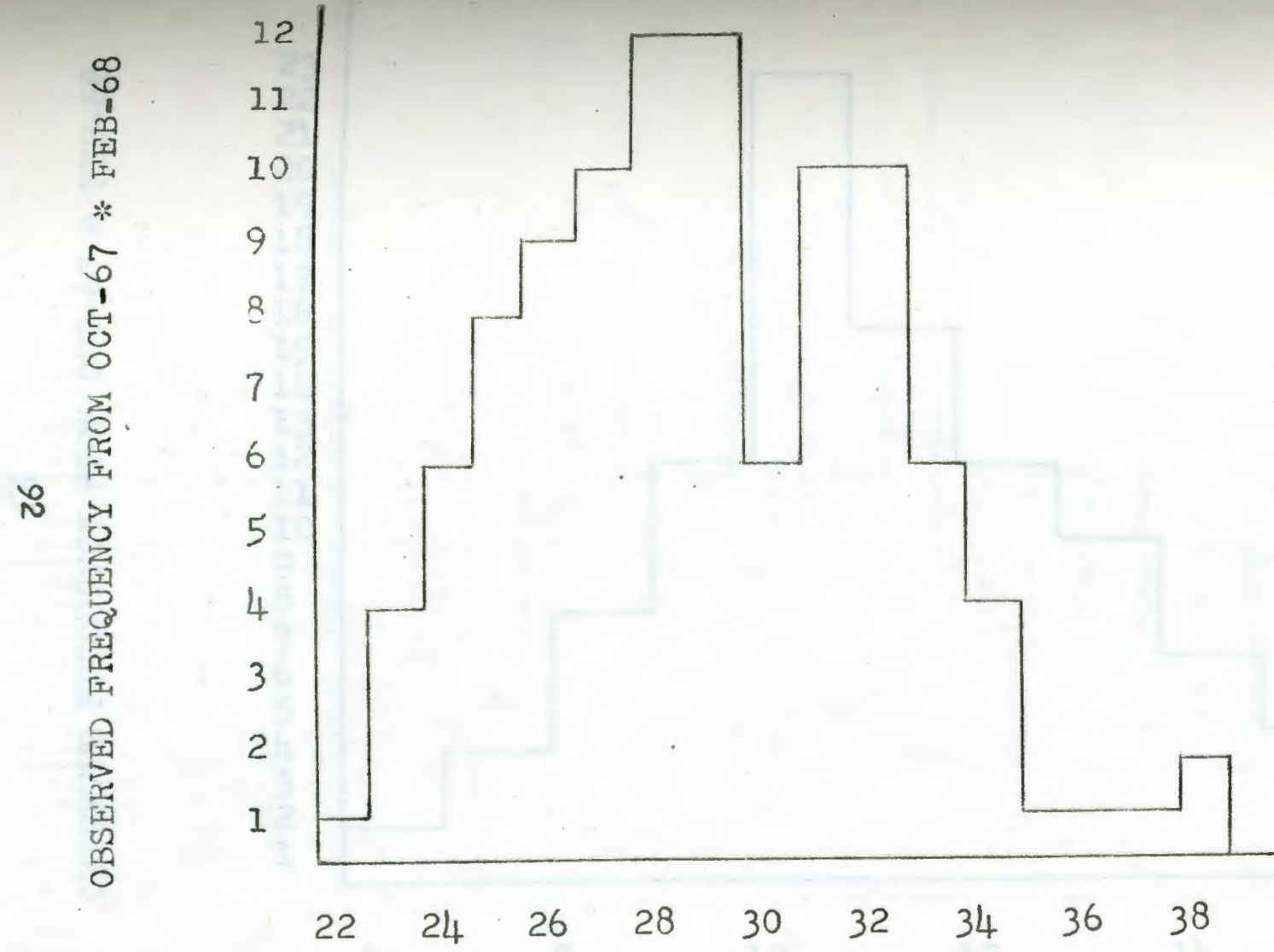

NUMBER OF SINGLE PATIENT MOVES 
FIGURE - 5

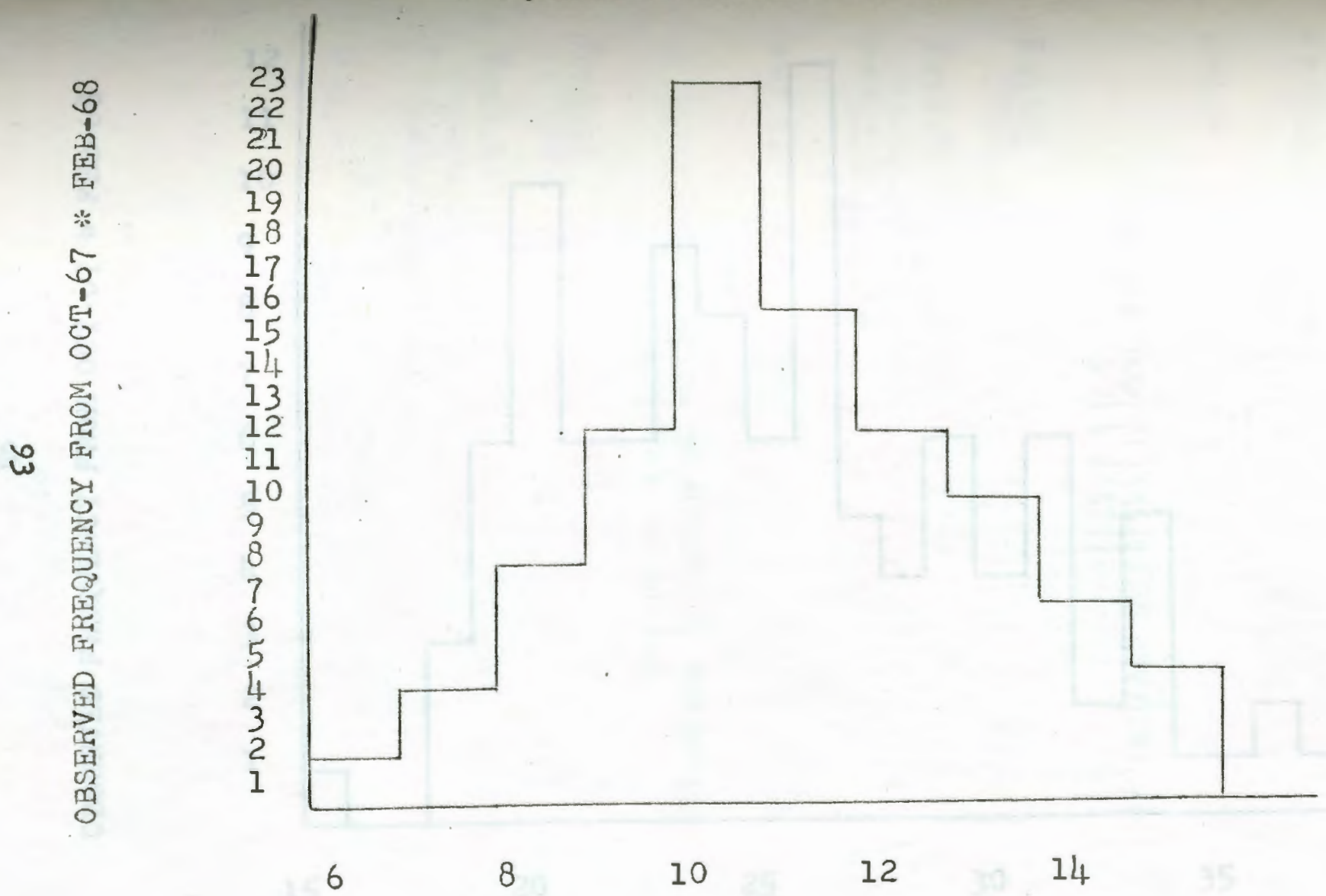

NUMBER OF SINGLE PATIENT MOVES 
FIOURE - 6

FREQUENCY DISTRIBUTION FOR $1-2$ and $2-3$ HOUR INTERVALS

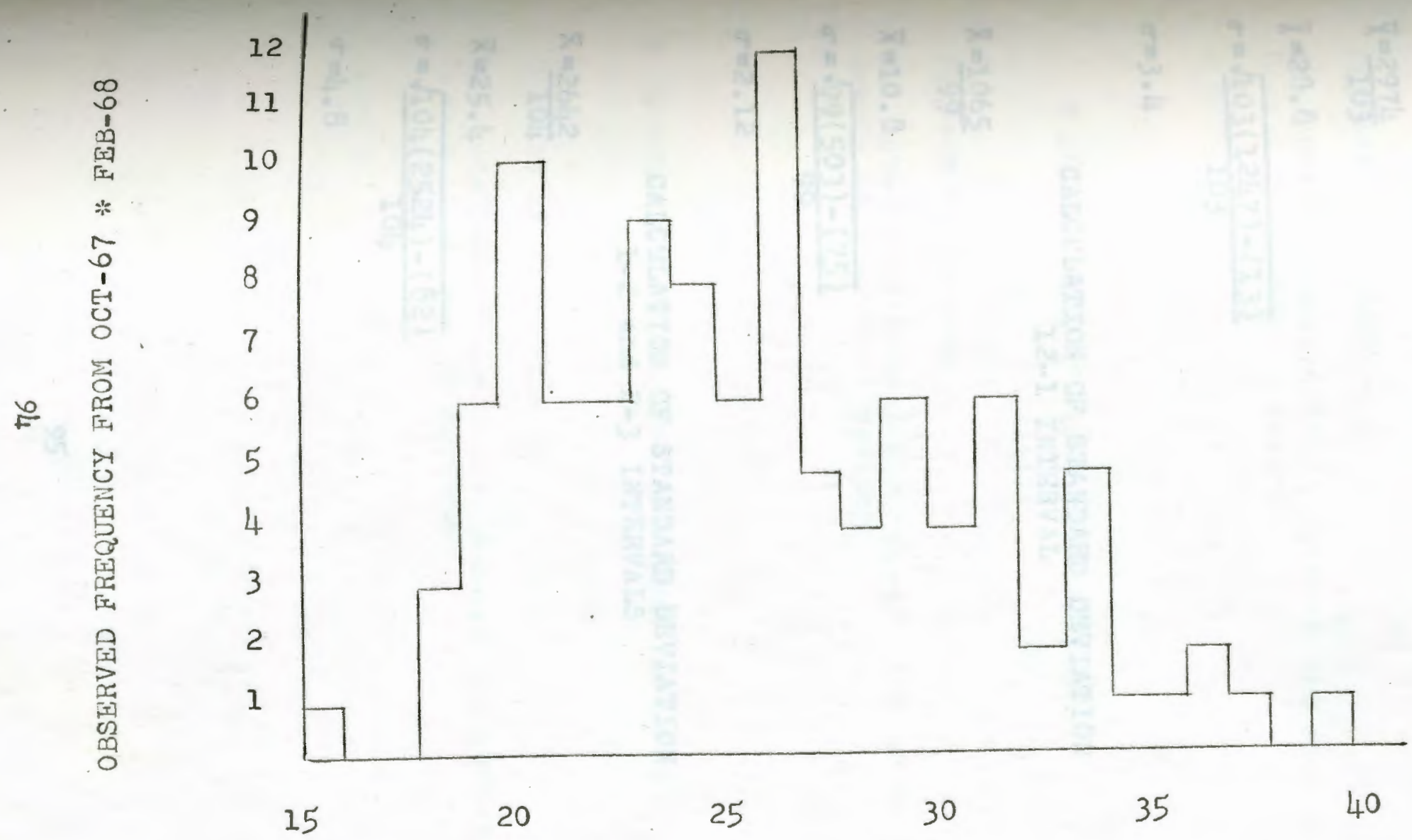

NUTBER OF SINGLE PATIEIT MOVES 


\section{FIGURE - 7}

CALCULATION OF STANDARD DEVIATION 9-10, 10-11 and 11-12 INTERVAIS

$$
\begin{aligned}
& \bar{x}=\frac{2974}{103} \\
& \bar{x}=28.8 \\
& \sigma=\frac{\sqrt{103(1247)-(13)}}{103} \\
& \sigma=3.4
\end{aligned}
$$

CALCULATION OF STANDARD DEVIATION 12-1 INTERVAL

$$
\begin{aligned}
& \bar{x}=\frac{1065}{99} \\
& \bar{x}=10.8 \\
& \sigma=\frac{\sqrt{99(503)-(75)}}{99} \\
& \sigma=2.12 \quad \text { CALCULATION OF STANDARD DEVIATION } \\
& \bar{x}=\frac{2642}{104} \\
& \bar{x}=25.4 \quad \text { and } 2-3 \text { INTERVALS } \\
& \sigma=\frac{\sqrt{104(2524)-(82)}}{104} \\
& \sigma=4.8 \quad
\end{aligned}
$$$$
\text { 1-2 and 2-3 INTERVALS }
$$ 
* SQUARE TEST ON 9-10, 10-11 and 11-12 HOUR INTERVALS

Degrees of freodom - 8

The total deviation falls between the probability levels of 90 and 80 percent

W SQUARE TEST ON 12-1 HOUR INTERVAL

Degrees of freedom - 5

The total deviation falls between the probability levels of 70 and 50 percent

X SQUARE TEST ON $1-2$ and $2-3$ HOUR INTERVALS

Degrees of froedom - 10

The total deviation falls between the probability

levels of 90 and 80 percent 
F-TEST BETWEEN DISCHARGE - ADMITTING

$$
\begin{aligned}
& \text { HYP.: } \sigma_{1}^{2}=\sigma_{2}^{2} \\
& \text { ALT. HYP.: } \sigma_{1}^{2} \neq \sigma_{2}^{2} \\
& F_{C}=\frac{.3547}{.4340} \\
& F_{C} \approx .83
\end{aligned}
$$$$
\sigma_{1}^{2}=.3547
$$$$
\sigma_{2}^{2}=.4340
$$$$
n_{1}=592
$$$$
\mathrm{n}_{2}=593
$$$$
\alpha=.01
$$

CRIPICAL REGION

$$
\begin{gathered}
F_{591,538,} .99<F_{c}<F_{591}, 538, .01 \\
.82<F_{c}<1.22
\end{gathered}
$$

$$
\text { Conclude: } \quad \sigma_{1}^{2}=\sigma_{2}^{2}
$$

T-TEST BETWEEN DISCHARGE - ADMITTING

HYP. : $\bar{X}_{1}=\bar{X}_{2}$

ALT. HYP.: $\overline{\bar{X}}_{1} \neq \bar{X}_{2}$

$T_{c}=7.0839-7.1110$

$\sqrt{\frac{.3547+.4340}{1129}}$

$T_{c} \neq 1$

$T_{T}=2.6$

$$
\begin{aligned}
& n_{1}=592 \\
& n_{2}=539 \\
& \alpha=.01
\end{aligned}
$$

\section{CRITICAL REGION}

$$
T_{6}<T_{T}
$$

Conclude: $\bar{X}_{1}=\bar{X}_{2}$

$$
\begin{aligned}
\text { AVERAGE POOLED TIME } & =\frac{8028.0124}{1131} \\
& =7.0981
\end{aligned}
$$


COMPUTER PROGRAM 
JCS GO, NOMAP, TIME 10

MAMESHAIN, LIST, NOREF

LPS PORTRAN D COMPILER

I.ARNLROGRAM

VALUES READ AS INPUT

COMMON DOIS(48.481, IGRPR(19.18).ITRESI

5.0002

INPRO (48), NSIAP( 48$), T$ TRES $(48)$

C AREAY VALUES COMPUTED BY PROGRAN

5.0002 COMMON IRST (15), ISYS(48), JARRY (35,30), JHRPR (50), KTOTAL (35), LHPPRESOLWHRPRESC

C SINGLE CELL VALUES COMPUTED OY PROGRAM

5.0003 COMMON IDDR IHR. ISA, ISTART LGROUP LSMTN LSMTY LSTAI E IME IIMEP

5.0004

5.0905

5.0006

5.0007

5.0008

5.0509

S.0310

5.0911

5.0012

5.0013

5.0 .1214

5.6015

5. 0216

5.0917

5.9718

S.0019

5. 920

S. 0021 COMMON ICDUNT. IOP, NCPS

DIMENSION LNAR (351. LYAR 15$)$

CALL INPUT

WRITEIIOP.1021

102 FORMAT( $1 \mathrm{HL})$

WRITE $10 P .4601$ LSTAT.

460 FORMATIIX, 24HTHE STARTING STATION IS $13 / 1$ )

C IVITIALIZATION

ITR $S=0$

$D C-5-1=2-4 B$

$5 \quad$ ISYS $(1)=0$

LSYS $(L S T A T .1=1$

NOPT $5=48$

10 ISTART $\# 0$

$N N=0$

NDONE $=0$

$I D D R=0$

$\therefore C L=0$

$131=0$

C TOTAL NO OF DEPTS NEEDED AT THUS IIME

5.9022

IC NUNT $=0$

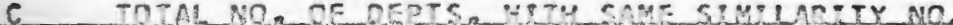

5. 2923

LSMTY $=0$

C TOFAL NO_ OF DEPTS WITH DIFFERENT SIHLLARITY NO.

$5.0024 \quad$ LSMTN $=0$

C _ OETERM?NE NO - DE_DEPTS - NEEDED

$5.0725001001=1$, NOPTS

FRAST TEST QAST TZZE TO SEE IF ALREAOY ONNE

5.0026

29 IF ETIMEP-TMRES (I) $3 \mathrm{C} \cdot 100.100$

MOU TEST PRESENT TIME

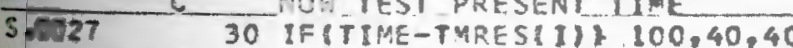

C STEP UP TOTAL NO COUNTER

SFA28 40 ICOUNT= ICOUNT+!

iSYSCI $1=0$

C SEE IF TMERE IS A SIMILAR NO. IN THE SIMILARITY ARRAY

TERSMM(I) R5.05.4.

$\sin 30$

5.0031

5.0932

5.0033

44 IFILSMTYI $60,60,45$

$450055:-1.15 M T Y$

ISUB=LYAR: J)

RE ANSIM(I)-NSIMUISUB) $55,50.55$

3.0095 THERE IS A SIMILAR NC.

3.0036

90037

3.0038

50.1 SMTY $=L$ LYYY\$

LYAR:LSMTYI $=I$

60 TO 100

55 CONTINUE

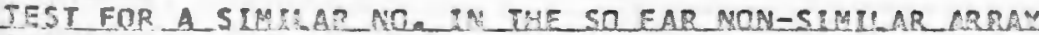

60 if (1SSMTN) 85.85 .65

$65.00 \quad 80 \quad J=1,15 M T M$

$\mathrm{JA}=\mathrm{J}$

[SUB $L$ NAPI J! 


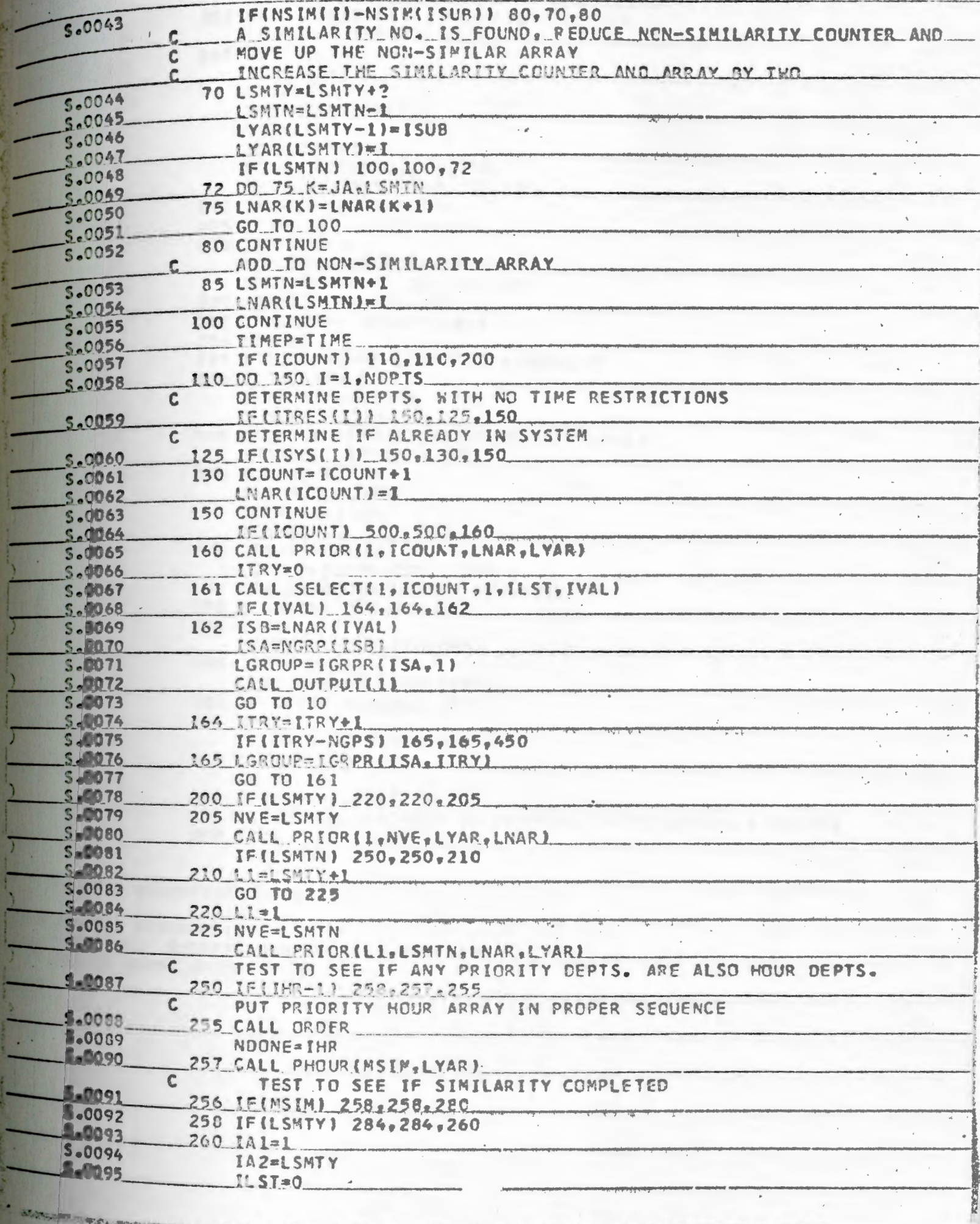


262 CALL SELECT (IA1,IA2,-1,ILST, IVAL)

LELIVALI $275,275,265$

265 ILST=1

B.:-20141

MS $I M=1$

IS $B=$ LYAR (IYAL)

ITRY $=1$

ISA=NGRP. (158)

LGROUP = IGRPR (ISA, ITRY)

RECRBL-LSTYL 2G2A2IO-2TO

S.0104

S.0105

5.0108

270 IFINNI $283,283,310$

275_IF(MSIM) 280,280,278

$5.0102 \quad-278$ ITRY $=$ ITR Y +1

5.0106

5.0109

S.0.110

LGROUP = IGRPR (ISA, ITRY 1

IF (ITRY-NGPS) $252,262,450$

S.OWUL 280 RERNN1 283.283.298

5.0112

5.02

5.0114

S.0125

S. 2116

S. 2417

5.7118

S.0229

S. 7120

S. 122

S. 2122

5.1223

$5.012 \%$

S. 0125

$5 \cdot 9126$

$5-427$

5.9228

5 - 122

$5+130$

5.0131

5.0132

5.9133

\$.9734

S. 135

S.0136

S. 2137

3.0138

S. 0239

9.0140

283 IF (LSMTN) $305,305.285$

284 MSIM=I.

285 IF(ICI+NOINE-LSMTN) $286,305,305$

236-IAI $=$ LSMTY $Y .1$

IA2. =LSMTNHLSMTY

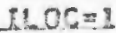

288 CALL SELECT IAL, IA2, ILOC, ILST, IVAL)

CEIVAL) $298,258.290$

290 IC $l=I C l+1$

RSB $=$ IVAL - L SMTX

ISR $=$ LNAR (ISB)

TRY=:

ISA $=$ NGRP (ISR)

CGROUP = IGRPR (ISA ITRY)

IF(ICI+NDONE-LSMTN) $292,295,295$

292 FIMSIMI 260,200.298

$295 \mathrm{NN}=1$

IF IMSIML 260.260 .310

298 ITRY $=$ ITR Y I I

LGR OUP $=$ IGR PR (ISA IITRY)

300 IFINSIM) 260,260,285

$305 R_{N}=1$

IFIMSIM: $278,278,310$

20_GAL OUTRUTL:

60 To 10

450-HRITE IOP=4512

451 FORMATI IX, 38HTHERE IS AN ERFCR TN SELECTING A GROUP I

500 . STOP

END

FETTAM DIAGNDSHIC MESSAGES.

G. GRAL OIAGNOSTICS

TOMBI16L SUGGEST. SUBOIVIDING PROGRAM

ED OF COMPILATION MAIN 


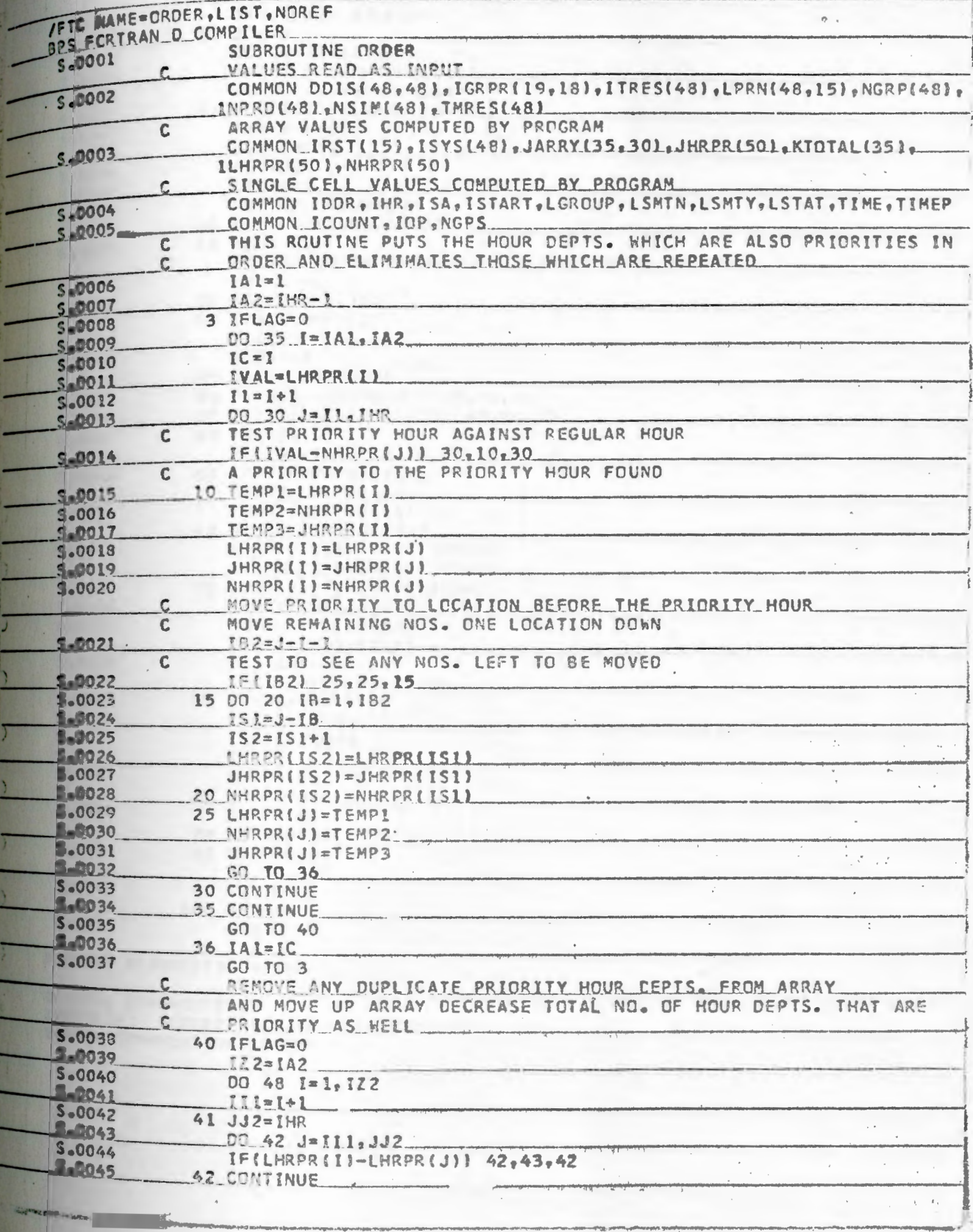




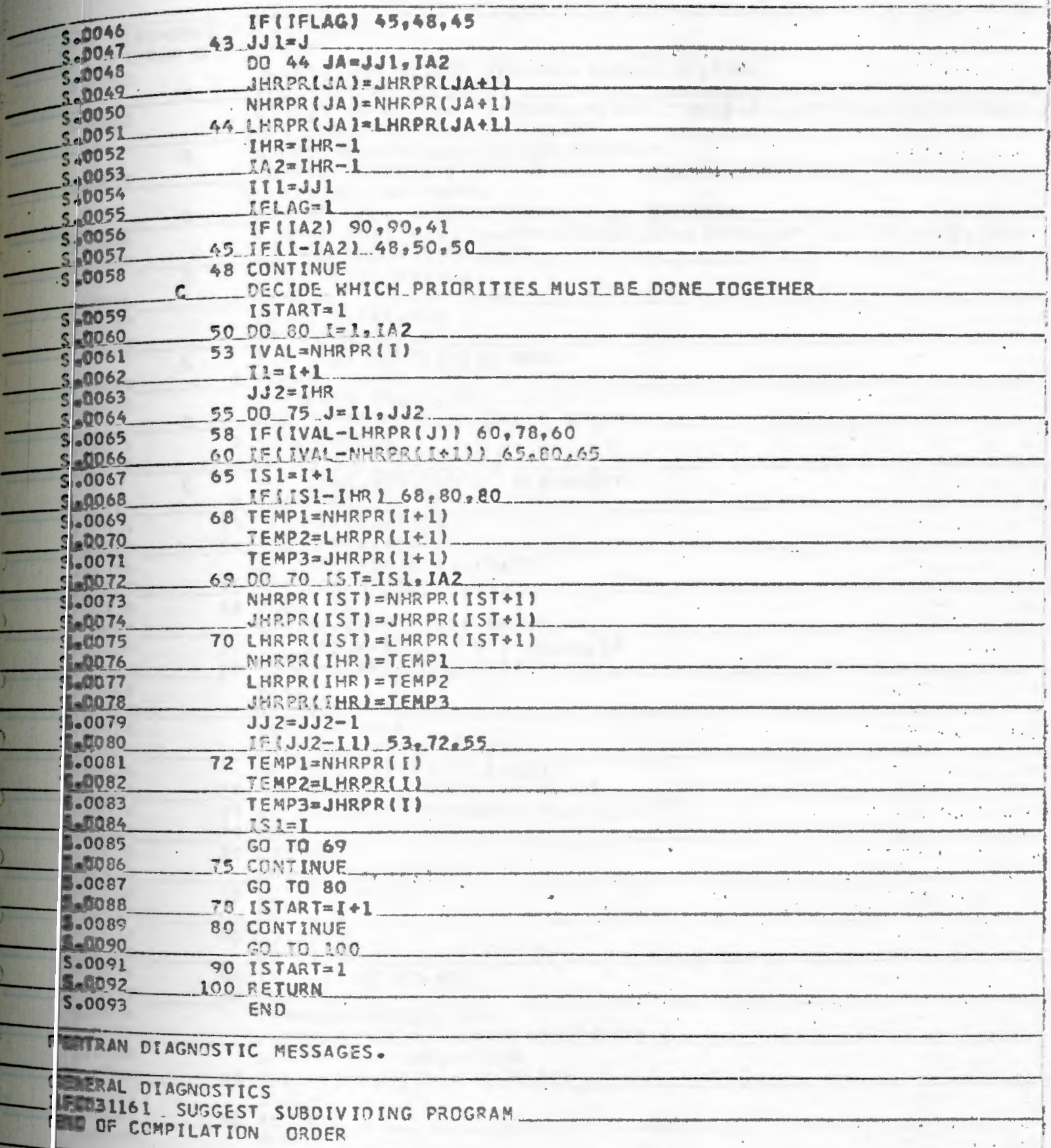




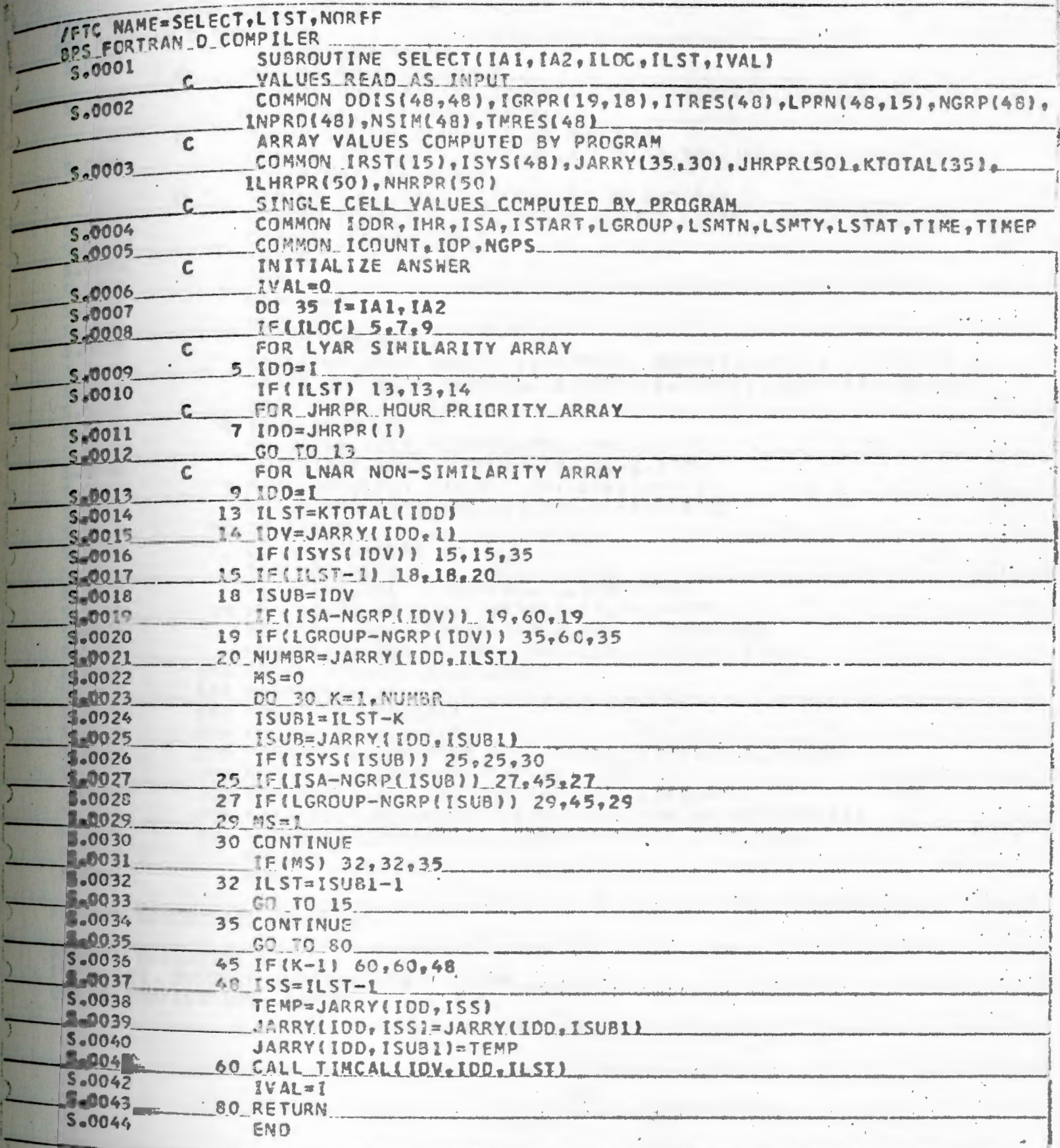

\section{POTRAN DIAGNOSTIC MESSAGES.}


C NAME INPUT, NOREF, LIST

IPTE NAMERAN D. COMPILEA

5.0001

SUBROUTINE INPUT

C YRLUES READ -AS INPUT

COMMON DDIS $(43,48)$, IGRPR $(19,18)$, ITRES $(48)$ LPRN $(48,15), N G R P(48)$ 2":ORD 481 -NSIMI 481 . TMRES 401

C ARRAY VALUES COMPUTED OY PROGRAM

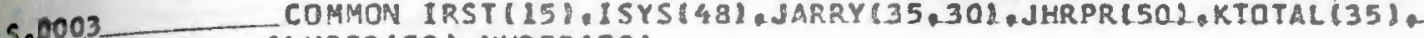
ILHRPR (5O). NHRPR(50)

C SINGLE CELL YALUES COHPUTED BY PROGRAM

5.0004 COMMON IDOR, IHR, ISA, ISTART, LEOUP, LSNTN, LSMTY, LSTAT, T IME, TIMEP COHMON ICOUNT. IOP, NGPS

$I N P=5$

$P 0 P=6$

NOPTS $=48$

$M G P S=12$

DO $50 \quad I=1$, NDPTS

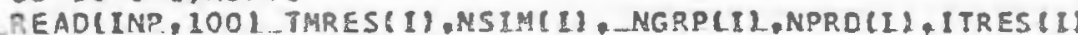

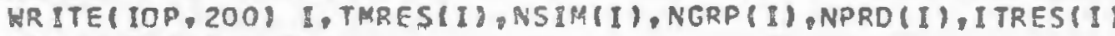
4F INPRD $(11) 5,5,4$

4 ISUB=NPRO II)

REAOCLNP. 1012 (LPENCI, IBI.IB = LISUBL

HRITE IOP, 201) (LPRNII, IB) IB=1, ISUB)

5 SEAD(INP, 1021. IDOIS II, IAI, IA=1,NDPTSI

MRITE(IOP, 2023 ROOISII, IA), ZA=1, NDPTSI

50 CONTINUE

DO $60 \mathrm{~J}=1$, NGPS

IGRPR $(J, 11$ Ed

READ (INP, 101) (IGRPR $(A, 1), I=2, N G P S)$

OO. HR ITE IIOP, 203) J, (IGRPR $(\mathrm{J}, I), 1=1$.NGPSI

READIINP, IO4I TIMEP,TIME,LSTAT,LGROUP,ISA

AT ITE(IOP, 204) TIMEP,TIME,LSTAT LCRCUR, ISA

3.0024

50025

$\$ .0026$

S- 1927

$\operatorname{sen} 28$

90029

$\$ .0030$

$\sin 31$

$\$ .0032$

$5-933$

3.0034

30.035

5.0036

100 FRRMAT IF $10.3,2(3,14,13)$

101.FORMAT. 24131

102 FORMAT $(619 \mathrm{~F} 8.21)$

2Q4 FORMATI2F10.3.3I3I

200 FORMAT (1X, 1 BHINPUT FOR STATICN $12 / 1$, F10.3,413!

202 EORMAT $1 X_{2}$. LOHPR IOP.ITIES/1 $x_{2} 24132$

202 FORMAT $(1 \mathrm{X}, 1.4 H T$ IHE DISTANCES/ $(1 \mathrm{X}, 9 \mathrm{~F} 8.4 /)$ )

203 FERMATL1 28 28RDUP PREFEPENCES FOR GROUP $12 / 24131$

204 FORMATIIX, 1 8HINITIAL CONDITIONS/IX, $F I n, 3,3131$ SETURN

ENO

FGITRAN DIAGNOSTIC MESSAGES.

G TAL DIAGNOSTICS

¿POB1161 SUGGEST SUEDIVIOING PROGRAM

EIS OF COMPILATION INPUT 
STC NAME T TMCAL, L IST, NOREF

DS FORTRAN O COMP ILER

SUBROUTINE TIMCAL MSTT. 100 ILST

5.0002

NALUES READ_AS_INPUT

COMMON DOIS $(4 B, 48), I G R P R(19,18), I T R E S(48), L P R N\{48,15), N G R P(4 B)$ IFPRO (48), NSIM(48), TMRE5(48)

ARRAY VALUES COMPUTEN GY PROGRAM

.0003

COMMON IRST(15).ISYS (42) IJARRY(35.30).JHRPR(5O) XTOTAL(35).

ILHRPR (50). NHRPR (50)

C SINGLE CELL YALUES COMRUIED_AY PROGRAM

COMHON IDOR, IHR, ISA, ISTART, LGRGUP, LSMTN, LSMTY, LSTAT, TIME, TIMEP COMYON ICOUNT IOP_ALPS

5 IF (ILST-1) 20,10,20

10. IF.ISYSIMSTTI) 15,15,70

$15 T I M E=D D I S(L S T A T, M S T T)+T I M E$ ISYSIMSTII $=1$

LSTAT $=$ MSTT

TEMP $=$ T IME/ 100 .

FRAC $=A M O D(T F M P, 1.1$

IF (FRAC - .599999) $60,00,17$

17 TIME $=$ (TEMP +.4I $10 \mathrm{C}$. GO TO_6O

20 NUMBR = JARR Y IIOD. ILST ?

OO $50 \quad K=1$. NUMBR

IEN $=$ ILST $-K$

MSTA J JAR \&Y ( IOD, IEN)

IF IISYSIMSTAI) $50,3 \mathrm{C}, 50$

30 TIME $=D D I S(L S I A T . M S T A L I L M E$

ISYS(MSTA) $=1$

$\angle O O R=100 R+1$

IRST (IDDR) = MSTA

STAT $=$ ASTA

TEMP $=$ TIME/ 100 .

FRAC $=A M O D$ CTEMP 1.1

IF (FRAC- -599993 ) 50.50 .40

40 TIME $=(T F M P+4)+100$.

50 CONTINUE

IL $S T=1 E N=1$

GO TO 5

1.0031

5.0032

.9033

S.0034

8.0035

5.0038

60 $300 R=000 R+$

IRST(IOOR) =MSTT

TO RETURN

END

FORTRAN DIAGNOSTIC MESSAGES.

GENERAL DIAGNOSTICS

TITO31161 SUGGEST SUBDIV:DING PROGRAE

ENO OF COMPILATION TIMCAL 
TFTC NAME $=$ PHOUR, L IST, NOREF

DPS EORTRAN D COMPLLER

5.0001

3.0002 c

SUBROUTINE PHOUR (MSIM,LYAR)

VALUES REAC AS INPUI

CDMMON ODIS $(40,48)$, IGRPR $(19,18)$, ITRES(48),LPRN $(48,15), N G R P(48)$, ZNPRD (481.NSIM1481, TMRES $(48)$

C ARRAY VALUES COMPUTED BY PROGRAM COMMON IRST (15).1SYSI481, JARRY (35,301.JHRPR(50), KTOTAL (35).

5.0003

5.0004

5.6005

5.0006

S. 0007

S. 0008

S.0009

5.0010

5.0011

5.0012

5.0013

5.0014

s.0015

5.0016

56017

$\$ .9018$

5.019

5.0020

5.0021

$5-6022$

56023

50024

5. 0025

5.0026

5.0027

S. 0028

$5-0029$

5.0030

5.0031

5.0032

5.0033

3.0034

s. 1035

$\$ .0036$

5.0037

..0035

$-7039$

3.0040

1.0041

3.0042

8. 0043

B.0044

.0045

3.0046

.0047

0.0048

A. 2049

5.0050

LHRPR (50), NHRPR $\$ 50$

SMGLECELL VALUES_CCMPUTED BY PROGRAM

COMMON IDOR, IHR, ISA, ISTART, LGROUP, LSMTN,LSMTY, LSTAT, TIME, TIMEP

COMMON ICOUNT, IOP NGPS

DIMENSION LYAR $\{15\}$

TRY $\mathrm{T}=1$

$I L O C=0$

$\mathrm{SOF}=0$

MS IM=0

$I B I=0$

$4|A|=1$

IF. (ISTART-L) 5.5 .10

3 IA $2=1 H R$

ZSEC =

Go ro 12

$20.22=1$

$15 E C=0$

h2 CALL SELECTUAI, IA2,ILOC, ILST,IVALI

IFIIVAL) $15,15,30$

15 IFCISECL $20,20,25$

$20 \quad I A L=I S T A R T$

60 TO 5

25 ITRY $=$ TTRY+ I

LGROUP = IGRPR (ISA, ITRY)

IF (IOP) $4,4,12$

30 - IS $\mathrm{r}=$ :HPOCLVALI

IF (MSIM) $105,40,105$

40 TF(LSMTY) 45.45 .50

45 MSIM=1

6070.05

50 DO $54 \mathrm{~J}=1$, LSMTY

"A. $8 \div$ -

IF $(\operatorname{VAR}(J)-I S T) 54,55.54$

54 CONTINUE

GO TO 105

55 . $15: M=1$

ILST $=1$

26. $2 \pi 5=0$

$|B|=1 B 1+1$

57 I $A=$ NGRP ( IST)

60 ITRY $=$ ITRY $Y+1$

$\angle G R O U P=I G R P R(I S A, I T R Y)$

IFI IBI-ISITY) $62,70,70$

62_EALL_SELECTULLSMTY - I.ILSTEVB

IF(IAB) $60,60,65$

65_IST $=$ LYAR (IAB) GO TO 56

70. IF(IVAL - ISTART) $110,132.132$

105 IF (IVAL - ISTART) IIC 130,130

$5.0052-1011=1$

111:2=1START-1

$05120\lceil\pi 11,12$

IOO=JHRPR II)

ASTA $T$ L LRR PR I I 
RLST =KTOTAL IMSTA

CALL TIMCALIMSTA, IDD, ILST)

120 CONTINUE

SEI FLAG IO_SAY DCUBLE PRLORIIIES HANOLEO

$100=1$

IT $R Y=1$

ISA = NGPP IMSTAI

LGROUP = IGRPR (LSA, ITRY)

IF (IHR - ISTART) $165,124,124$

124. IA. $=1$ START

60 TO 5

230. IS B = LHRPR ( IVAL)

ISA $=$ NGRP (ISR )

QTRY=1.

LGROUP $=$ IGRPR (ISA, ITRY)

32. IE(IVAL-IHR L 135.145 .145

135 IANI $=$ IVAL+ I

DO 140 IAN=IAN I, IHR

JHRPR (IAN-1) = JHRPR (IAN)

AHRPR $(1 A N-1)=$ NHRPR (IAN)

140 LHRPR (IAN-1) =LHRPR (IAN)

IAS $T H R=R H R-1$

IF (IHR) $165,165,155$

155 IF (THR - ISTART 2 160.158.158

158 IF (IDP) $4,4,20$

160 IF (ROP) $162.162,165$

$16211=1$ 60 Ta 111

165 RETURN

END

GTMRAN D:AGNOSTIG MESSAGES.

CINERAL DEAGNOSTICS

IC031161 SUGGEST SURDIVIOING PRUGRAM

OF COMORLIION PHOUR 


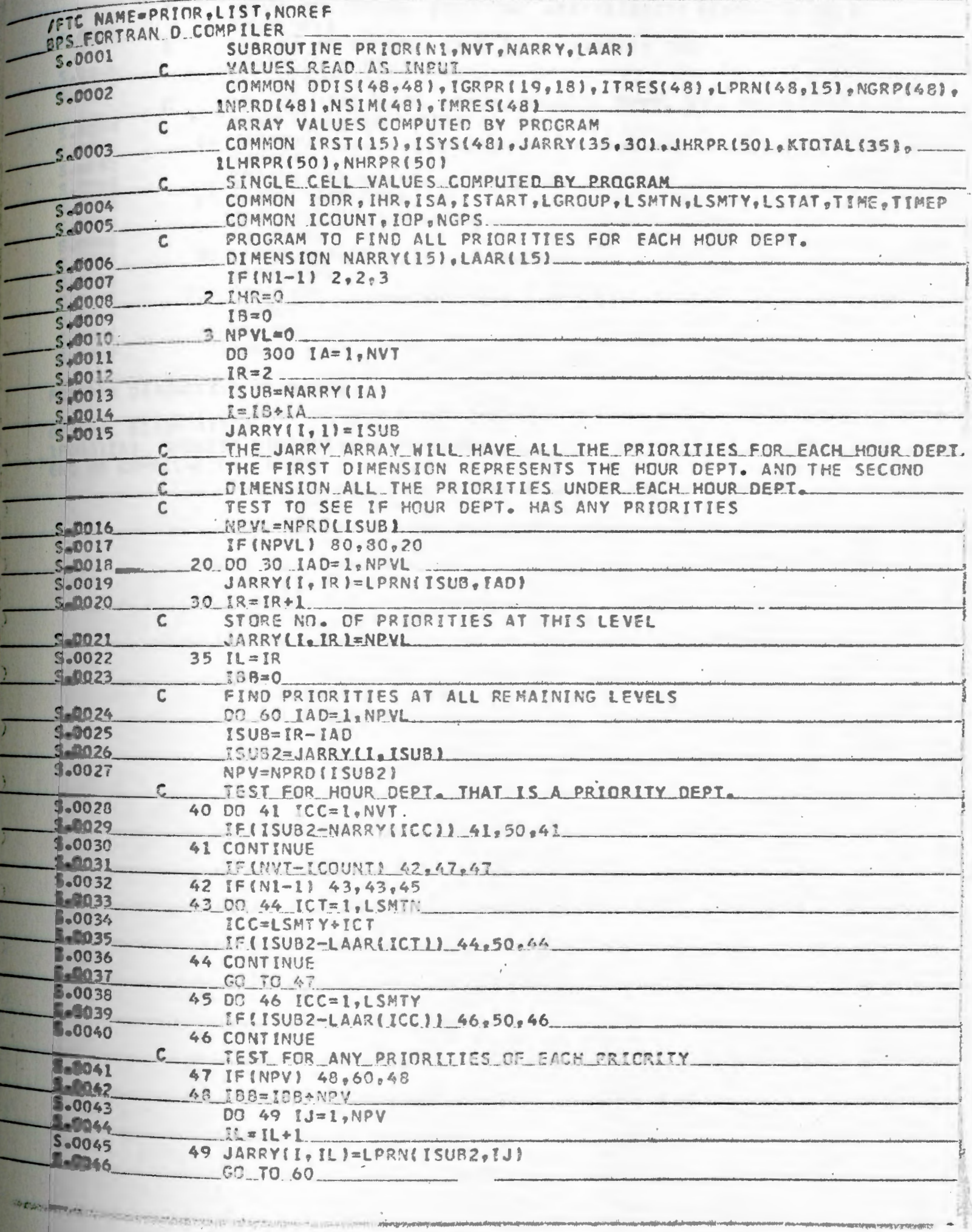




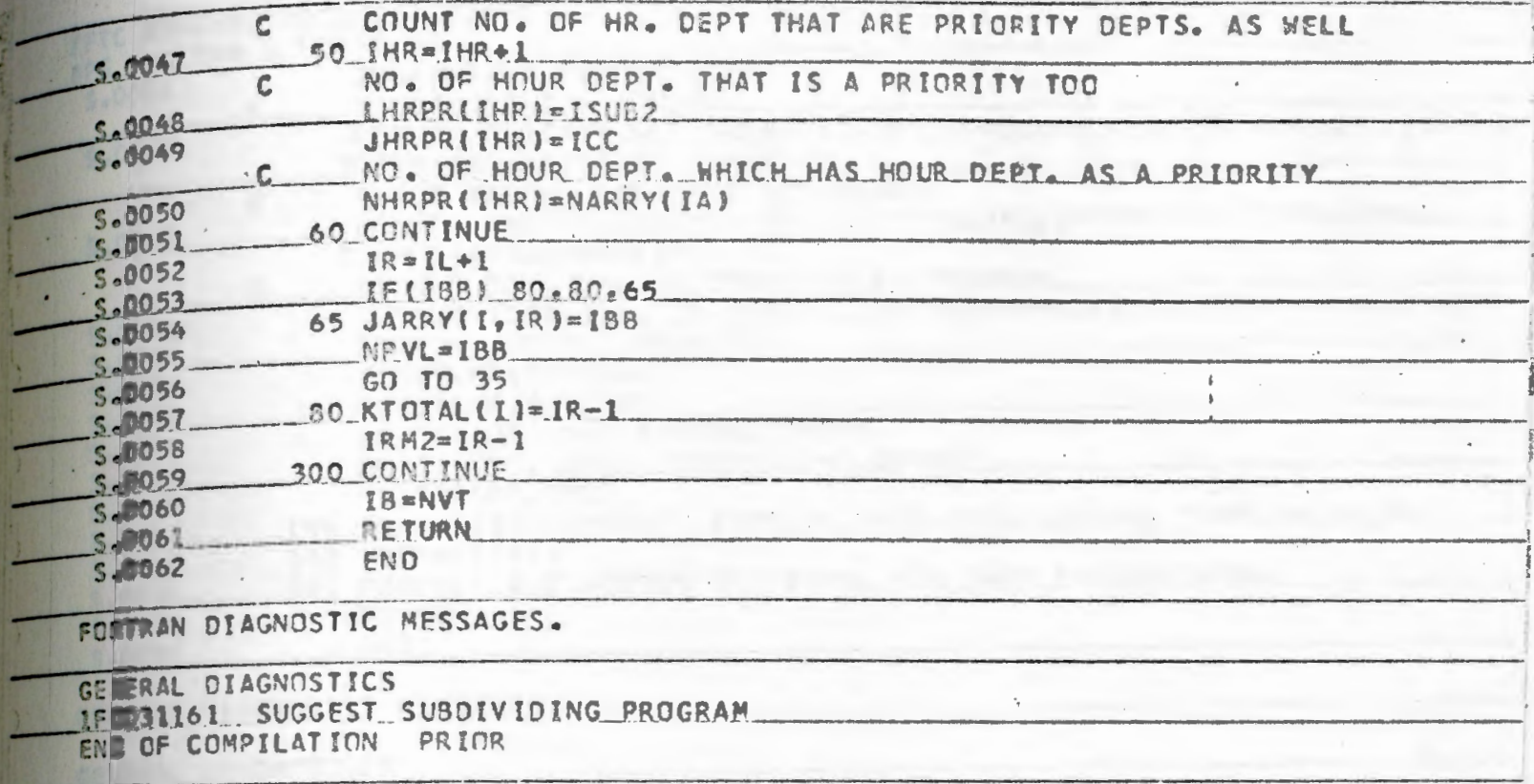




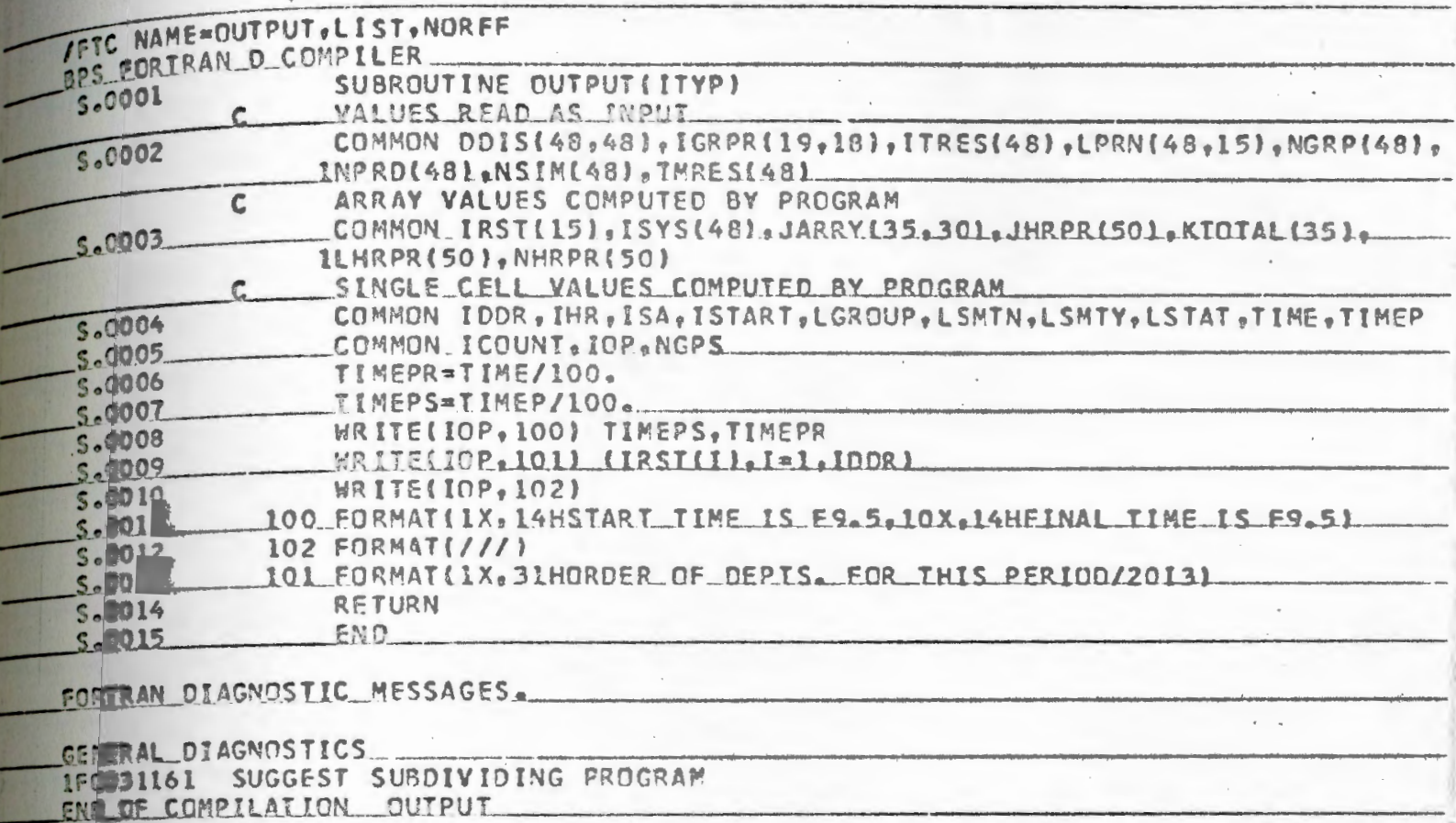




\section{DATA}

I 
$1 0 \longdiv { 1 7 }$

NOTCOCOR STAT:ON__ 0.0 LTANCES

eits

$\begin{array}{lllllllll}1.9800 & 3.8729 & 1.8281 & 3.8340 & 2.6863 & 2.8615 & 2.9105 & 2.9349\end{array}$

(2.872

do

$\begin{array}{llllllll}3.8481 & 3.9949 & 4.1003 & 4.1661 & 4.3947 & 4.1664 & 4.0680 & 4.0359\end{array}$

3947

4.24354 .417

7110

$3.8408 \quad 3.7098$

$\begin{array}{llll}4.1338 & 3.8403 & 3.7424\end{array}$

$\sqrt{4} 492$

3.497

$\begin{array}{lll}3.0358 & 3.8249 & 3.4249\end{array}$

I TR EOR STAILCN 2

$\begin{array}{ll}0.0 & 2 \\ \text { DISTANCES } & \end{array}$

$\begin{array}{llllllllll}1.9800 & 0.0 & 3.4894 & 2.1278 & 3.2778 & 2.7800 & 2.2501 & 2.2990 & 2.3153\end{array}$

$\begin{array}{lllllllll}3.0165 & 3.2121 & 3.3426 & 3.4567 & 3.5220 & 3.7519 & 3.5073 & 3.5073 & 3.5236\end{array}$

$\begin{array}{lllllllll}3.9476 & 3.5236 & 3.5562 & 3.7763 & 3.3279 & 3.0996 & 3.7845 & 3.1648 & 3.0344\end{array}$

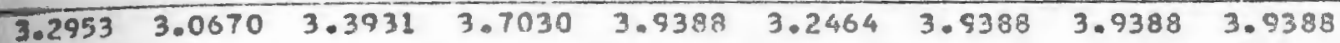

$\begin{array}{lllllllll}3.1322 & 2.6499 & 2.6499 & 3.0086 & 3.2858 & 3.1253 & 3.2821 & 2.4453 & 1.5700\end{array}$

$3.0358 \quad 3.2053 \quad 2.8453$

TIPUT FOR STATIOW 3

$800.0-3111$

17

Tin DISTANCES

$\begin{array}{llllllllll}3.8729 & 3.4894 & 0.0 & 3.5301 & 4.6634 & 3.7299 & 3.8155 & 3.8644 & 3.9256\end{array}$

$4.4351 \quad 4.7939 \quad 4.9243 \quad 5.0385 \quad 5.1037 \quad 5.7358 \quad 4.9749 \quad 4.9912 \quad 4.3933$

$5.3010 \quad 5.0727 \quad 5.2912 \quad 5.5847 \quad 4.5814 \quad 4.5835 \quad 4.2864 \quad 4.7140 \quad 4.5020$

$\begin{array}{lllllllll}4.7486 & 4.5509 & 4.5509 & 5.2684 & 6.0352 & 4.7140 & 6.6352 & 6.0352 & 3.0352\end{array}$

$4.5998 \quad 3.8729 \quad 3.8729 \quad 3.9149 \quad 4.2035 \quad 4.5466 \quad 3.8639 \quad 4.0556 \quad 3.8729$

$3.958 \quad x+156 \quad 4.4556$

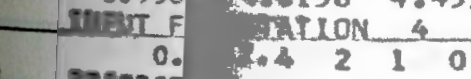

$\begin{array}{r}278 \\ 22 \\ \hline\end{array}$

PRI- DISTANCES

$\begin{array}{llllllllll}1.8261 & 2.1278 & 3.5301 & 0.0 & 3.1632 & 2.0707 & 2.2501 & 2.3153 & 2.3329\end{array}$

$\begin{array}{lllllllll}3.8697 & 3.2611 & 3.3752 & 3.4404 & 3.4567 & 3.6867 & 3.4237 & 3.4237 & 3.3279\end{array}$

$\begin{array}{llllllllll}3.7356 & 3.6377 & 3.7274 & 4.0209 & 3.1485 & 3.0344 & 4.1725 & 3.1322 & 3.0018\end{array}$

$3.23013 .0670 \quad 3.3931 \quad 3.6703 \quad 4.2293 \quad 3.1875 \quad 4.2293 \quad 4.2293 \quad 4.2293$

$\begin{array}{lllllllllll}3.0996 & 3.8660 & 4.6735 & 3.6214 & 3.3279 & 3.6601 & 3.3311 & 2.4829 & 1.4761\end{array}$

$\begin{array}{lll}3.5779 & 3.2229 & 2.8629\end{array}$

DUTUIFOR_STATION 5 


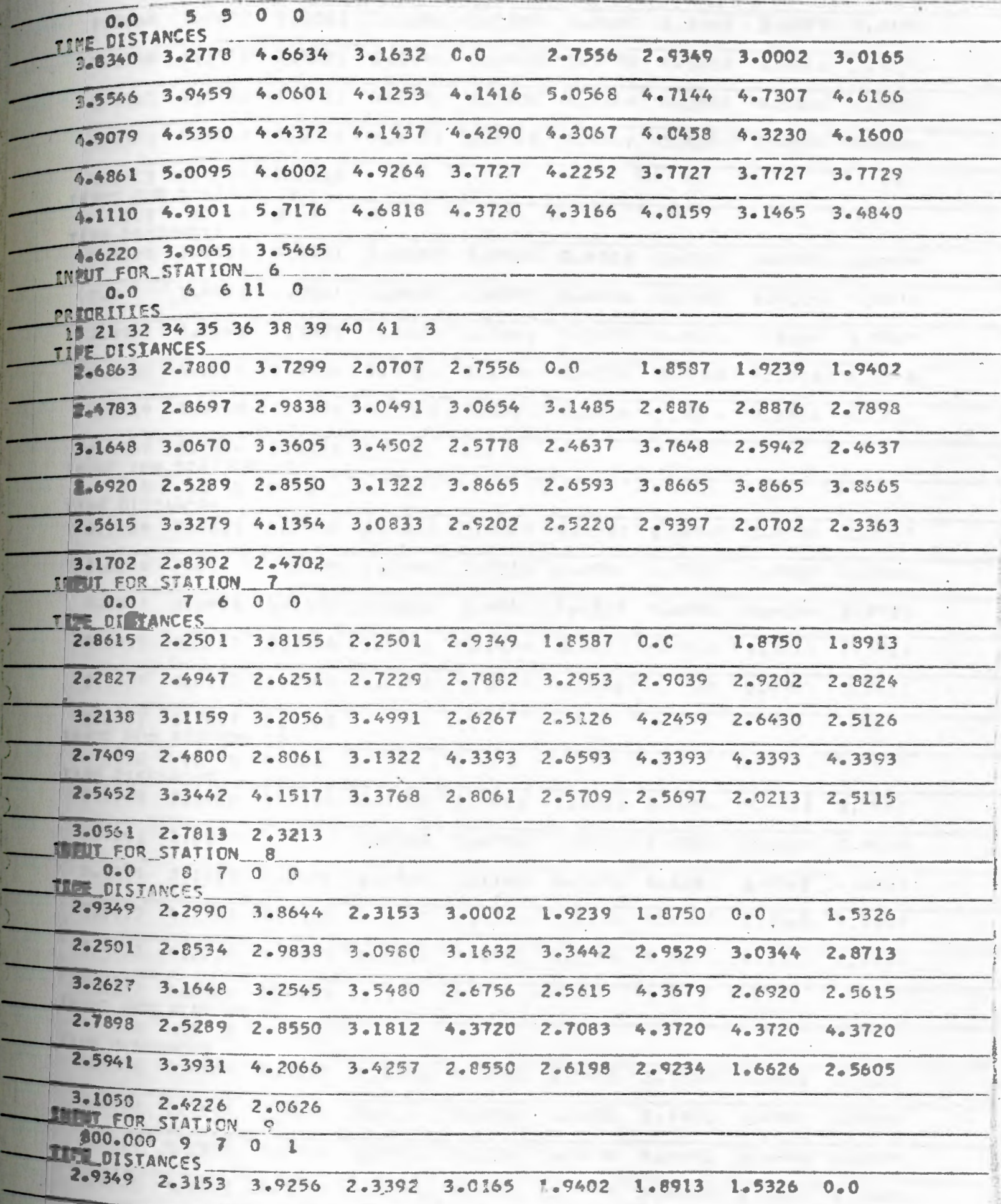




\begin{tabular}{|c|c|c|c|c|c|c|c|c|}
\hline 2.2664 & 2.3697 & 3.0002 & 3.1143 & 3.1795 & 3.3605 & 2.9692 & 3.0527 & 2.8876 \\
\hline 3.2790 & 3.1812 & 3.2708 & 3.5644 & 2.6920 & 2.5778 & $4 \cdot 3883$ & 2.7033 & 2.5778 \\
\hline 2.8061 & 2.5452 & 2.8713 & 3.1975 & 4.3383 & 2.7246 & 4.3883 & 4.3883 & 4.3883 \\
\hline 2.6104 & 3.4044 & 4.2169 & 3.4421 & 2.8713 & 2.6361 & 2.9397 & 1.6630 & 2.5849 \\
\hline $\begin{array}{l}3.1213 \\
\text { TEUT FOR }\end{array}$ & $\begin{array}{l}2.4230 \\
\text { STATLON }\end{array}$ & $\begin{array}{l}2.0626 \\
10\end{array}$ & & & & & & \\
\hline TLE OISTA & $\begin{array}{c}1010 \\
\text { ANCES }\end{array}$ & $0 \quad 0$ & & & & & & \\
\hline 3.5220 & 3.0165 & 4.4351 & 2.8697 & 3.5546 & 2.4783 & 2.2827 & 2.2501 & 2.2564 \\
\hline 0.0 & 1.6956 & 1.8261 & 1.9402 & 2.0055 & 2.6906 & 2.7395 & 2.9515 & 2.7884 \\
\hline 2.3971 & 3.0493 & 3.1390 & 3.4325 & 2.9841 & 3.0620 & 4.5024 & 3.4244 & 3.2939 \\
\hline 3.3755 & 4.1407 & 3.6364 & 3.9768 & 5.1098 & 3.4733 & 5.1098 & 5.1098 & 5.1098 \\
\hline 3.3429 & 4.0930 & 4.9005 & 3.7342 & 3.4407 & 3.2055 & 1.7656 & 2.3964 & 3.1720 \\
\hline $\begin{array}{l}3.6907 \\
\text { TIUT FOR }\end{array}$ & $\begin{array}{l}3.1564 \\
\text { STATION }\end{array}$ & $\begin{array}{l}3.84 B L \\
-11^{8}\end{array}$ & & & & & & \\
\hline TIVE_CISTA & $\begin{array}{ll}\text { II } 8 \\
\text { ANCES }\end{array}$ & 0 & & & & & & \\
\hline 2.7964 & 3.2121 & 4.7939 & 3.2611 & 3.9459 & 2.8697 & 2.4947 & 2.8534 & 2.8697 \\
\hline 1.6956 & 0.0 & 1.6304 & 1.7445 & 1.7935 & 2.6905 & 2.7395 & 2.9515 & 2.7884 \\
\hline 2.3971 & 3.0493 & 3.1390 & 3.4325 & 2.9841 & 3.0820 & 4.6981 & 3.4244 & 3.2939 \\
\hline 3.3755 & 4.1407 & 3.6364 & 3.9788 & 5.3014 & 3.4733 & 5.3014 & 5.3014 & 5.3014 \\
\hline 3.3429 & 4.0930 & 4.9005 & 3.7342 & 3.4407 & 3.2055 & 1.5700 & 2.9997 & 3.4981 \\
\hline $\begin{array}{l}3.6507 \\
\text { mivit For }\end{array}$ & $\begin{array}{l}3.7597 \\
\text { STATION }\end{array}$ & $\begin{array}{l}3.3997 \\
12\end{array}$ & & & & & & \\
\hline rese $\begin{array}{l}0.0 \\
0.5 I A\end{array}$ & $\begin{array}{c}12 \\
\text { ANCES }\end{array}$ & 00 & & &. & & & \\
\hline 3.9949 & 3.3426 & 4.9243 & 3.3752 & 4.0601 & 2.9838 & 2.6251 & 2.9838 & 3.0002 \\
\hline 1.8261 & 1.6304 & 0.0 & $1.6: 4.1$ & 1.6793 & 2.8211 & 2.8700 & 3.0820 & 2.9189 \\
\hline 2.5275 & 3.1739 & 3.2695 & 3.5589 & 3.1146 & 3.2124 & 4.8285 & 3.5548 & 3.424 .4 \\
\hline 3.5059 & 4.2712 & 3.7668 & 4.1093 & 5.4360 & 3.6038 & 5.4360 & 5.4360 & 5.4360 \\
\hline 3.4733 & 4.2234 & 5.0309 & 3.8697 & 3.5712 & 3.3359 & 1.5604 & 3.1302 & 3.6449 \\
\hline $\begin{array}{l}3.82: 2 \\
\text { NhT For }\end{array}$ & $\begin{array}{l}3.6902 \\
\text { STATCCN }\end{array}$ & $\begin{array}{l}3.4302 \\
83\end{array}$ & & & & & & \\
\hline MRE_CISTA & $\begin{array}{l}13 \\
\text { ANCES }\end{array}$ & 00 & & & & & & \\
\hline 4.1008 & 3.4567 & 5.0385 & 3.4404 & 4.1253 & 3.0491 & 2.7229 & 3.0980 & 3.1143 \\
\hline 1.4402 & 1.7445 & 1.6141 & 0.0 & 1.5652 & 2.9352 & 2.9841 & 3.1961 & 3.0330 \\
\hline 2.6417 & 3.2939 & 3.3836 & 3.5771 & 3.2287 & 3.3266 & 4.6492 & 3.6690 & 3.5385 \\
\hline 3.6201 & 4.3853 & 3.6158 & 4.2234 & 5.4849 & 3.7179 & 5.4849 & 5.4849 & 5.4849 \\
\hline
\end{tabular}




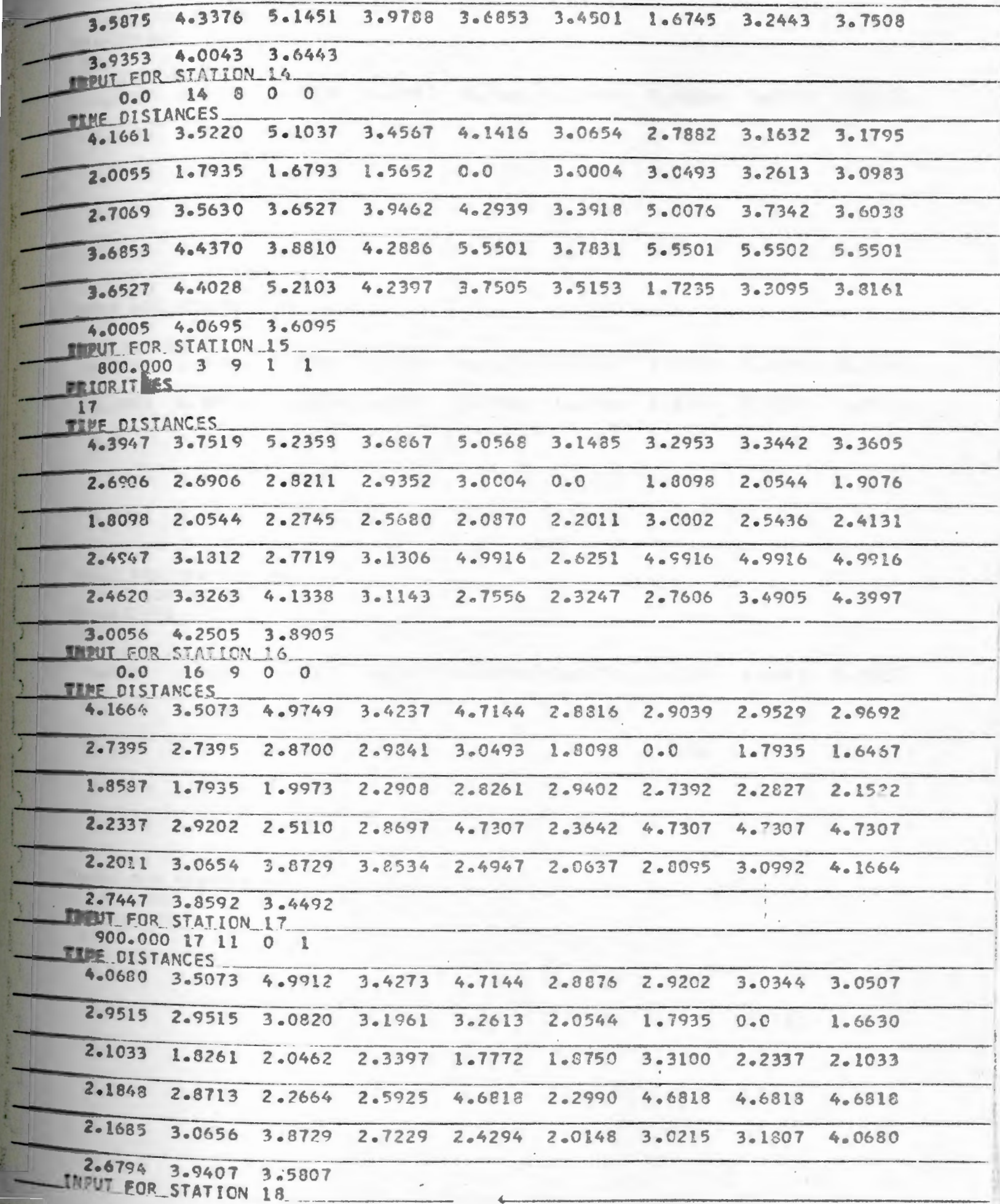




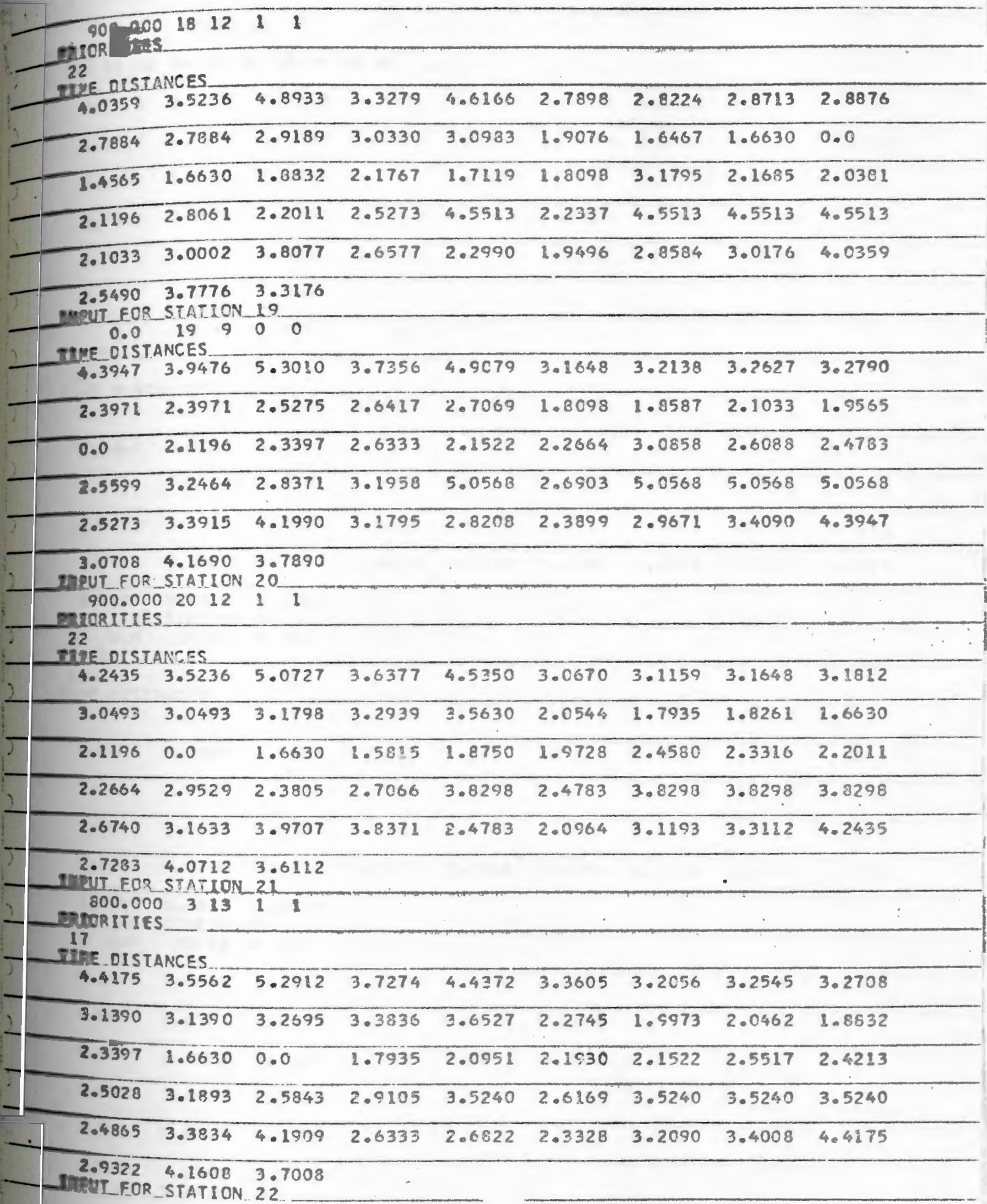


0.0

2213110

$152132 \quad 34 \quad 35 \quad 36 \quad 38 \quad 3940$ 41 3

$\begin{array}{llllllllll} & 4.7110 & 3.7763 & 5.5847 & 4.0209 & 4.1437 & 3.4502 & 3.4991 & 3.5680 & 3.5644\end{array}$

$\begin{array}{lllllllllll}0.4325 & 3.4325 & 3.5589 & 3.6771 & 3.9462 & 2.5680 & 2.2908 & 2.3397 & 2.1767\end{array}$

$\begin{array}{lllllllllll}2.6333 & 1.5815 & 1.7935 & 0.0 & 2.3887 & 2.4865 & 2.1848 & 2.8452 & 2.6740\end{array}$

$\begin{array}{lllllllll}2.7963 & 3.4828 & 2.8779 & 3.2040 & 3.5566 & 2.8860 & 3.5566 & 3.5566 & 3.5566\end{array}$

$\begin{array}{lllllllll}2.7800 & 3.6769 & 4.4844 & 3.3344 & 2.9757 & 2.6263 & 3.5025 & 3.6944 & 4.7110\end{array}$

$3.2357 \quad 4.4544 \quad 4.0944$

mPUT FOR STAIICV 23

$0.023 \quad 1110$

BUIORITLES

22

TIME DISTANCES

$\begin{array}{lllllllll}3.8403 & 3.3279 & 4.6814 & 3.1985 & 4.4205 & 2.5773 & 2.6267 & 2.6756 & 2.6920\end{array}$

$\begin{array}{llllllllll}2.9841 & 2.9841 & 3.1146 & 3.2287 & 4.2939 & 2.0970 & 2.8261 & 1.7772 & 1.2119\end{array}$

$\begin{array}{llllllllll}2.1522 & 1.8750 & 2.0951 & 2.3887 & 0.0 & 1.6630 & 2.5436 & 1.9728 & 1.8424\end{array}$

$1.9402 \quad 2.6267 \quad 2.0544 \quad 2.3805 \quad 4.4372 \quad 2.0218 \quad 4.4372 \quad 4.4372 \quad 4.4372$

$\begin{array}{llllllllll}1.8913 & 2.7892 & 3.5957 & 2.4620 & 2.1685 & 2.7702 & 3.0541 & 2.8220 & 3.9403\end{array}$

$2.4185 \quad 3.5820 \quad 3.1220$

QUL FOR STATION 24

$$
0.0 \quad 24 \quad 15 \quad 10
$$

IORTTLES

32

DIHE DISTANCES

$\begin{array}{llllllllll}3.7095 & 3.0996 & 4.5835 & 3.0344 & 4.3067 & 2.5126 & 2.4637 & 2.5615 & 2.5778\end{array}$

$\begin{array}{lllllllll}3.0320 & 3.0820 & 3.2124 & 3.3256 & 3.3918 & 2.2011 & 2.5402 & 1.8750 & 1.8098\end{array}$

$\begin{array}{llllllllll}2.2664 & 1.9728 & 2.1930 & 2.4865 & 1.6630 & 0.0 & -2.4294 & 1.8587 & 1.7282\end{array}$

$1.8098 \quad 2.4953 \quad 1.9239 \quad 2.2501 \cdot 4.2904 \quad 1.9402 \quad 4.2904 \quad 4.290 \% \quad 4.2904$

$\begin{array}{lllllllllll}1.8098 & 2.6740 & 3.4815 & 2.3479 & 2.0544 & 1.6398 & 3.9520 & 2.7078 & 3.7098\end{array}$

$2.3044 \quad 3.4678 \quad 3.0578$

MEUT FCR STATION 25

$0.0 \quad 25$ I 3 - 0 O

DAE DISTANCES

$\begin{array}{llllllllll}4.1338 & 3.7845 & 4.2864 & 4.1725 & 4.0458 & 3.7543 & 4.2459 & 4.3679 & 4.3883\end{array}$

$\begin{array}{lllllllllll}4.502 / 4 & 4.6981 & 4.0285 & 4.6492 & 5.0076 & 3.0002 & 2.7397 & 3.3100 & 3.1795\end{array}$

$\begin{array}{llllllllll}3.0858 & 2.4580 & 2.1522 & 2.1848 & 2.5436 & 2.4294 & 0.0 & 2.4457 & 2.3153\end{array}$

$\begin{array}{llllllllll}2.6088 & 3.1975 & 2.7066 & 3.0328 & 3.1957 & 2.3316 & 3.1857 & 3.1857 & 3.1857\end{array}$

$\begin{array}{llllllllll}2.2011 & 3.1143 & 3.9218 & 2.7882 & 2.4783 & 2.9388 & 4.7681 & 4.5183 & 4.1338\end{array}$

$2.7283 \quad 5.2783 \quad 4.8183$

UIT FCR_STATION 26 
$0.0 \quad 26 \quad 1500$

TIE DISTANCES

$\begin{array}{lllllllllll}.8403 & 3.2648 & 4.7140 & 3.1322 & 4.3230 & 2.5941 & 2.6430 & 2.6920 & 2.7063\end{array}$

\begin{tabular}{llllllllll}
\hline .4244 & 3.4244 & 3.5548 & 3.6690 & 3.7342 & 2.5438 & 2.2827 & 2.2337 & 2.1685
\end{tabular}

\begin{tabular}{lllllllllll}
\hline .6088 & 2.3316 & 2.5517 & 2.8452 & 1.9728 & 1.8587 & 2.4457 & 0.0 & 1.6630
\end{tabular}

$\begin{array}{llllllllll}0.0055 & 2.5615 & 2.1359 & 2.4620 & 4.3393 & 4.9569 & 4.3393 & 4.3393 & 4.3393\end{array}$

\begin{tabular}{llllllllll}
\hline 5261 & 2.7056 & 3.5141 & 2.3153 & 2.0018 & 1.8355 & 3.4944 & 2.8383 & 3.8403
\end{tabular}

$2.27183 .5983 \quad 3.1383$

i. UT FOR. STATION 27 0.027 15 00

UTE DISTANCES

$\begin{array}{llllllllll}3.7424 & 3.0344 & 4.5020 & 3.0018 & 4.1600 & 2.4637 & 2.5126 & 2.5615 & 2.5778\end{array}$

$\begin{array}{llllllllll}3.2939 & 3.2939 & 3.4244 & 3.5385 & 3.6038 & 2.4131 & 2.1522 & 2.1033 & 2.0381\end{array}$

$\begin{array}{llllllllllll}2.4763 & 2.2011 & 2.4213 & 2.6740 & 1.8420 & 1.7282 & 2.3153 & 1.6630 & 0.0\end{array}$

$\begin{array}{llllllllll}1.8424 & 2.3984 & 1.9728 & 2.2990 & 4.1763 & 1.7935 & 4.1763 & 4.1763 & 4.1763\end{array}$

$\begin{array}{lllllllllll}1.6630 & 2.5436 & 3.3511 & 2.1522 & 2.8587 & 1.6224 & 3.3639 & 2.7078 & 3.7424\end{array}$

$3.1087 \quad 3.4678 \quad 3.0578$

MVI FOR SIALZON 28

$0.0 \quad 28 \quad 1500$

JTHE OISTANCES

$\begin{array}{lllllllll}3.4925 & 3.2953 & 4.7466 & 3.2301 & 4.4861 & 2.6920 & 2.7409 & 2.7896 \cdots 2.8061\end{array}$

$\begin{array}{lllllllllll}3.3755 & 3.3755 & 3.5059 & 3.6201 & 3.6853 & 2.4947 & 2.2337 & 2.1848 & 2.1196\end{array}$

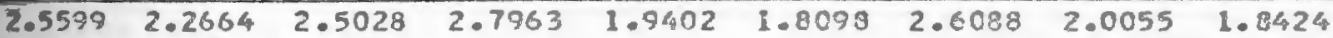

$\begin{array}{lllllllll}0.0 & 2.6756 & 2.1033 & 2.4294 & 4.4698 & 2.0070 & 4.4698 & 4.4698 & 4.4698\end{array}$

$\overline{1.9565} 2.8534 \quad 3.6609 \quad 2.4620 \quad 2.1522 \quad 3.6981 \quad 2.9022 \quad 4.4925 \quad 2.9361$

$3.4355 \quad 1.6730 \quad 3.2361$

T. TLFOR_STATION 29

$0.029 \quad 2500$

THE DISTANCES

$\begin{array}{lllllllllll}3.8077 & 3.0670 & 4.5509 & 3.0670 & 5.0095 & 2.5280 & 2.4800 & 2.5289 & 2.5452\end{array}$

$\begin{array}{lllllllll}4.1407 & 4.1407 & 4.2712 & 4.3953 & 4.4370 & 3.1212 & 2.9202 & 2.8713 & 2.8062\end{array}$

$\begin{array}{lllllllllll}3.2464 & 2.9529 & 3.1893 & 3.4828 & 2.6267 & 2.4963 & 3.1975 & 2.5615 & 2.3964\end{array}$

$2.6756 \quad 0.0 \quad 2.8224 \quad 3.1485 \quad 5.0585 \quad 5.2560 \quad 5.0585 \quad 5.0585 \quad 5.0525$

$\begin{array}{lllllllll}606104 & 3.4247 & 4.2332 & 3.0344 & 2.7409 & 2.5055 & 4.2107 & 2.0752 & 3.8077\end{array}$

$2.9909 \quad 3.4352 \quad 3.0152$

UTROR_STATION_30

$0.0 \quad 30 \quad 24000$

DISTANCES

$\begin{array}{lllllllllll}3.5467 & 3.3931 & 4.5509 & 3.3931 & 4.6002 & 2.8550 & 2.8061 & 2.8550 & 2.8783\end{array}$

$\begin{array}{llllllllll}3.6364 & 3.6364 & 3.7660 & 3.9158 & 3.8810 & 2.7710 & 2.5110 & 2.2664 & 2.2011\end{array}$ 


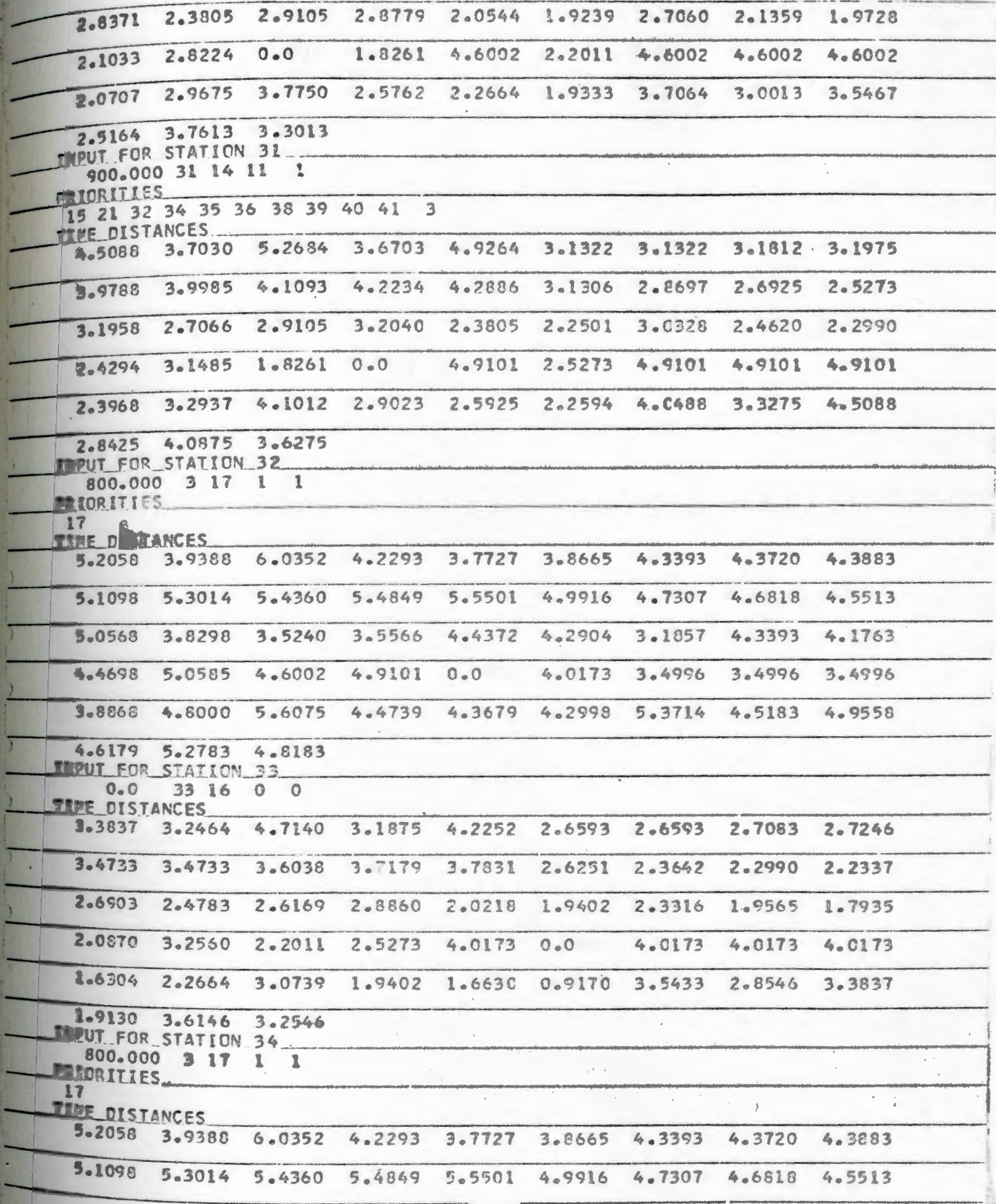




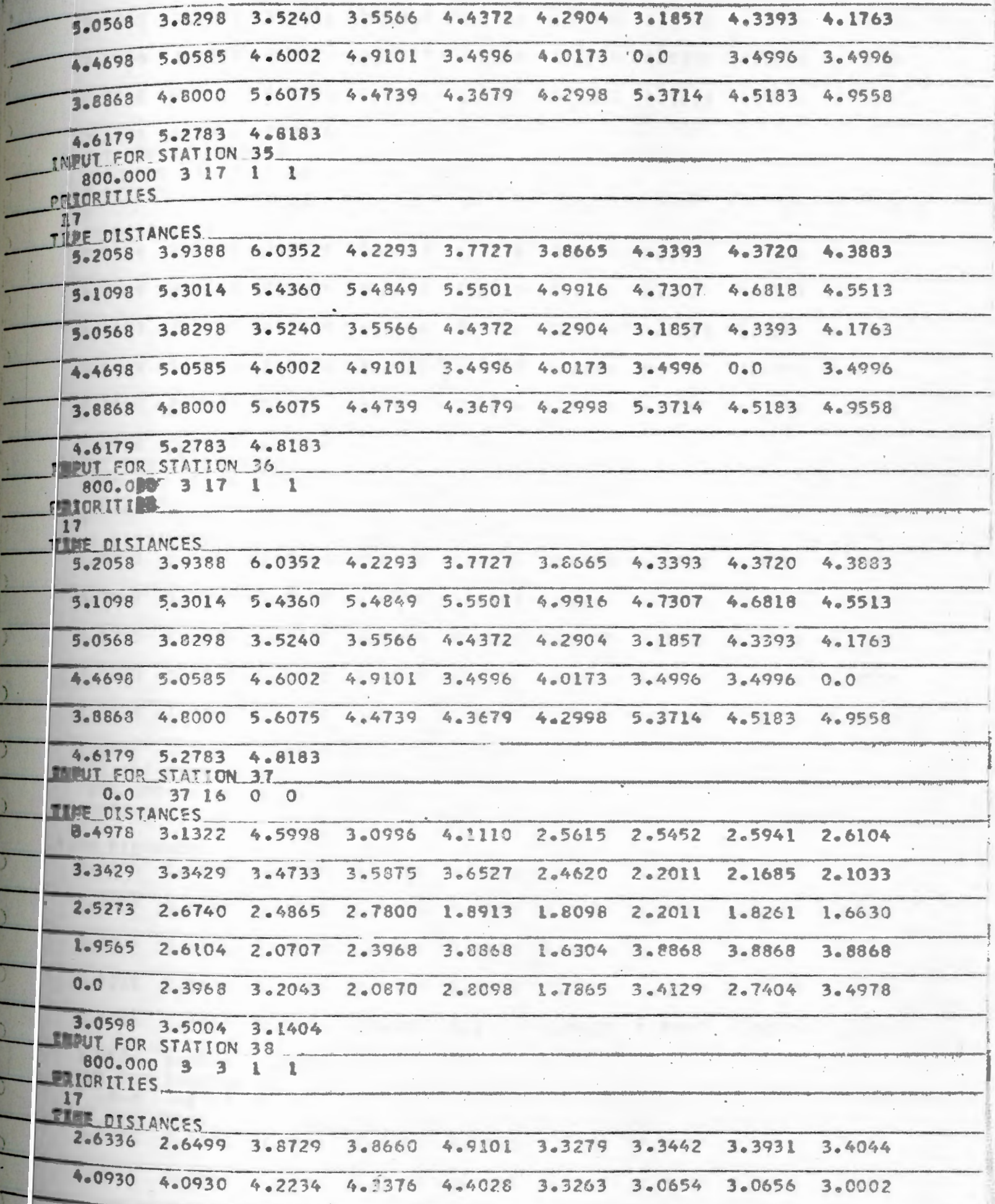


$\begin{array}{lllllllll}3.3915 & 3.1632 & 3.3634 & 3.6769 & 2.7882 & 2.6740 & 3.1143 & 2.7056 & 2.5436\end{array}$

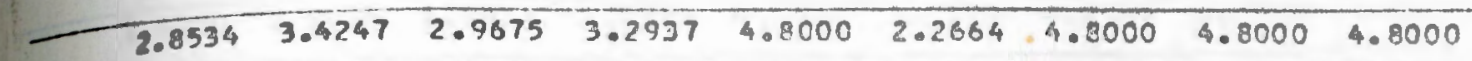

\begin{tabular}{llllllllll}
\hline 2.3968 & 0.0 & 2.3075 & 1.9565 & 2.2501 & 3.0853 & 4.1630 & 3.5344 & 2.6336
\end{tabular}

$2.6590 \quad 4.29443 .8544$

THPUT_FOR STATION 39

$800.000 \quad 3 \quad 3 \quad 11$

MUORUT:ES

17

TUE DISTANCES

$\begin{array}{lllllllll}2.6336 & 2.6499 & 3.8729 & 4.6735 & 5.7176 & 4.1354 & 4.1517 & 4.2066 & 4.2239\end{array}$

$\begin{array}{lllllllll}4.9005 & 4.9005 & 5.0309 & 5.1451 & 5.2103 & 4.1338 & 3.8729 & 3.8729 & 3.8077\end{array}$

$\begin{array}{llllllllll}4.1990 & 3.9707 & 4.1909 & 4.4844 & 3.5957 & 3.4815 & 3.9218 & 3.5141 & 3.3511\end{array}$

$\begin{array}{lllllllll}3.6609 & 4.2332 & 3.7750 & 3.2937 & 5.6075 & 2.2664 & 5.0075 & 5.6075 & 5.6075\end{array}$

$\begin{array}{lllllllll}2.3968 & 2.3075 & 0.0 & 2.7640 & 3.0576 & 3.4909 & 4.9705 & 4.3469 & 2.6336\end{array}$

$2.00015 .1069 \quad 4.7469$

THPUT FOR STATION 40

$800.000 \quad 3 \quad 4 \quad 11$

MUORITIES

17

TREE DISTANCES

$\begin{array}{lllllllll}3.0249 & 3.0086 & 3.9149 & 3.6214 & 4.6818 & 3.0333 & 3.3768 & 3.4257 & 3.4421\end{array}$

$\begin{array}{llllllllll}3.7342 & 3.7342 & 3.8647 & 3.9788 & 4.2397 & 3.1143 & 3.0534 & 2.7229 & 2.6577\end{array}$

$\begin{array}{lllllllll}3.1795 & 2.8371 & 2.6333 & 3.3344 & 2.4620 & 2.3479 & 2.7882 & 2.3153 & 2.1522\end{array}$

$\begin{array}{llllllllll}2.4620 & 3.0344 & 2.5762 & 2.9023 & 4.4739 & 1.9402 & 4.4739 & 4.4739 & 4.4739\end{array}$

$\begin{array}{lllllllll}2.0870 & 1.9565 & 2.7640 & 0.0 & 1.9402 & 2.2620 & 3.8042 & 3.5722 & 3.0249\end{array}$

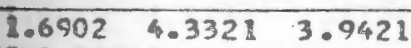

TPUT ECR STAE:ON R

800.0003411

MIORITIL:

17

THE DISTANCES

$\begin{array}{llllllllll}3.2858 & 3.2858 & 4.2085 & 3.3279 & 4.3720 & 2.9202 & 2.8061 & 2.3550 & 2.8713\end{array}$

$\begin{array}{lllllllll}3.4407 & 3.4407 & 3.5712 & 3.6853 & 3.7505 & 2.7556 & 2.4947 & 2.4294 & 2.2990\end{array}$

$\begin{array}{llllllllll}2.8208 & 2.4783 & 2.6822 & 2.9757 & 2.1685 & 2.0544 & 2.4783 & 2.0218 & 2.0587\end{array}$

$\begin{array}{lllllllll}2.1522 & 2.7409 & 2.2664 & 2.5925 & 4.3679 & 1.6630 & 4.3679 & 4.3679 & 4.3679\end{array}$

$\begin{array}{lllllllll}2.8098 & 2.2501 & 3.0576 & 1.9402 & 0.0 & 1.9922 & 3.5107 & 3.0013 & 3.2858\end{array}$

1.7. 3.76133 .3013

DTUT FOR STATION 42

0.0 \& 15 O 0

DTIE OISTANCES

$\begin{array}{lllllllll}4.3225 & 3.1253 & 4.5966 & 3.6601 & 4.3161 & 2.5220 & 2.5709 & 2.6198 & 2.6361\end{array}$

$\begin{array}{lllllllll}3.2035 & 3.2055 & 3.3359 & 3.4501 & 3.5153 & 2.3247 & 2.0637 & 2.0149 & 1.9496\end{array}$ 
\begin{tabular}{llllllllll}
\hline 09 & 2.0964 & 2.3328 & 2.6263 & 1.7702 & 1.6398 & 2.9388 & 1.8355 & 1.6224
\end{tabular}

$\begin{array}{llllllllll}1.6730 & 2.5056 & 1.9333 & 2.2594 & 4.2998 & 1.9170 & 4.2998 & 4.2998 & 4.2998\end{array}$

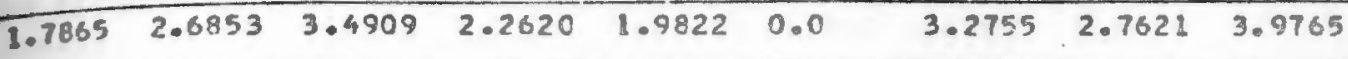

$2.1322 \quad 3.5221 \quad 3.1621$

TNRUT_FOR_STATION 43

$0.0 \quad 43$ B 0 O

TIRE CISIANCES

$\begin{array}{llllllllll}3.9181 & 3.2821 & 3.8639 & 3.3311 & 4.0159 & 2.9397 & 2.5697 & 2.9234 & 2.9397\end{array}$

$\begin{array}{llllllllll}1.7656 & \$ .5700 & 1.5604 & 1.6745 & 1.7235 & 2.7606 & 2.0095 & 3.0225 & 2.8584\end{array}$

$\begin{array}{llllllllll}2.9671 & 3.1193 & 3.2090 & 3.5025 & 3.0541 & 3.1520 & 4.7681 & 3.4944 & 3.3639\end{array}$

$\begin{array}{llllllllll}3.4355 & 4.2107 & 3.7064 & 4.0489 & 5.3714 & 3.5433 & 5.3714 & 5.3714 & 5.3714\end{array}$

$\begin{array}{lllllllll}3.4129 & 4.1630 & 4.9705 & 3.9042 & 2.0567 & 3.2755 & 0 . C & 3.0657 & 3.5721\end{array}$

$3.65073 .8257 \quad 3.4657$

MVUT EOR STATION_44

MVE O. OTANCES

$\begin{array}{lllllllll}3.0649 & 2.4453 & 4.0556 & 2.4629 & 3.1485 & 2.0702 & 2.0213 & 1.6626 & 1.6630\end{array}$

$\begin{array}{llllllllll}2.3964 & 2.9997 & 3.1302 & 3.2443 & 3.3095 & 3.4905 & 3.0992 & 3.1807 & 3.0176\end{array}$

$\begin{array}{lllllllll}3.4090 & 3.3112 & 3.4008 & 3.6944 & 2.8220 & 2.7078 & 4.5183 & 2.8383 & 2.7078\end{array}$

$\begin{array}{lllllllll}2.9361 & 2.6752 & 3.0013 & 3.3275 & 4.5183 & 2.8546 & 4.5183 & 4.5183 & 4.5183\end{array}$

$\begin{array}{lllllllllll}2.7404 & 3.5344 & 4.3469 & 3.5722 & 3.0013 & 2.7621 & 3.0657 & 0.0 & 2.7189\end{array}$

$3.3013 \quad 2.2600 \quad 1.8600$

TIVUT FCR STATION 45

$0.0 \quad 65200$

THE OISTANCES

$\begin{array}{lllllllll}1.8460 & 1.5700 & 3.8729 & 1.4761 & 3.4840 & 2.3363 & 2.5115 & 2.5605 & 2.5849\end{array}$

$\begin{array}{llllllllll}3.1720 & 3.4981 & 3.6449 & 3.7508 & 3.8161 & 4.3997 & 4.1664 & 4.0680 & 4.0359\end{array}$

$\begin{array}{lllllllll}4.3947 & 4.2935 & 4.4175 & 4.7110 & 3.8403 & 3.709 & 4.1339 & 3.8403 & 3.74 .24\end{array}$

$\begin{array}{llllllllll}4.4925 & 3.8077 & 3.5467 & 4.5082 & 4.9558 & 3.3837 & 4.9558 & 4.9558 & 4.9558\end{array}$

$\begin{array}{lllllllll}3.4978 & 2.6336 & 2.6336 & 3.0249 & 3.2858 & 3.9765 & 3.5721 & 2.7189 & 0.0\end{array}$

$3.1749 \quad 3.4789 \quad 3.0189$

MEUT_FOR STATICN 46

0.0461600

TIRE DISTANCES

$\begin{array}{lllllllll}3.0358 & 3.0358 & 3.5585 & 3.5779 & 4.6220 & 3.1702 & 3.0561 & 3.1050 & 3.1213\end{array}$

$\begin{array}{lllllllll}3.6907 & 3.6907 & 3.6212 & 3.9353 & 4.0005 & 3.0056 & 2.7447 & 2.6794 & 2.5480\end{array}$

$\begin{array}{lllllllll}3.0708 & 2.7283 & 2.9322 & 3.2397 & 2.4185 & 2.3044 & 2.7283 & 2.2718 & 3.1097\end{array}$

$\begin{array}{lllllllll}2.9022 & 2.9909 & 2.5164 & 2.8425 & 4.6179 & 1.9130 & 4.6179 & 4.6179 & 4.6179\end{array}$

$\begin{array}{llllllllll}3.0998 & 2.6590 & 2.0001 & 1.6902 & 1.7500 & 2.8322 & 3.6307 & 3.3013 & 3.5749\end{array}$ 
$0.0 \quad 4.06133 .6013$

MPUI EGR STATION 47

TUE OISTANEES

$\begin{array}{lllllllll}3.8249 & 3.2053 & 4.8156 & 3.2229 & 3.9665 & 2.8302 & 2.7813 & 2.4226 & 2.4230\end{array}$

$\begin{array}{lllllllll}3.1564 & 3.7597 & 3.8902 & 4.0043 & 4.0695 & 4.2505 & 3.8592 & 3.9407 & 3.7776\end{array}$

$\begin{array}{lllllllll}4.1690 & 4.6712 & 4.1608 & 4.4544 & 3.5220 & 3.4678 & 5.2783 & 3.5983 & 3.4678\end{array}$

$\begin{array}{llllllllll}3.6961 & 3.4352 & 3.7613 & 4.0875 & 5.2783 & 3.6146 & 5.2783 & 5.2783 & 5.2783\end{array}$

$\begin{array}{llllllllll}3.5004 & 4.2944 & 5.1009 & 4.3321 & 3.7613 & 3.5221 & 3.8257 & 2.2600 & 3.4789\end{array}$

$4.0620 .0 \quad 1.1300$

MEUT EOR STATIONL48

TIME_ORSTANCES

$\begin{array}{lllllllll}3.4249 & 2.8453 & 4.4556 & 2.8629 & 3.5465 & 2.4702 & 2.3213 & 2.0626 & 2.0626\end{array}$

$\begin{array}{llllllllll}2.7964 & 3.3997 & 3.4302 & 3.6443 & 3.6095 & 3.2905 & 3.4492 & 3.5807 & 3.3176\end{array}$

$\begin{array}{lllllllll}3.7890 & 3.6112 & 3.7008 & 4.0944 & 3.1220 & 3.0578 & 4.6283 & 3.1383 & 3.0578\end{array}$

$\begin{array}{lllllllll}3.2361 & 3.0152 & 3.3013 & 3.5275 & 4.6283 & 3.2546 & 4.8183 & 4.8183 & 4.8133\end{array}$

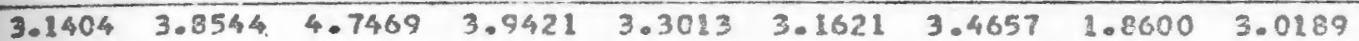

$3.60131 .1300 \quad 0.0$

MACUP PREFERENCES. FOR GROUP 1

$\begin{array}{lllllllllllllll}2 & 3 & 4 & 5 & 6 & 710 & 26 & \$ 5 & 14 & 11 & 1213 & \$ 7 & 9\end{array}$

CQOUP PREFERENCES FOR GROUP 2

$215 b^{2} \quad \begin{array}{lllllllllllll} & 10 & 8 & 15 & 14 & 16 & 4 & 3 & 11 & 12 & 13 & 17 & 9\end{array}$

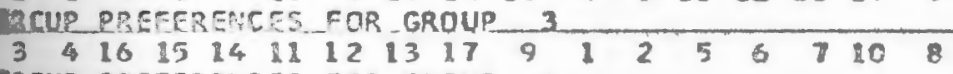

CRCUP PREFERENCES FOR GRTUP \&

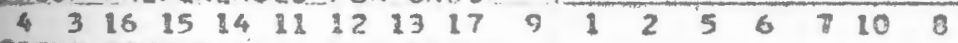

ARCUP PREFERENCES FOR GROUP 5

$\begin{array}{llllllllllllllll}5 & 6 & 7 & 2 & 10 & 6 & 17 & 12 & 11 & 15 & 14 & 9 & 16 & 4\end{array}$

TOUP EREEERENCES EOR GROUP 6

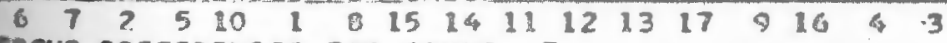

MCUP PREFERENCES FOR GRTUP 7.

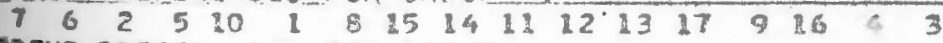

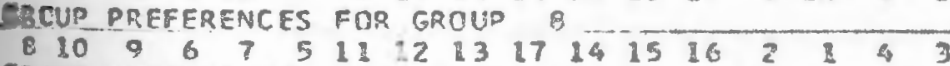

- GCUP DRERTRENCES FOR GROUP 2

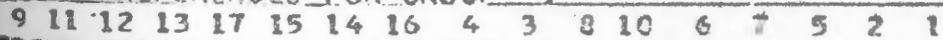

ACUP PREEERENCES EOR, GROUP 10

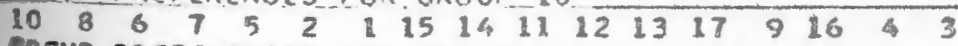

RCUP RREFERENCES_FOR GROUP 11

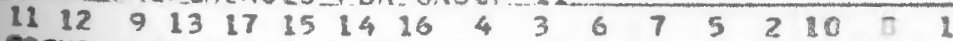

CRCUP PREEERENCES FOR GROUP 12

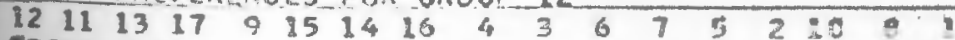

MTUP PREFEREACES FOR GROUP 13

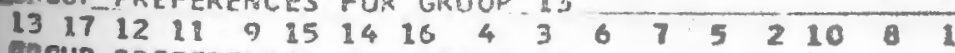

HCUP PREFERENCES FOR GROUP 14.

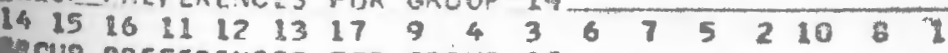

CKCUP PREFERENCES FOR GROUP 15

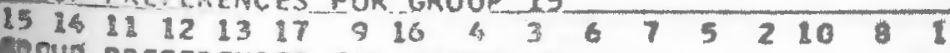

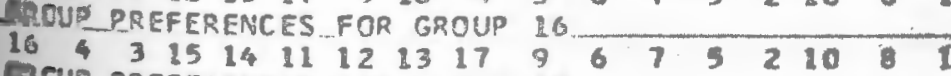

PCUP PREFERENCES FOR GROUP IT. 
FLOW DIAGRAMS 



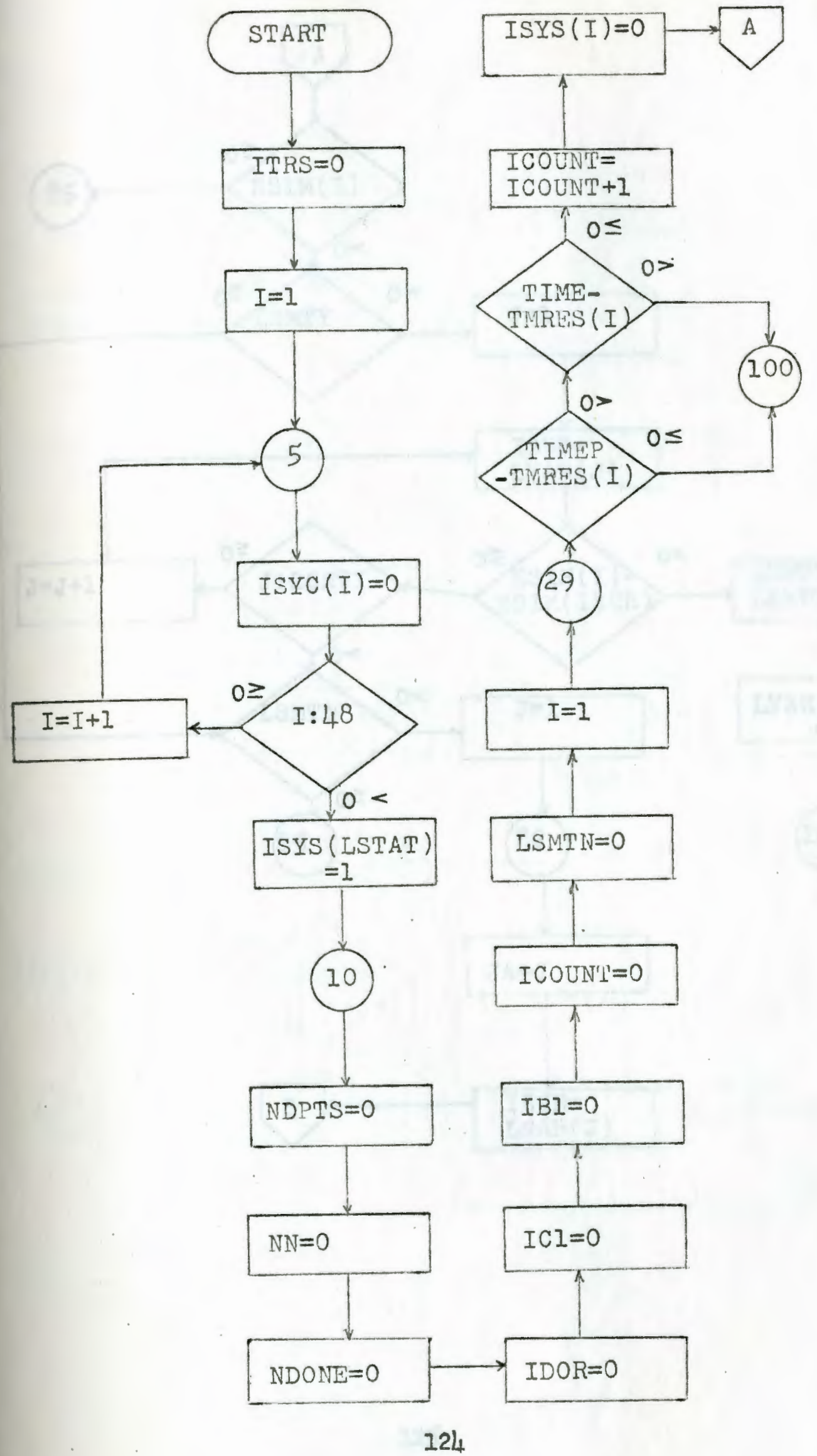




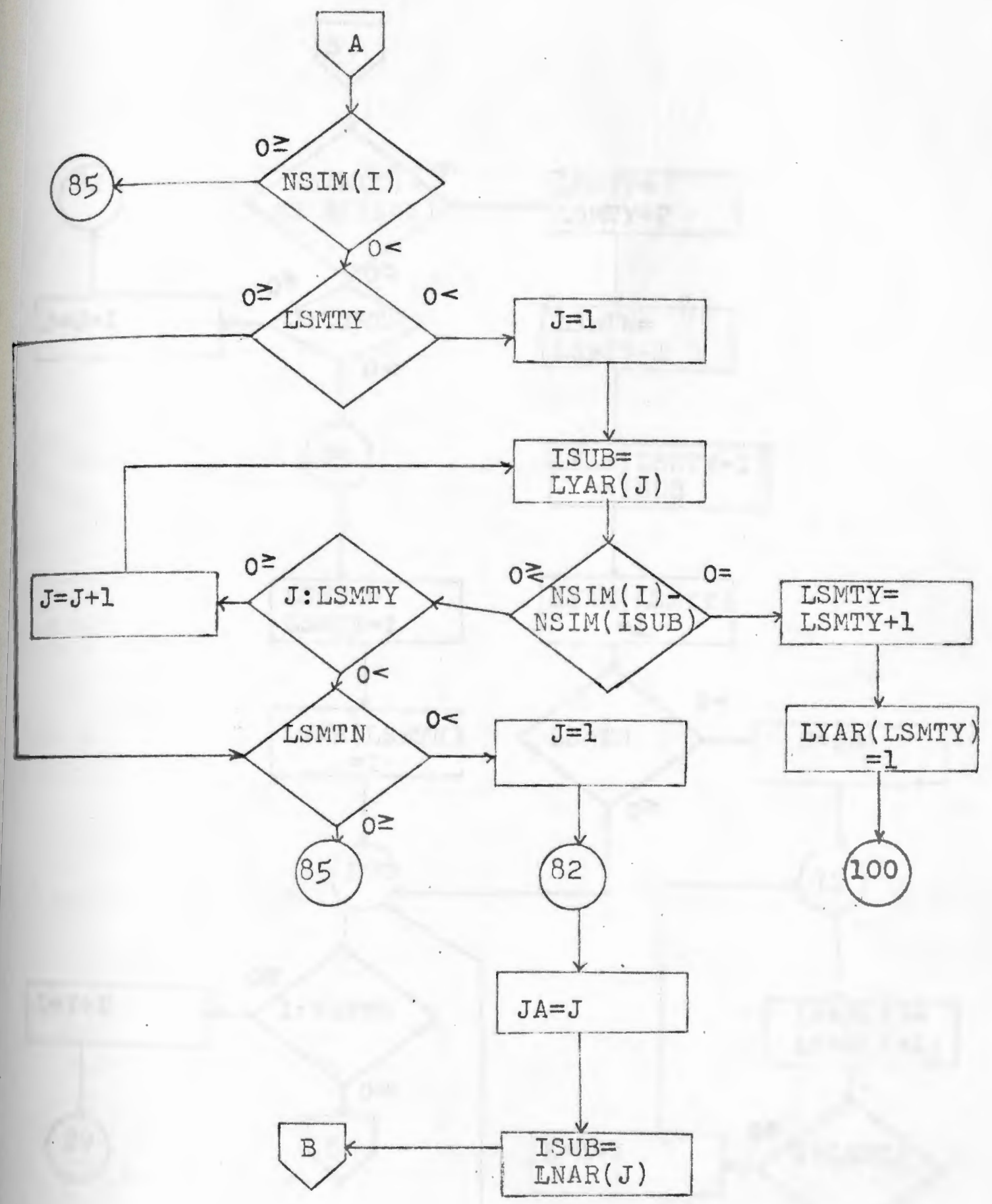




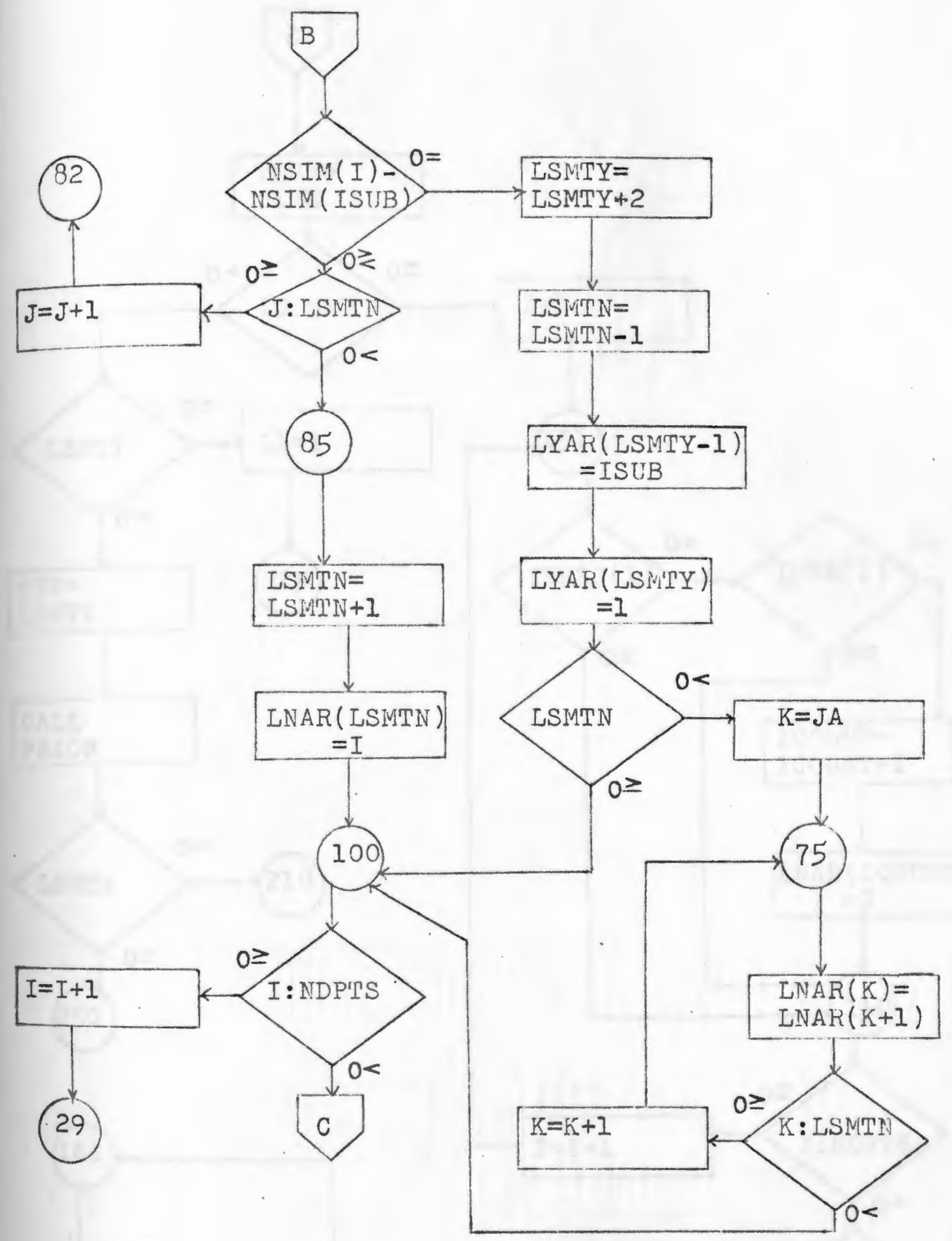




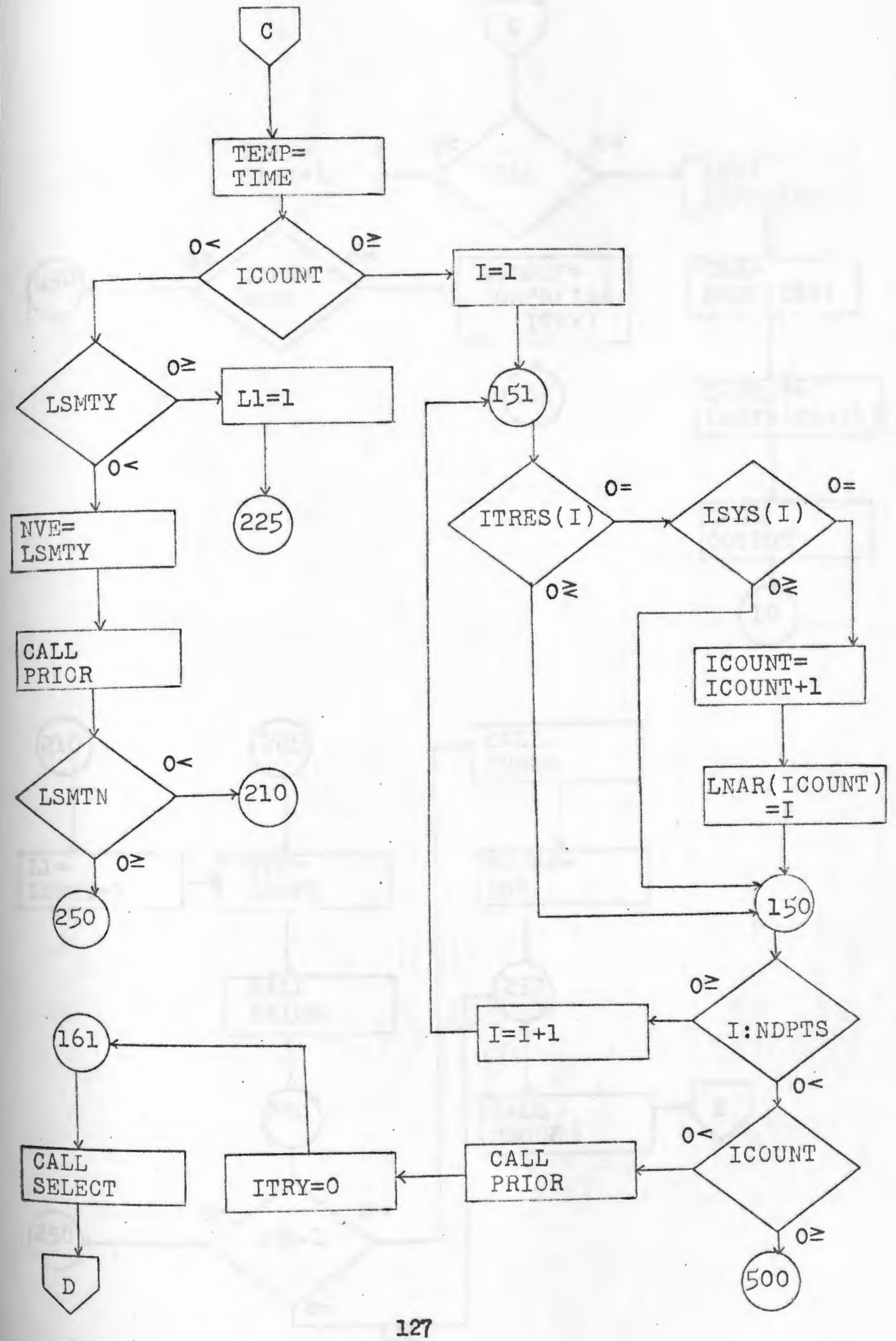



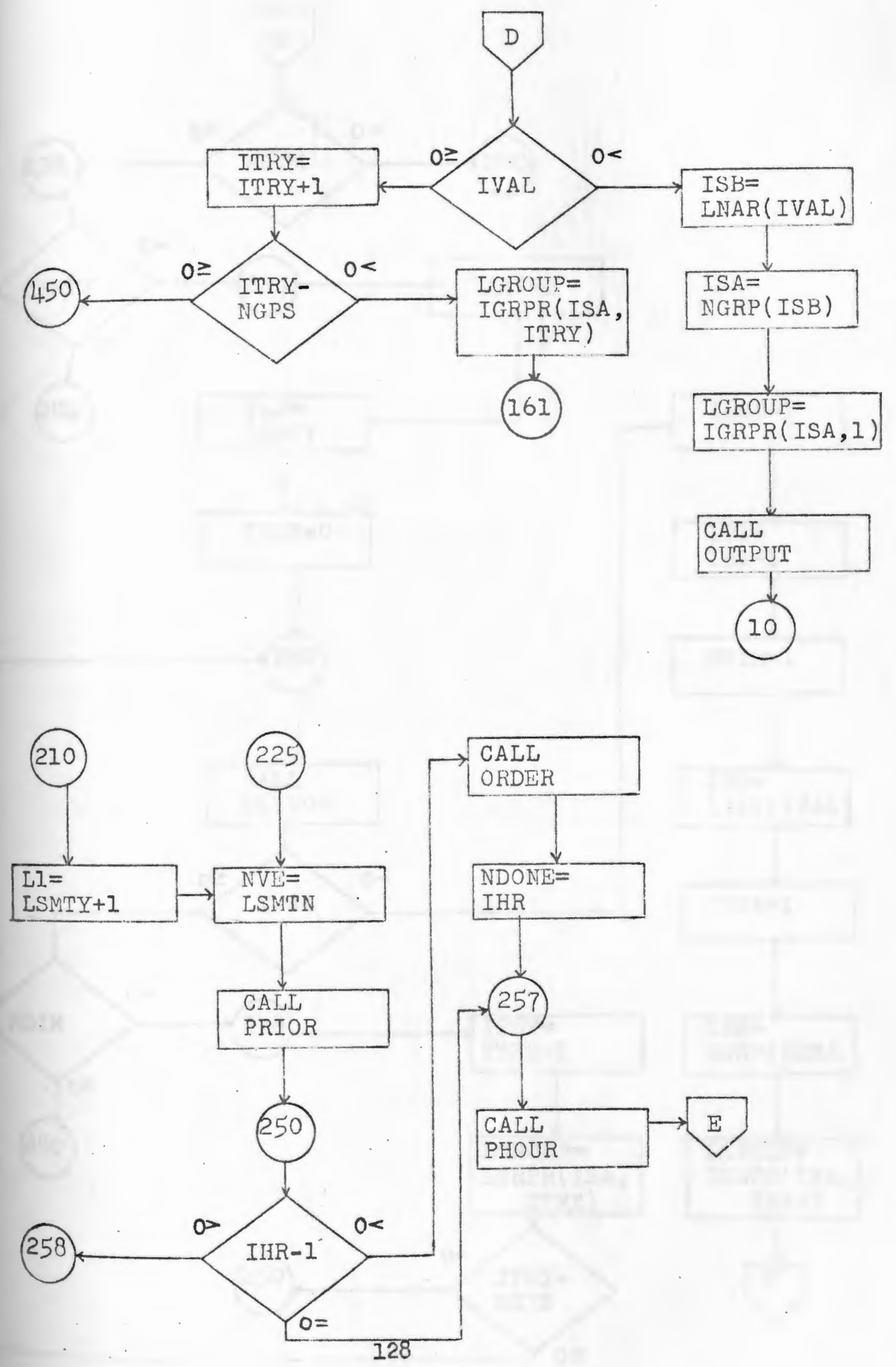


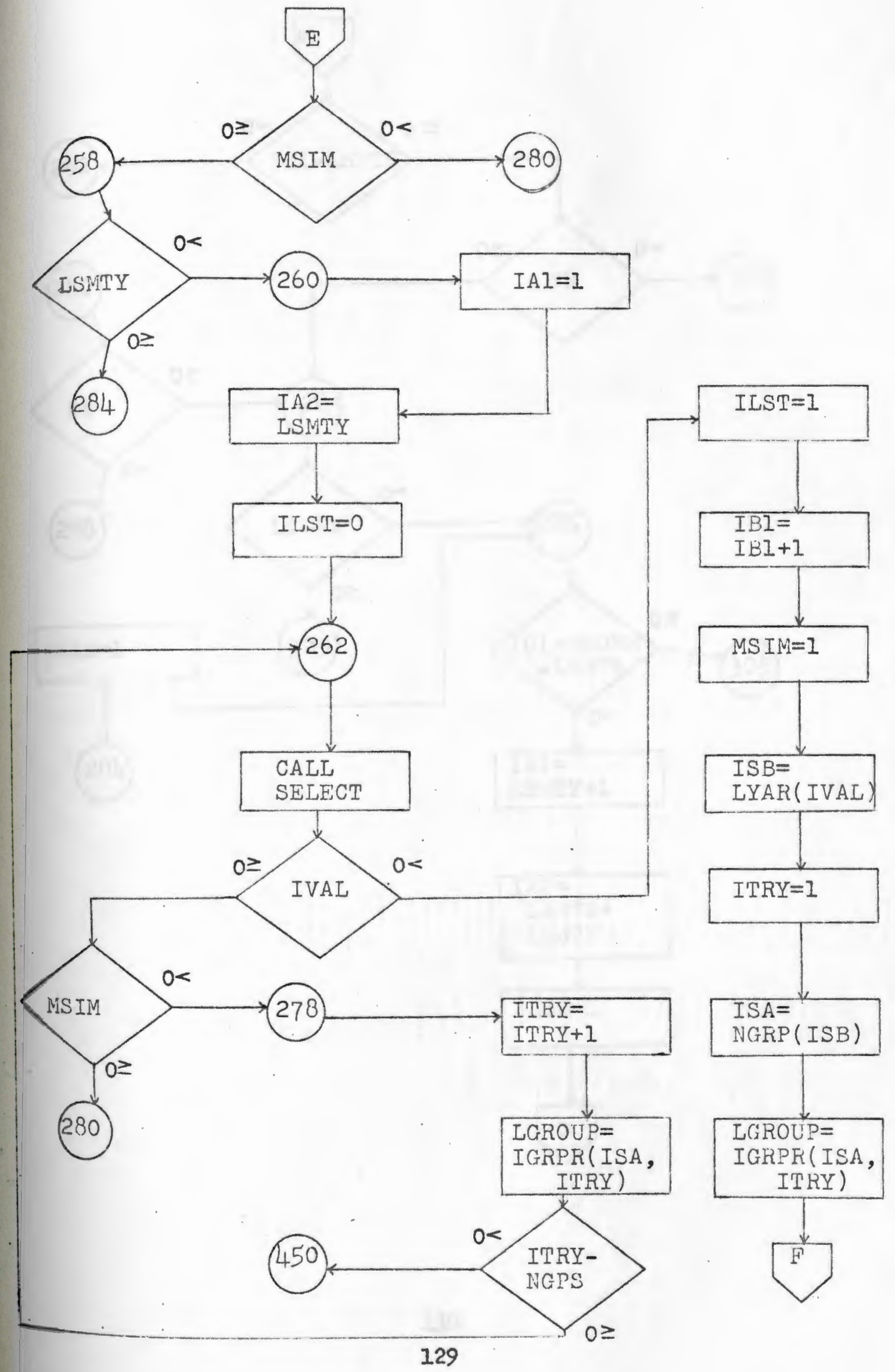




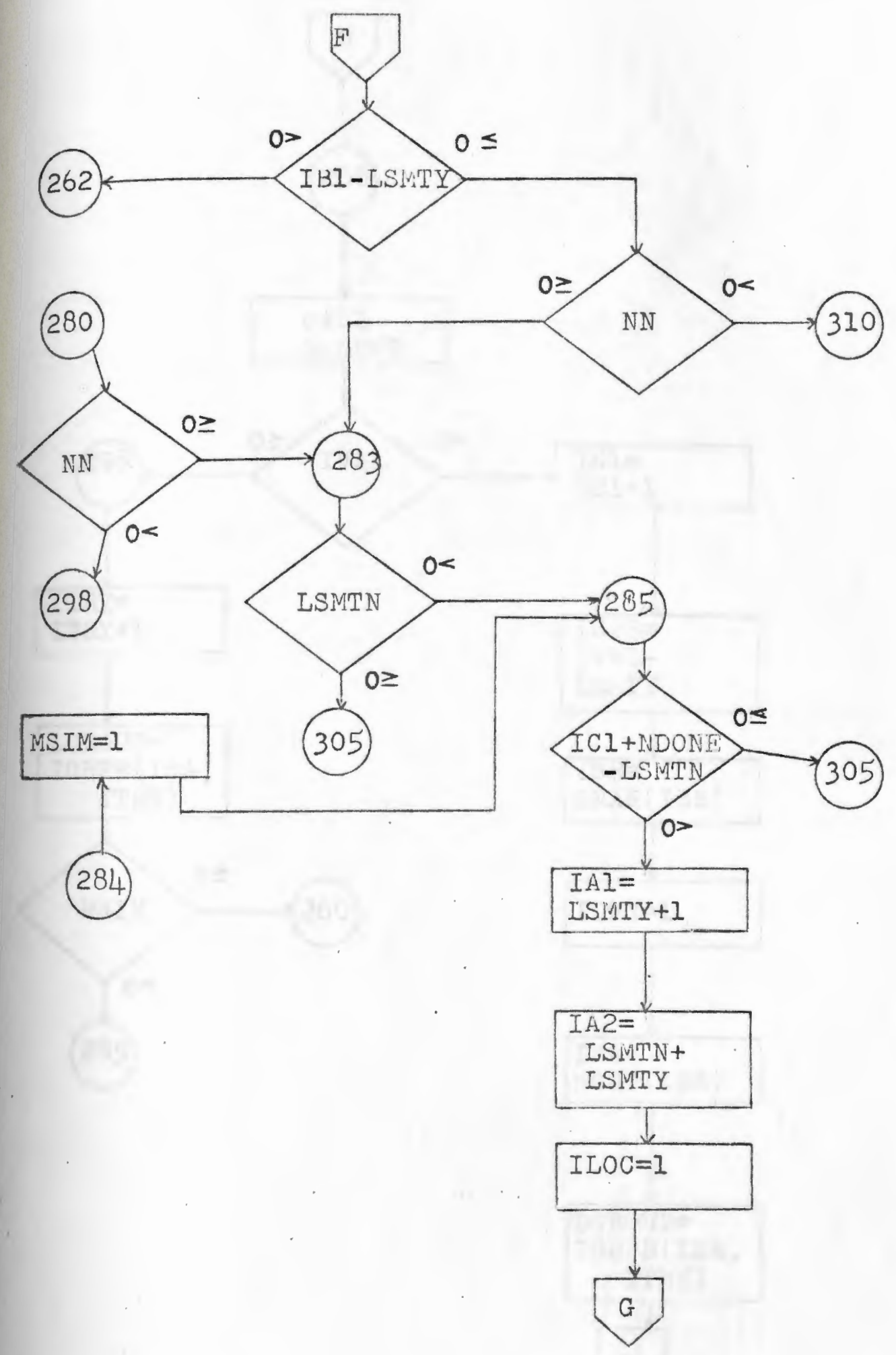




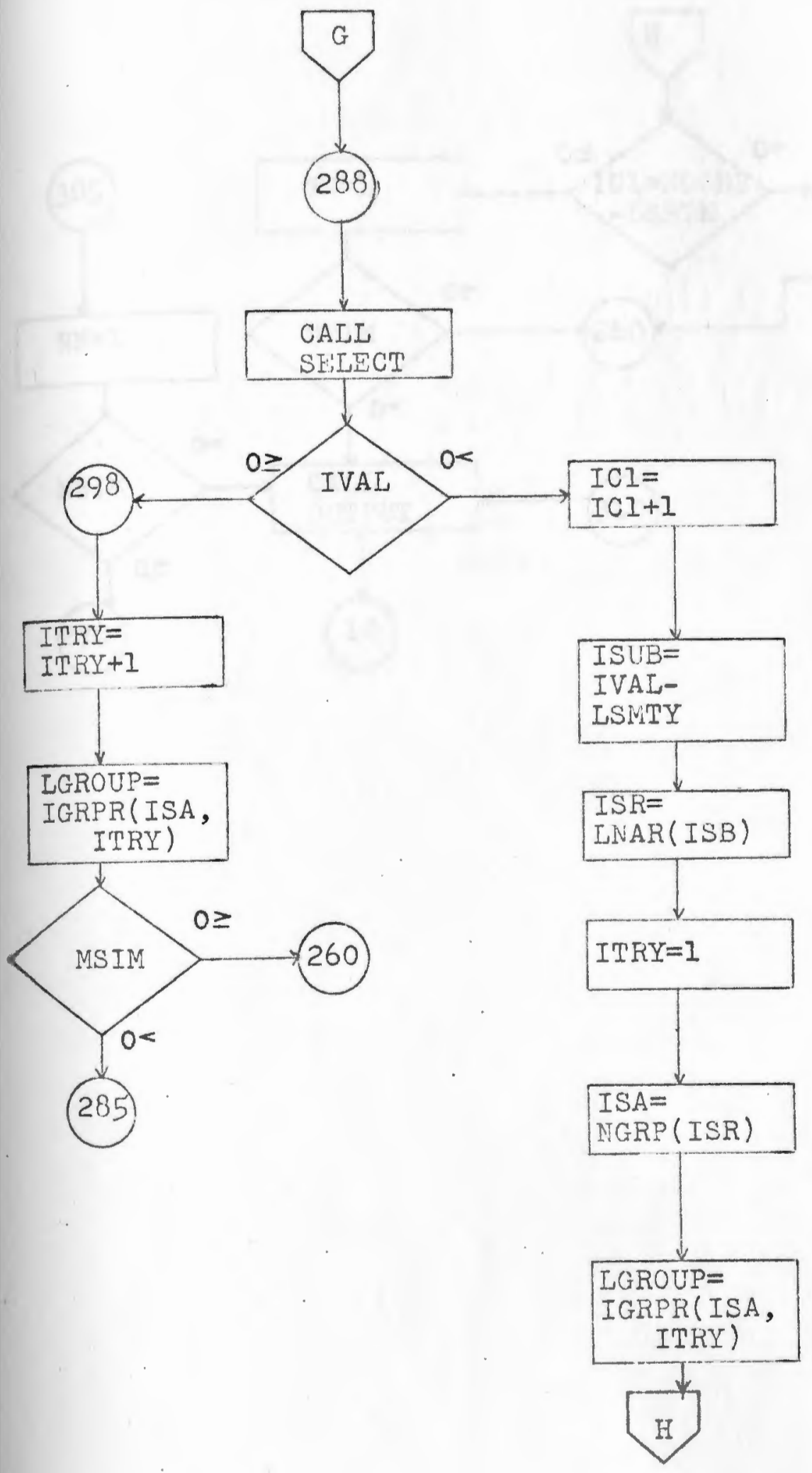




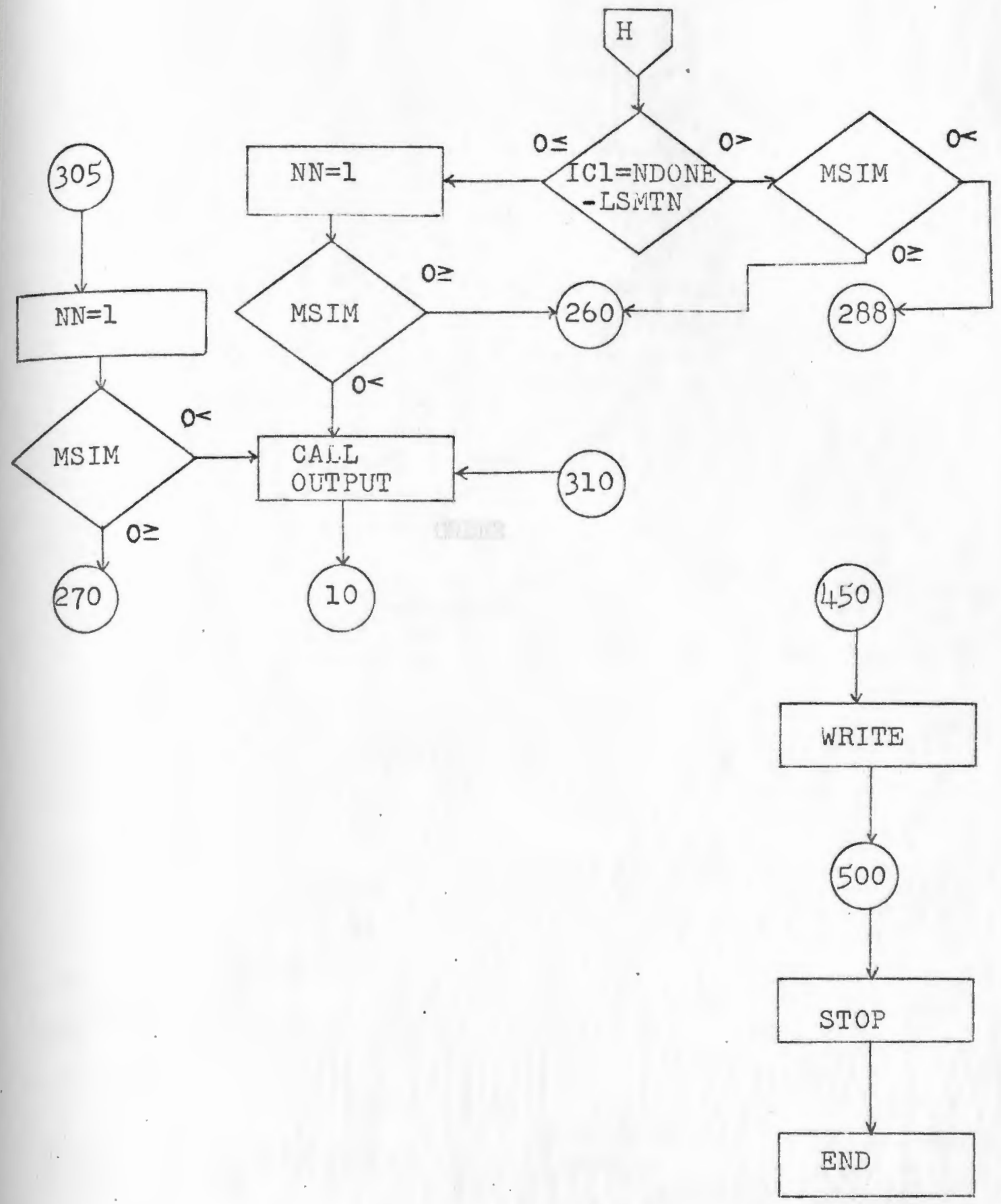


ORDER

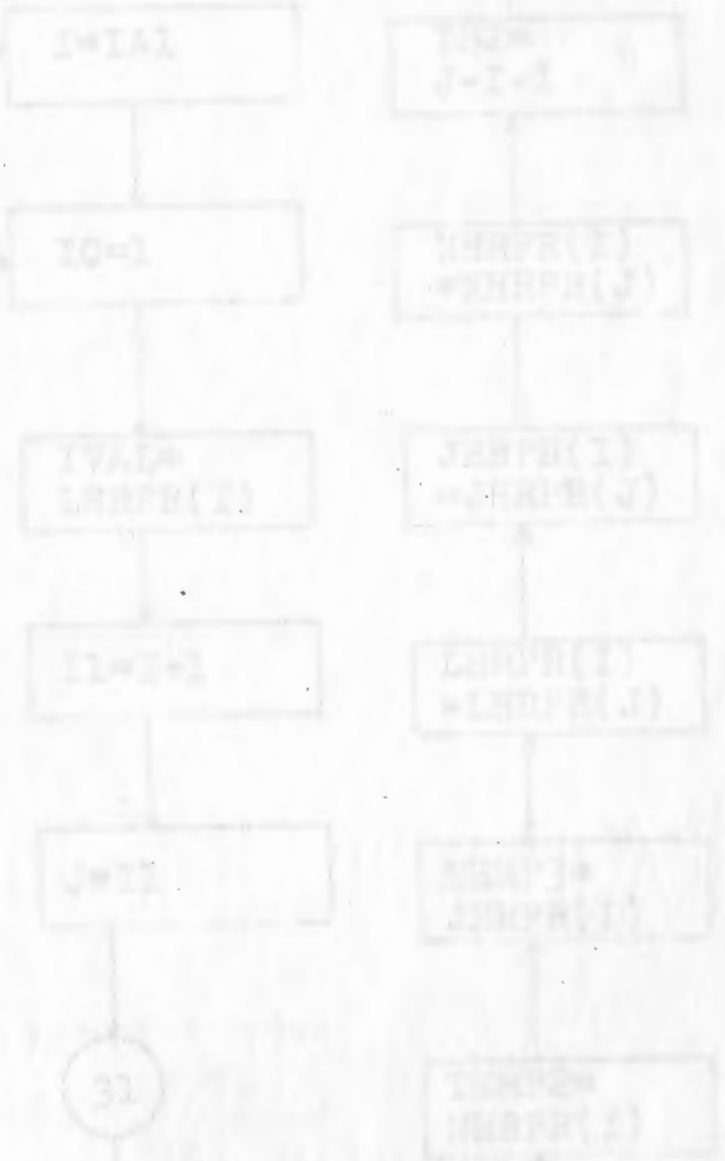




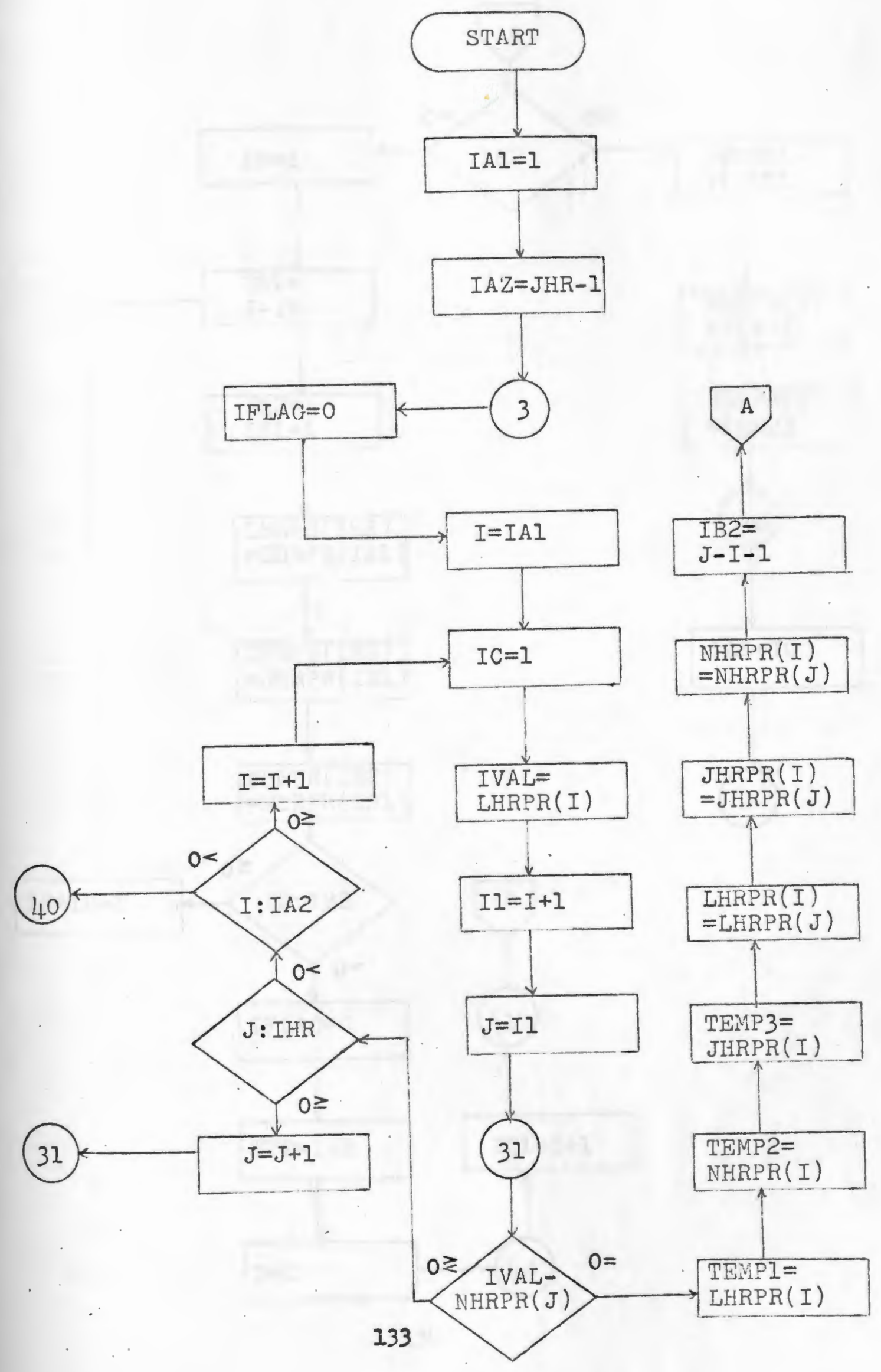




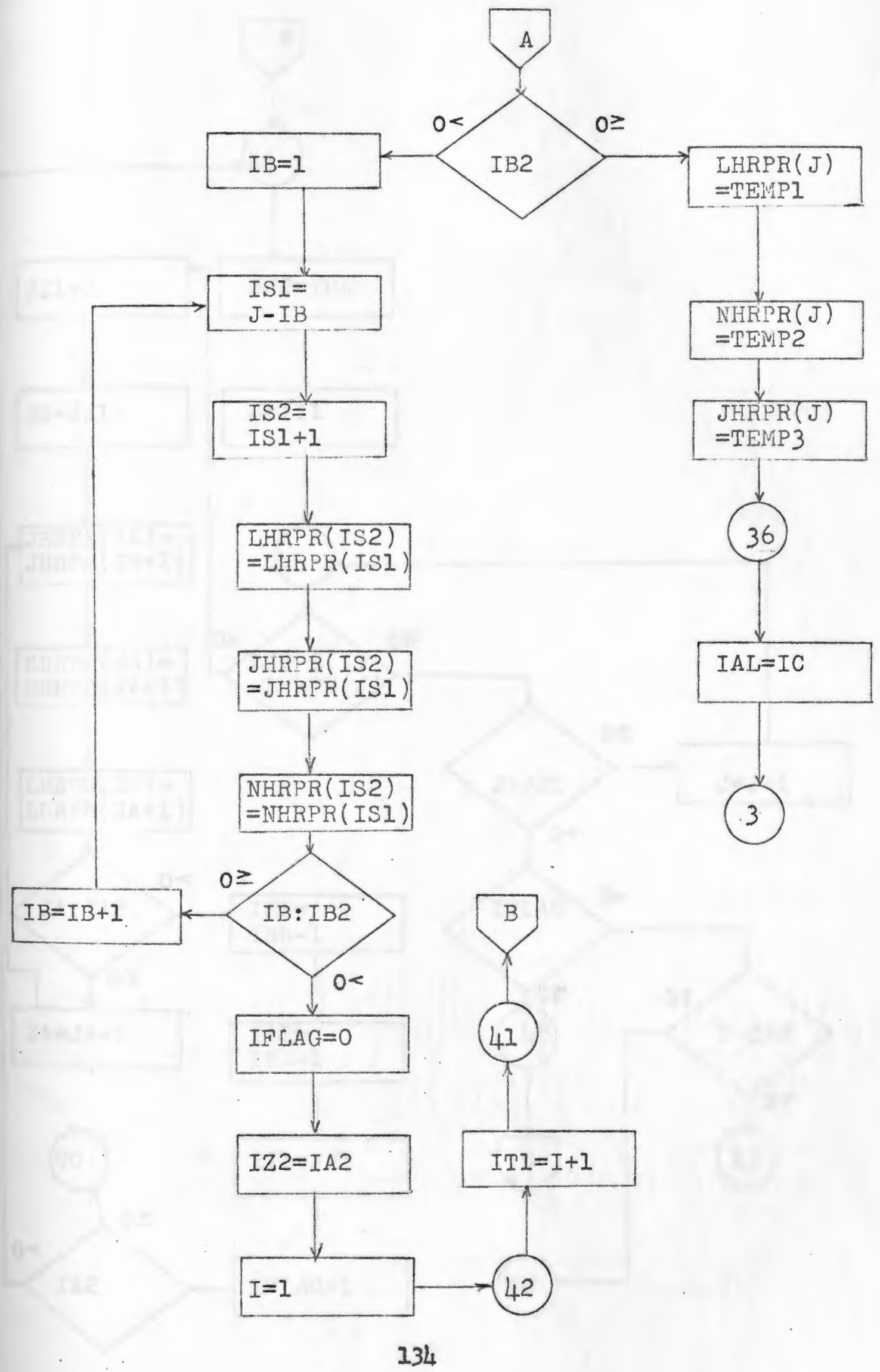




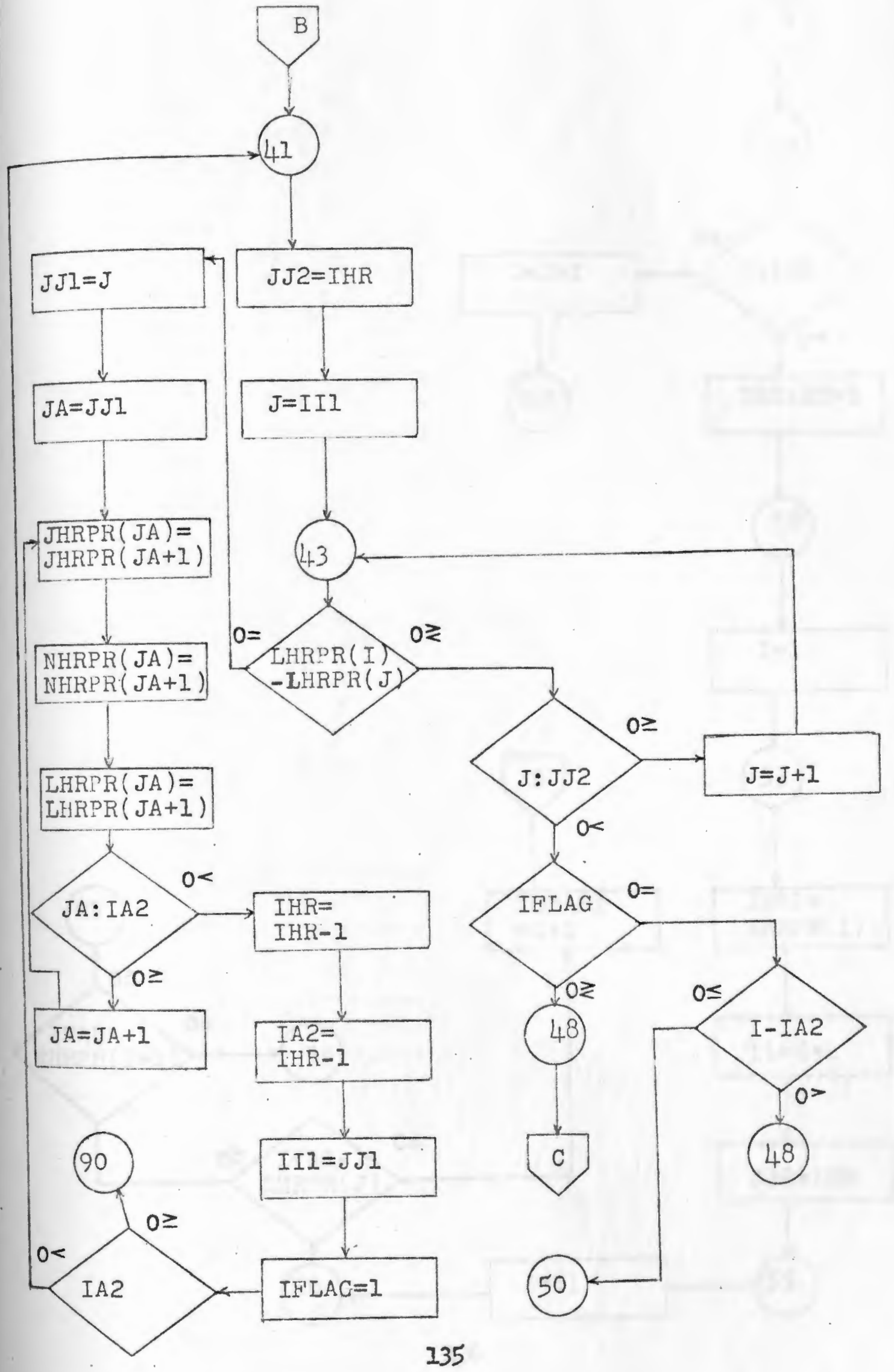




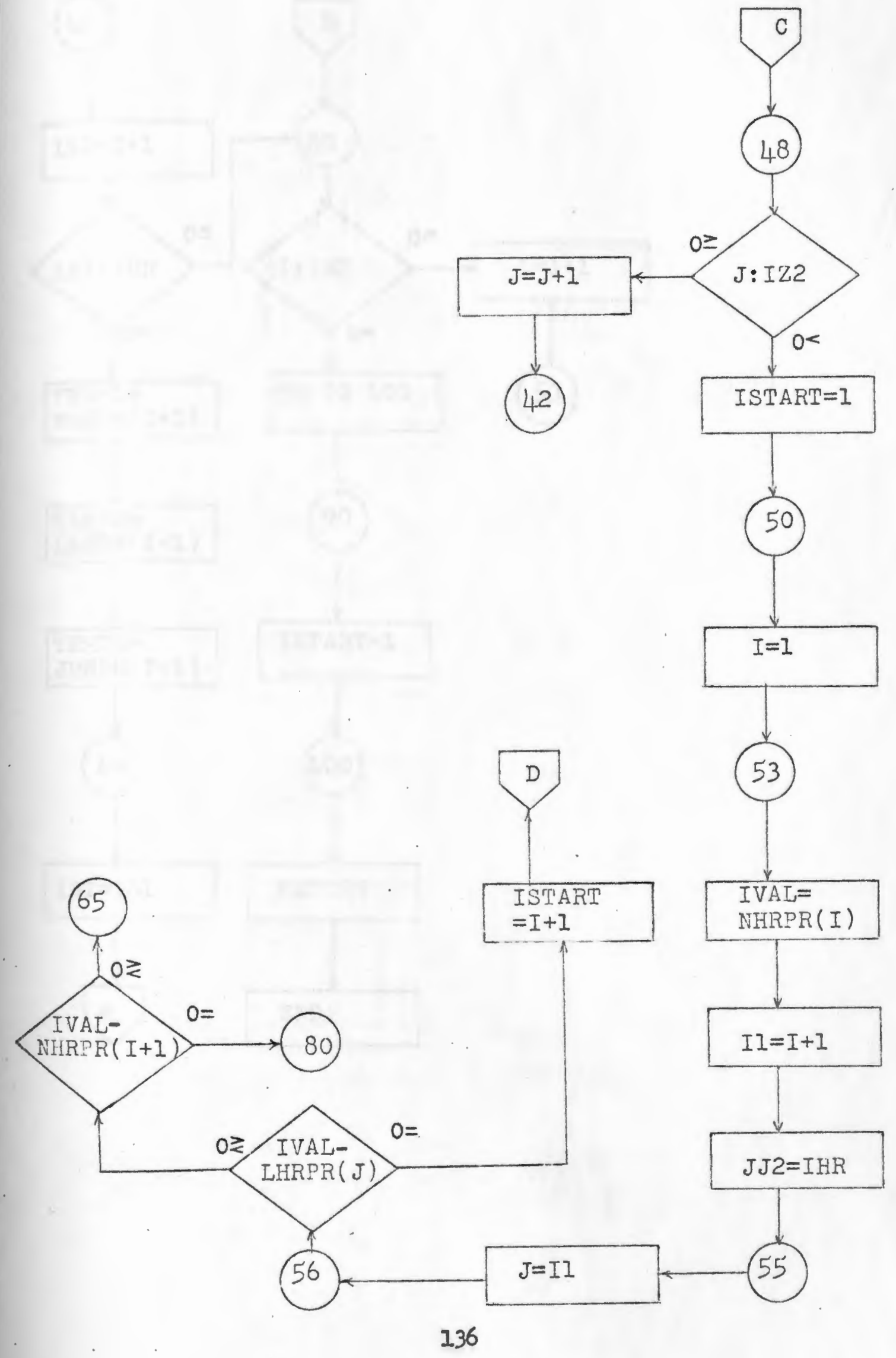




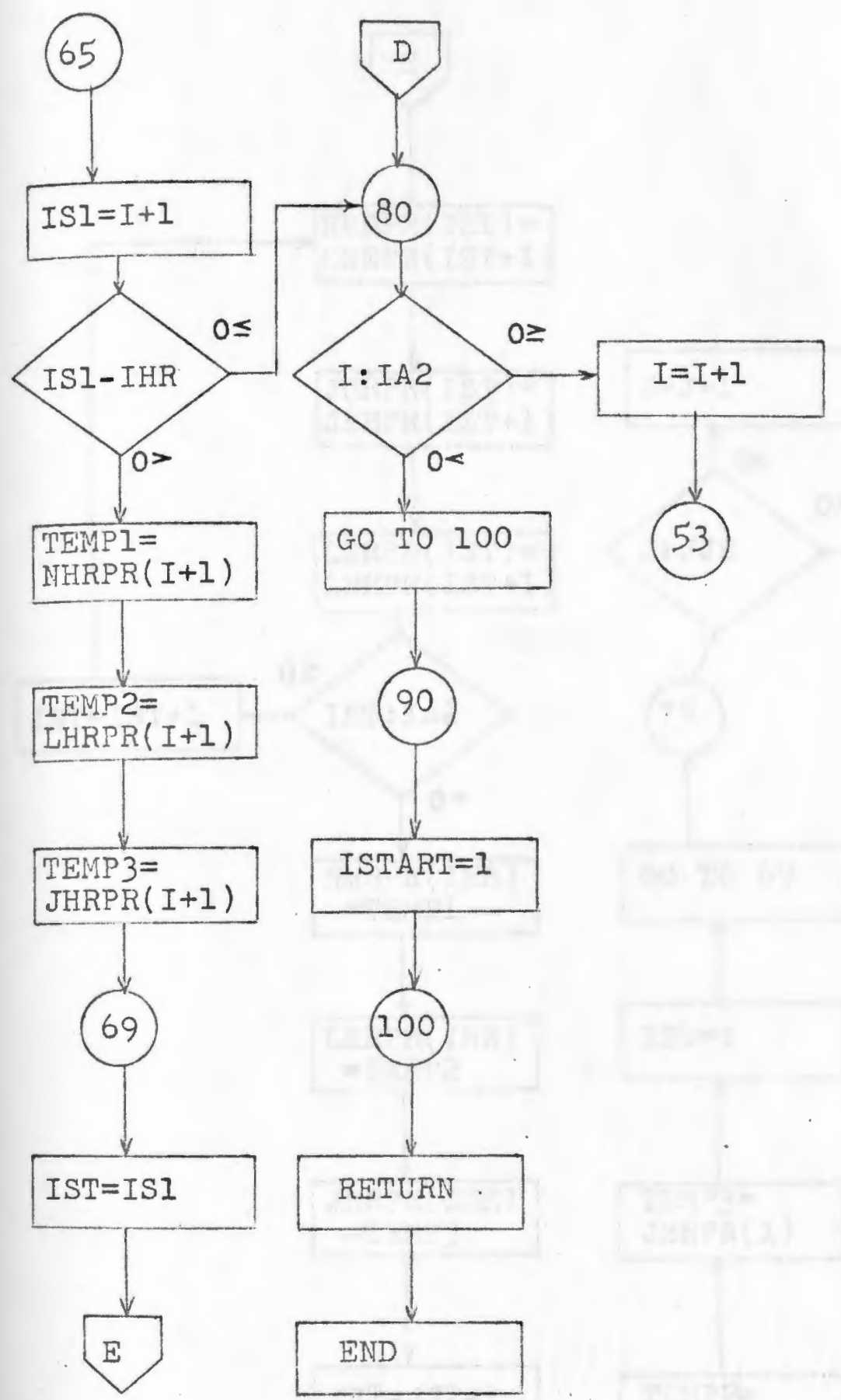




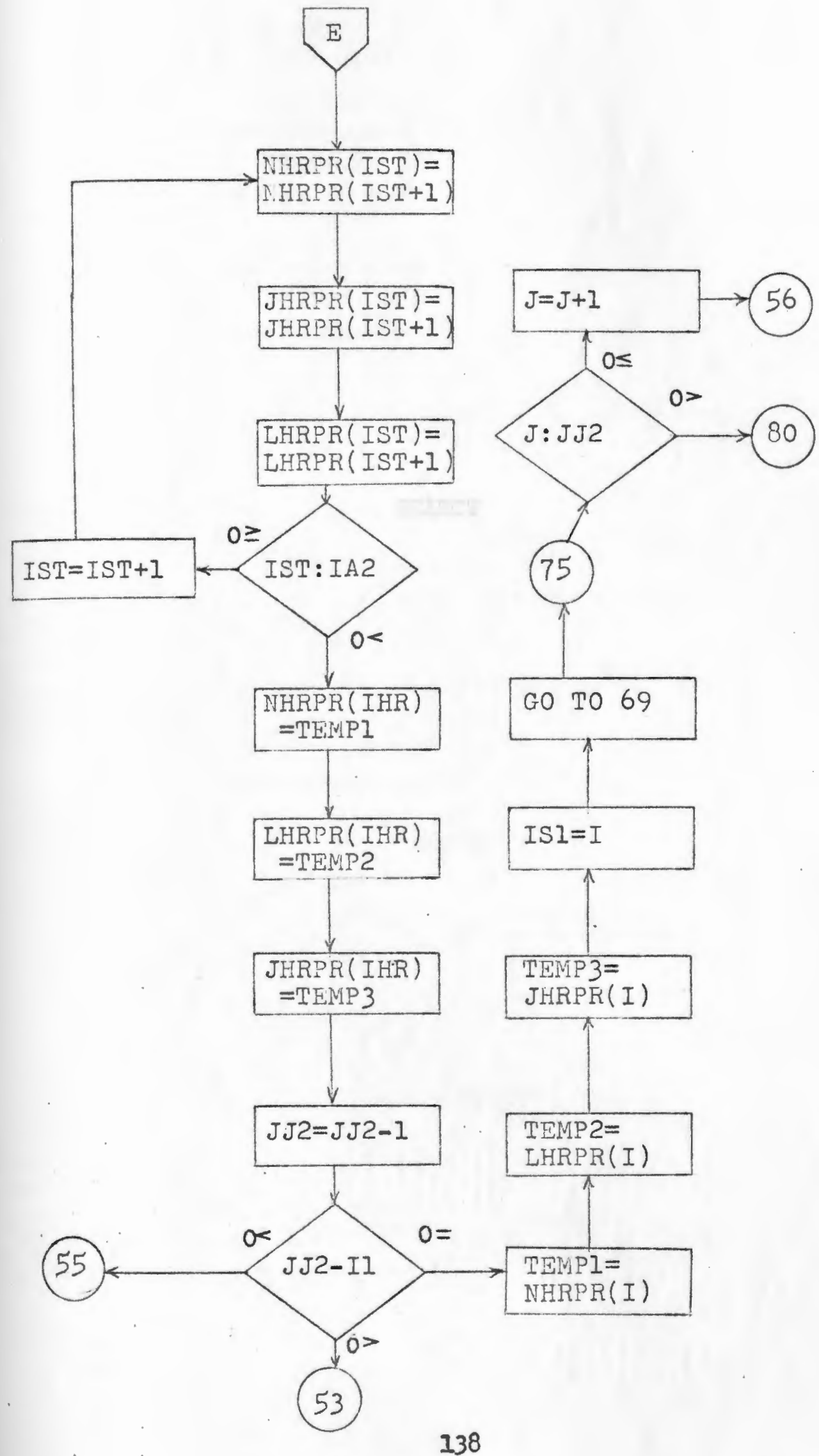


SELECT 


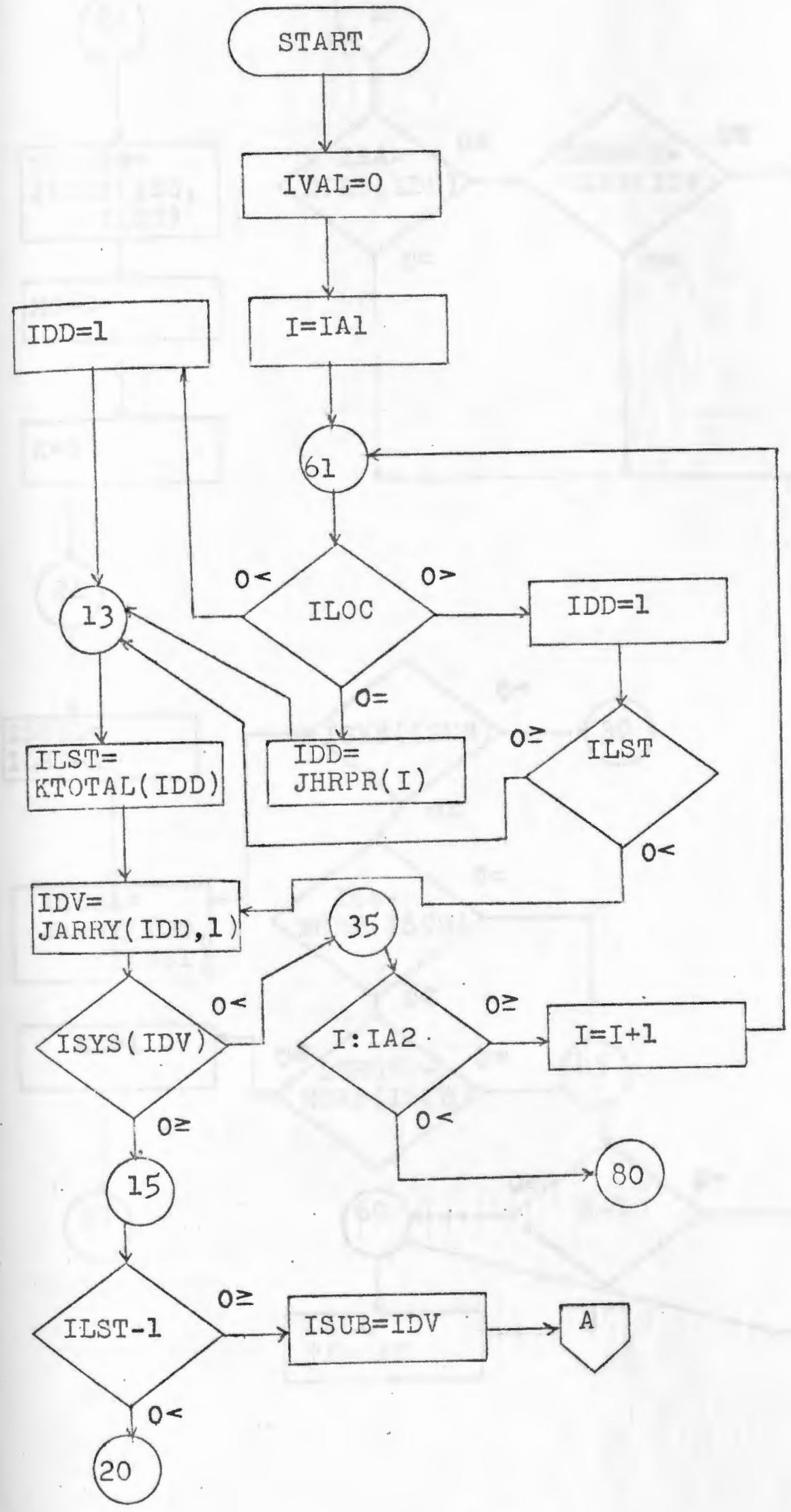




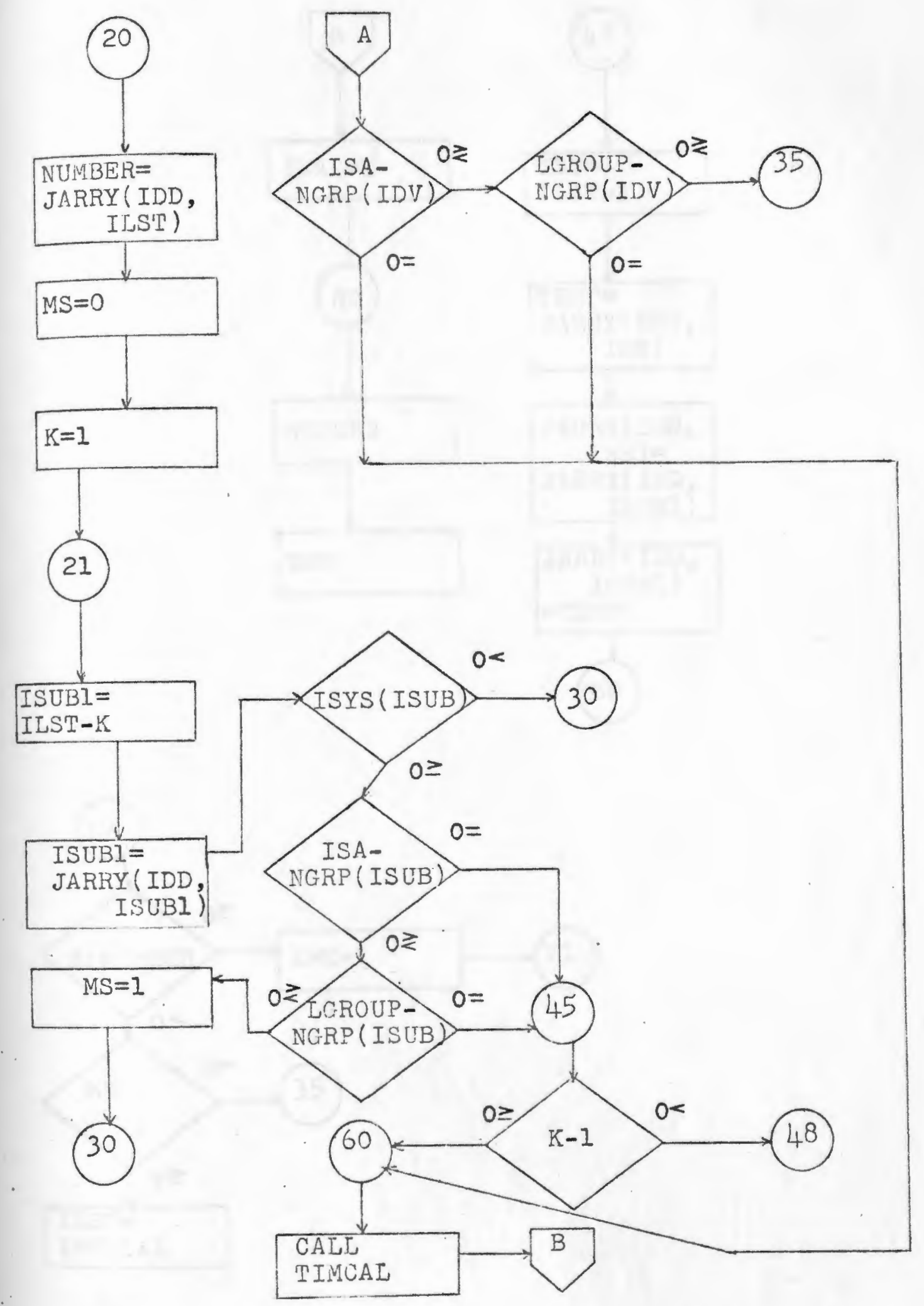



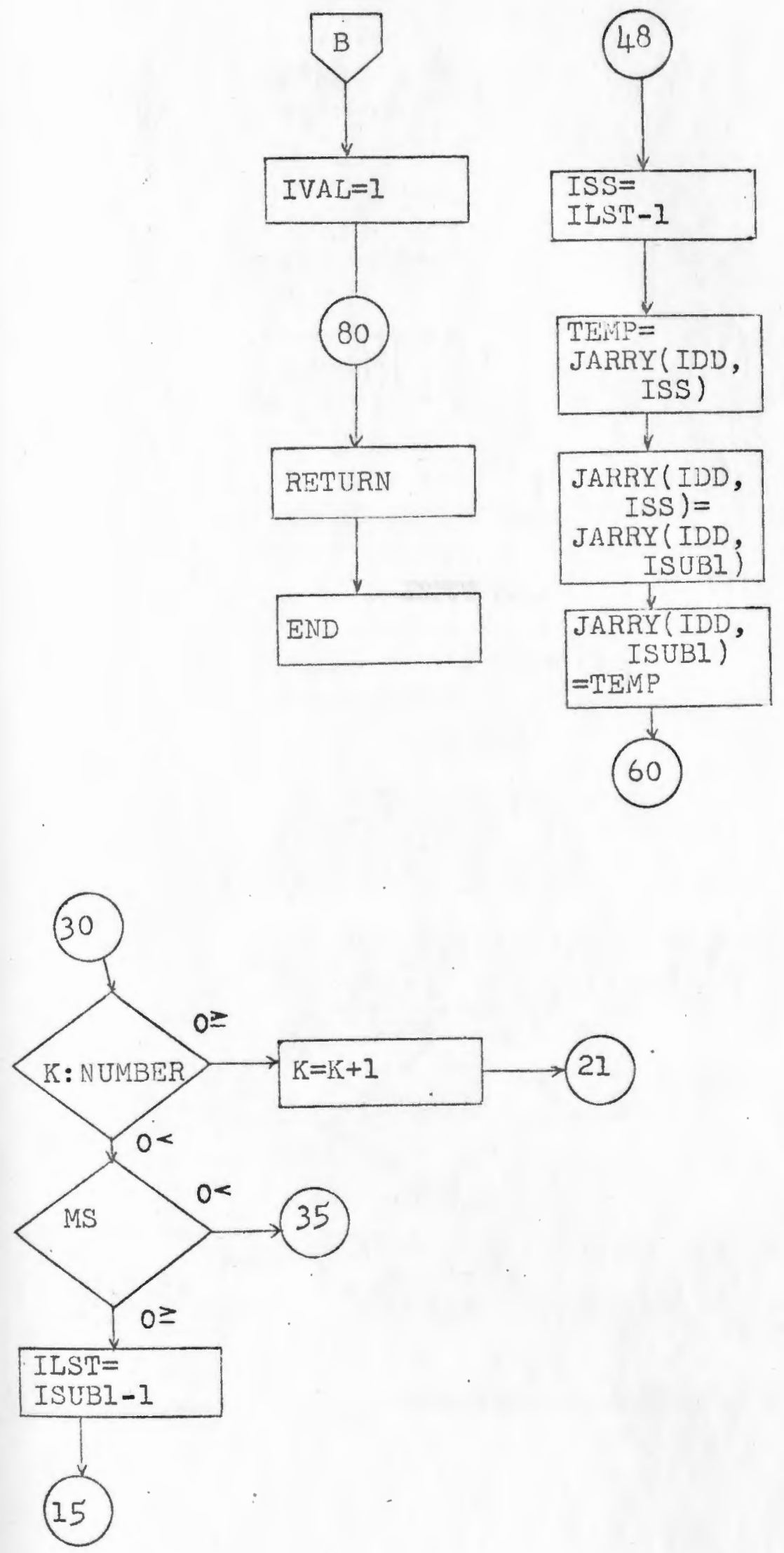


\section{INPUT}




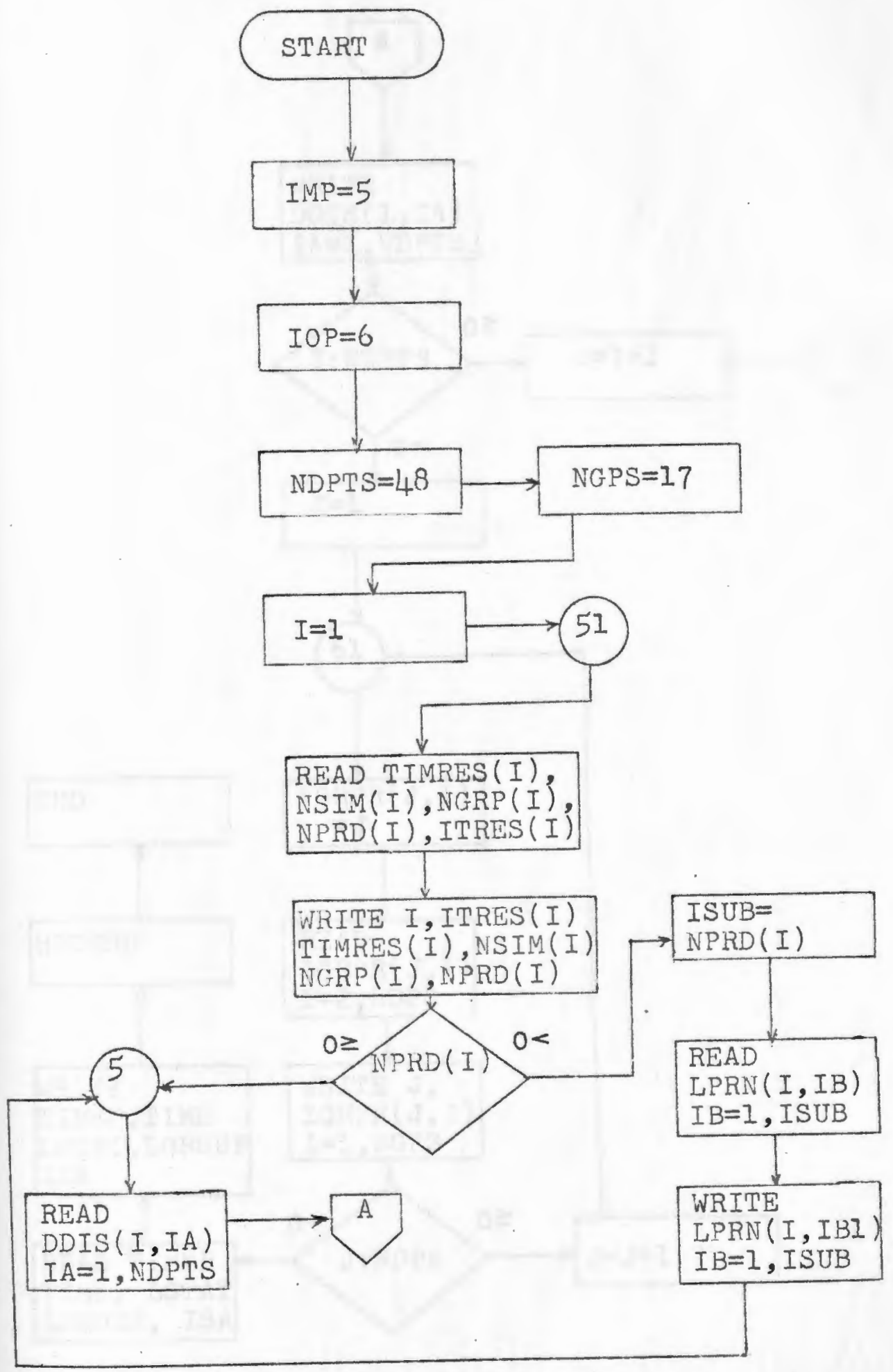




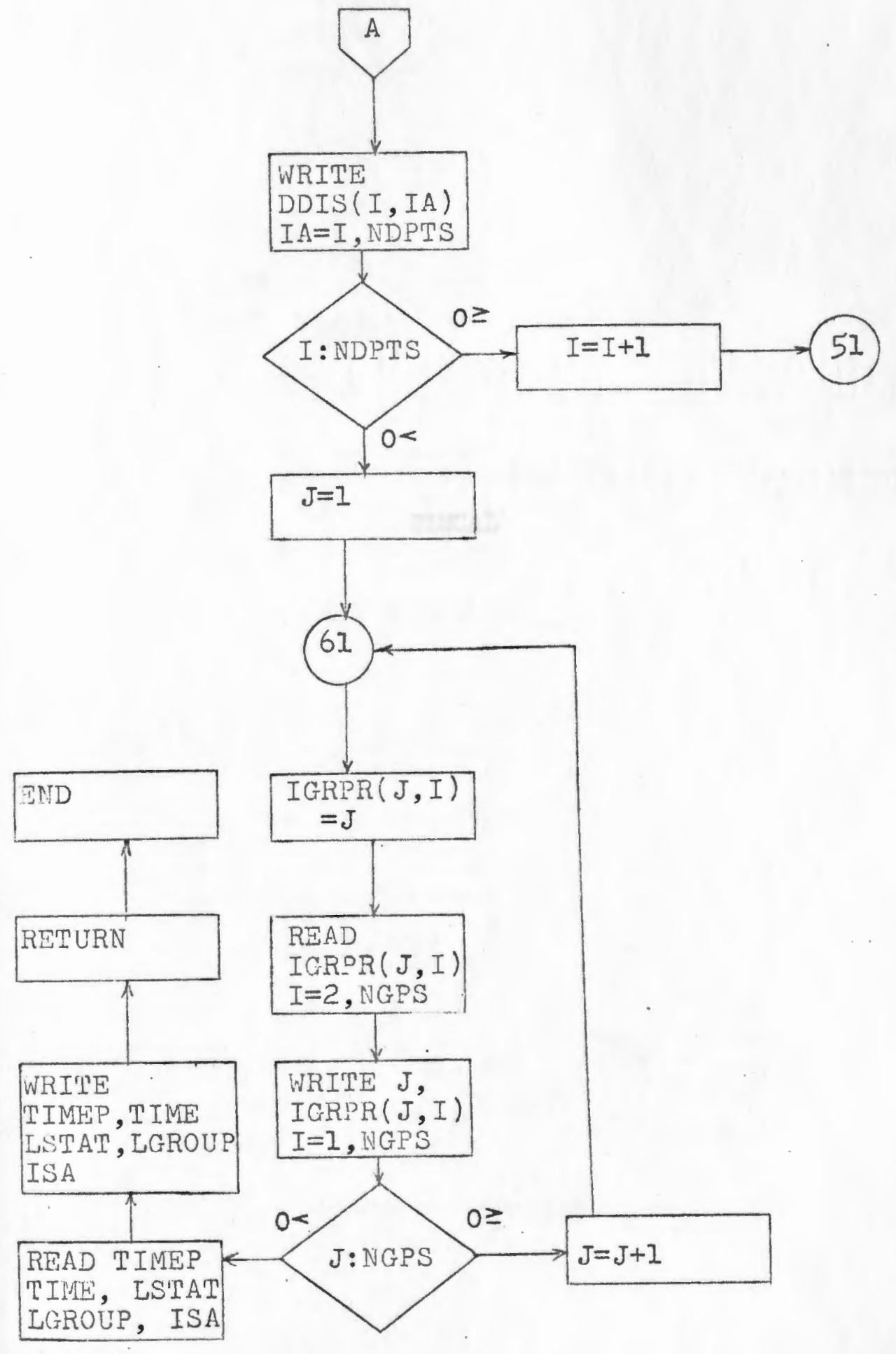


TDMCAL

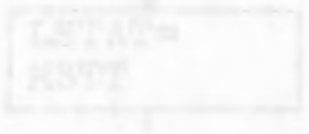




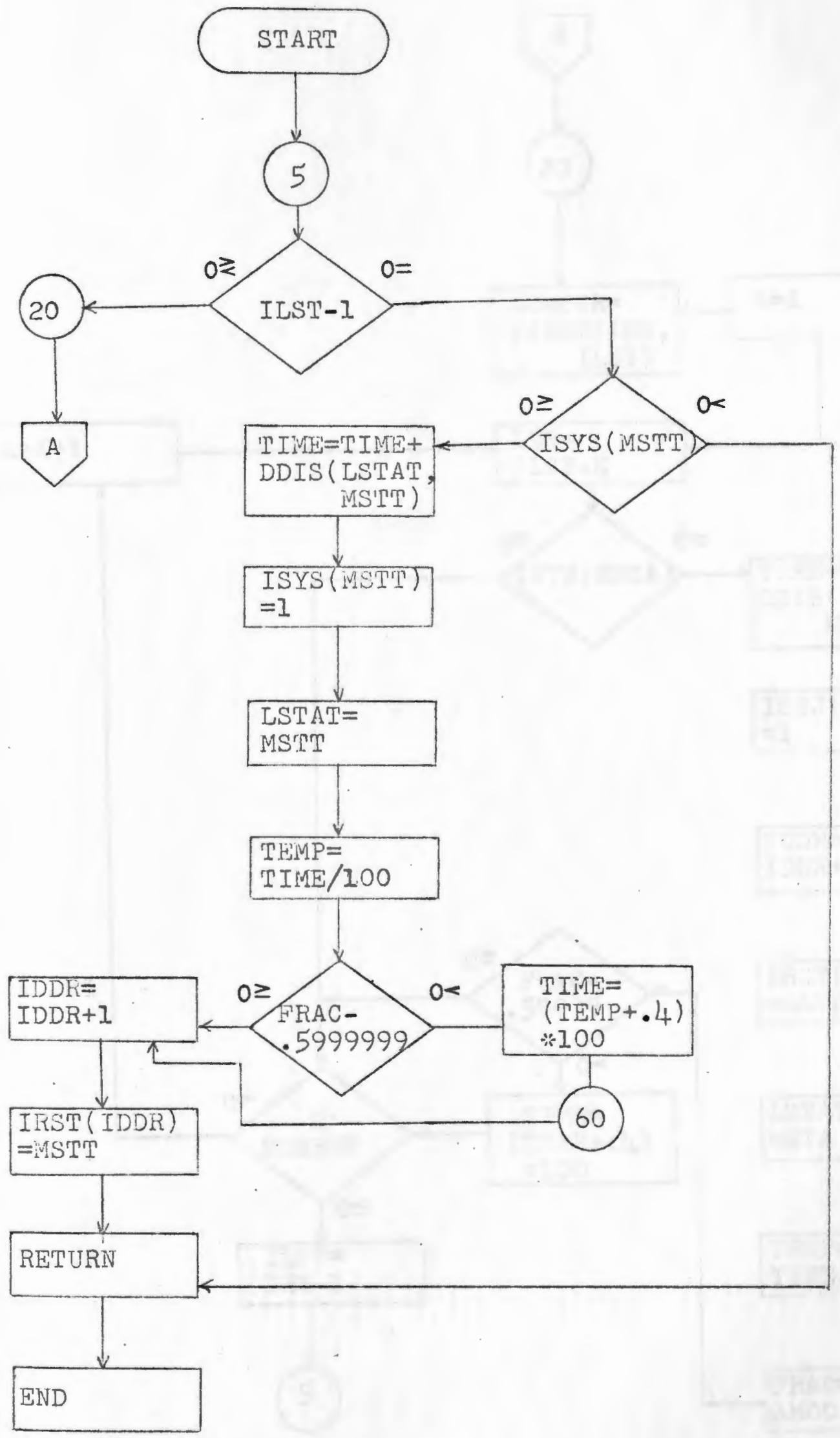



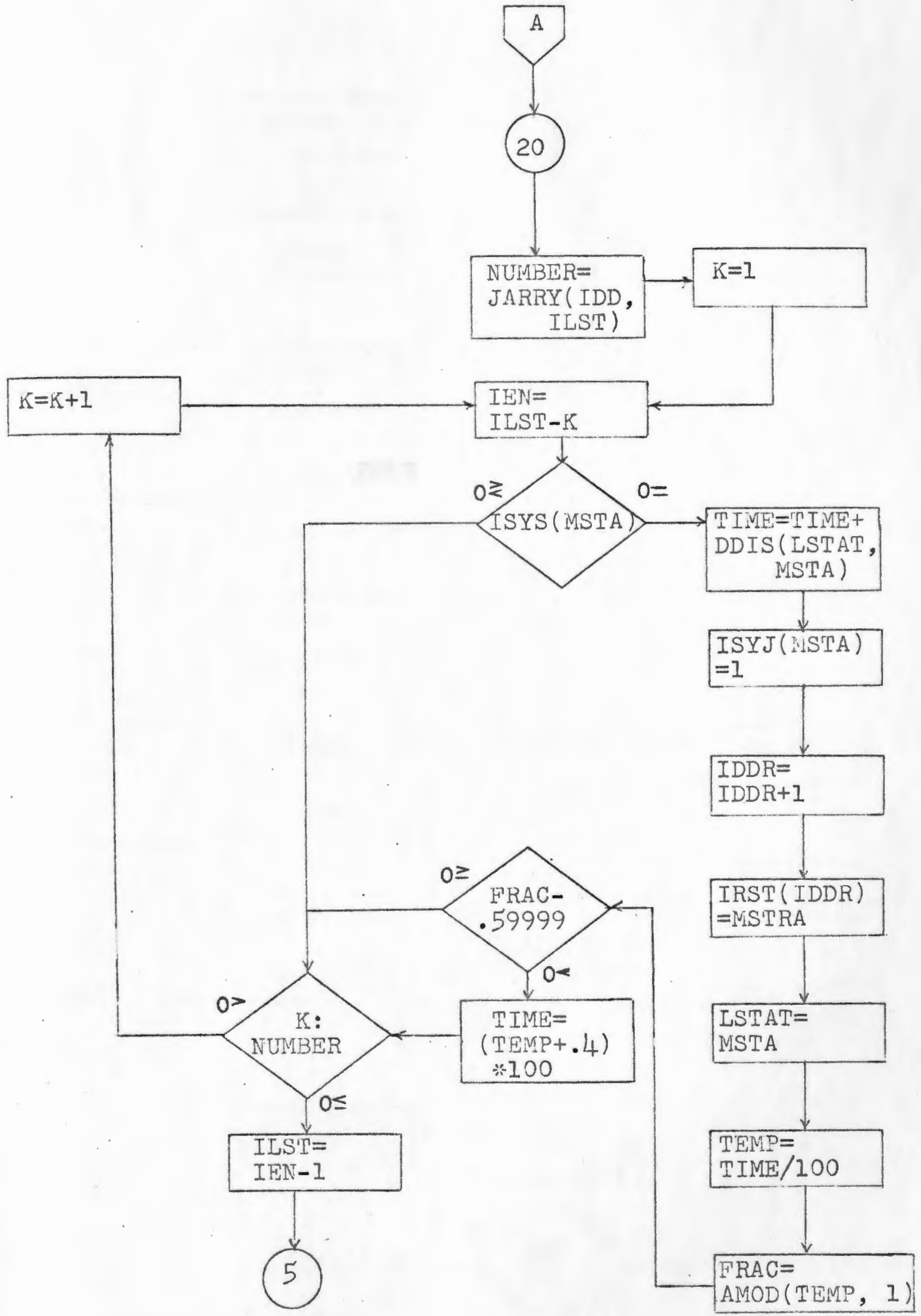
PHOUR 


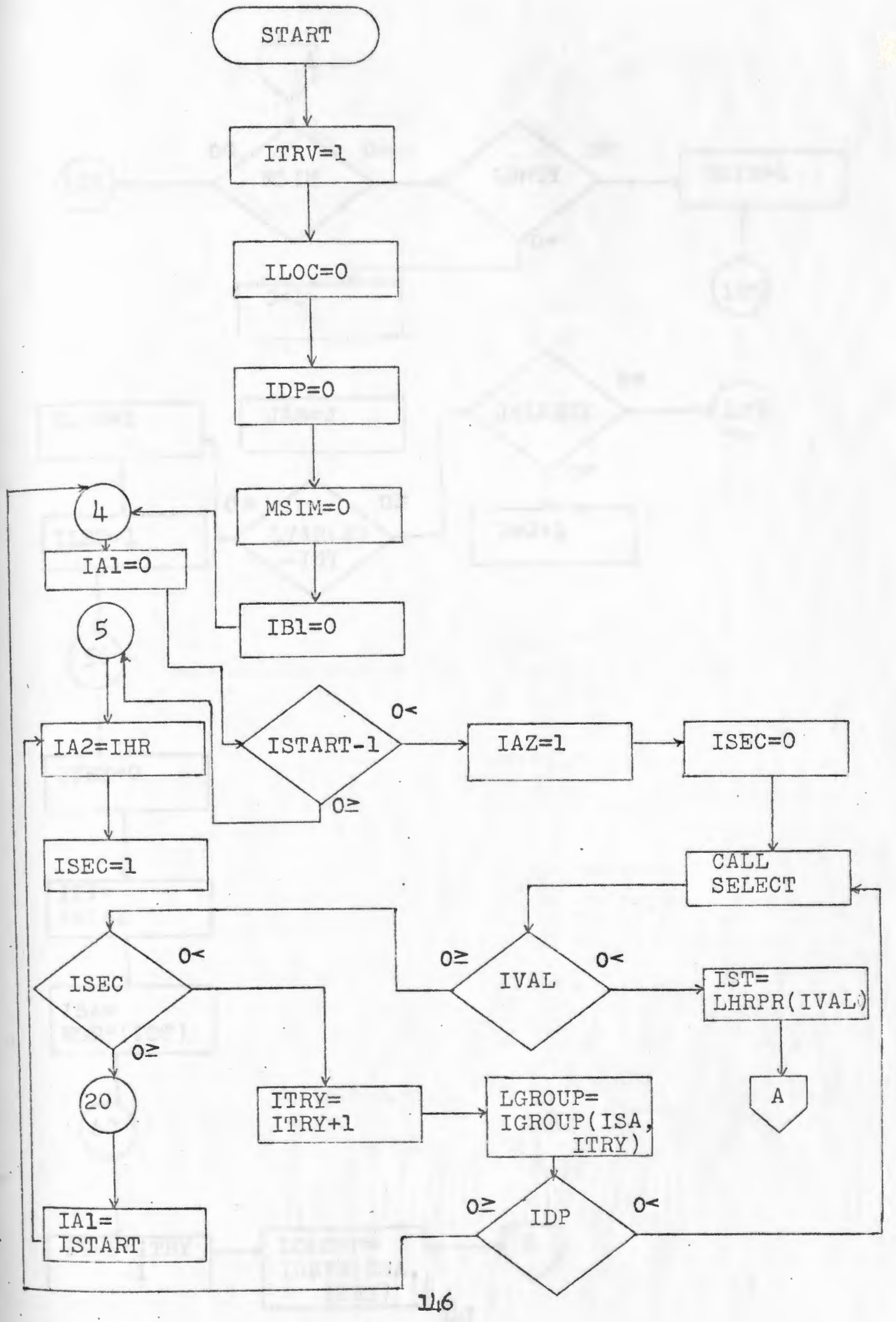




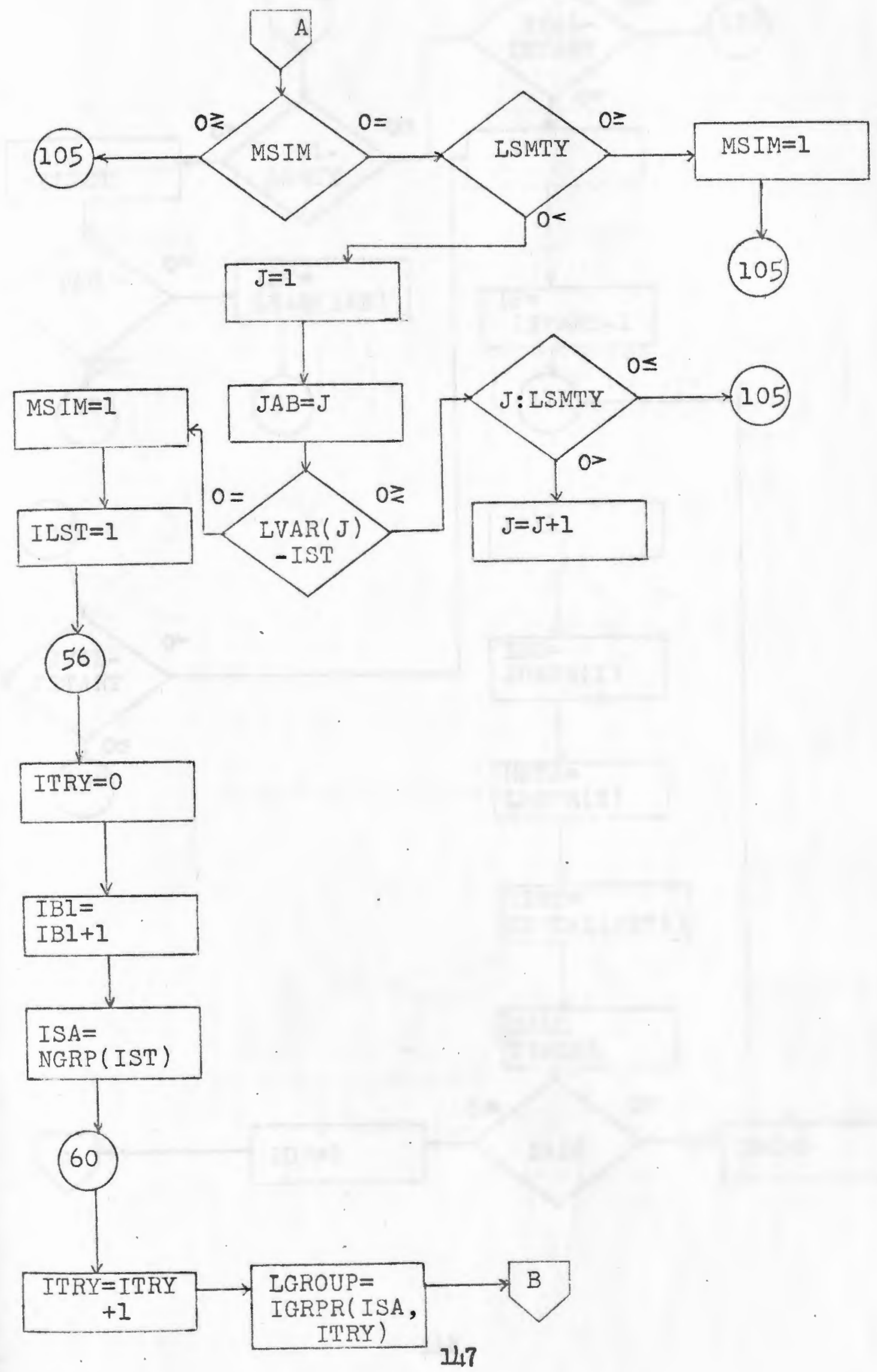




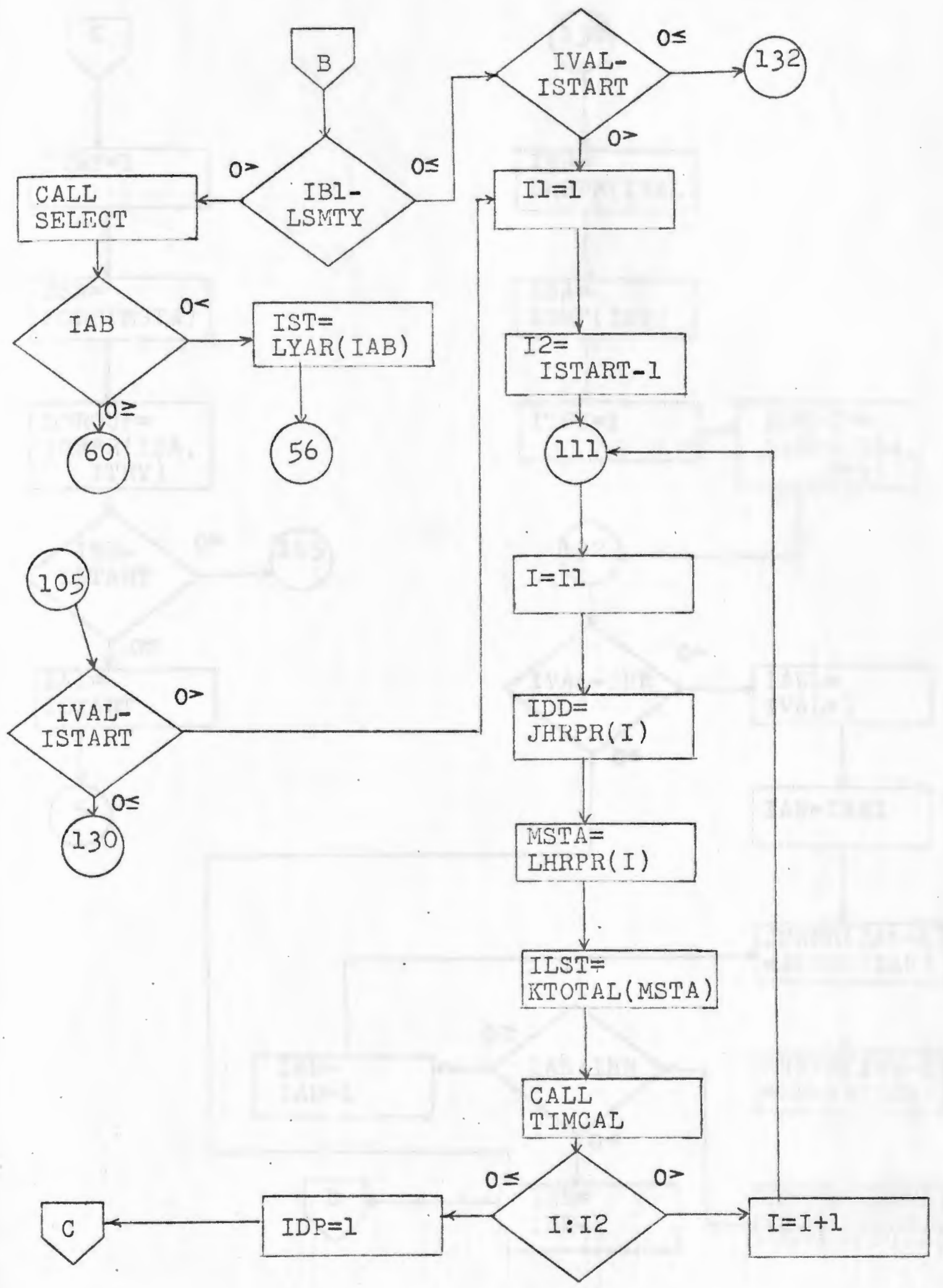




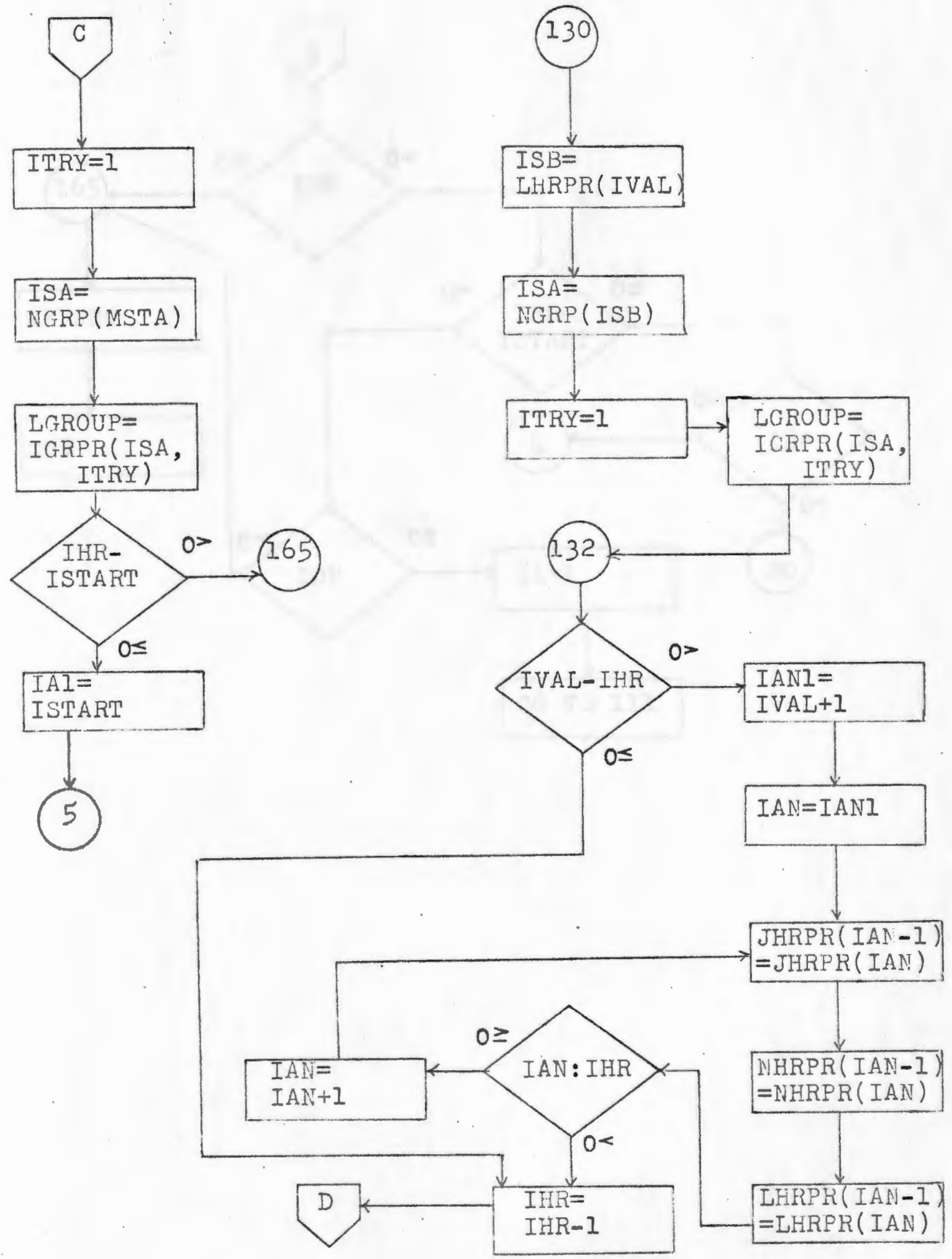




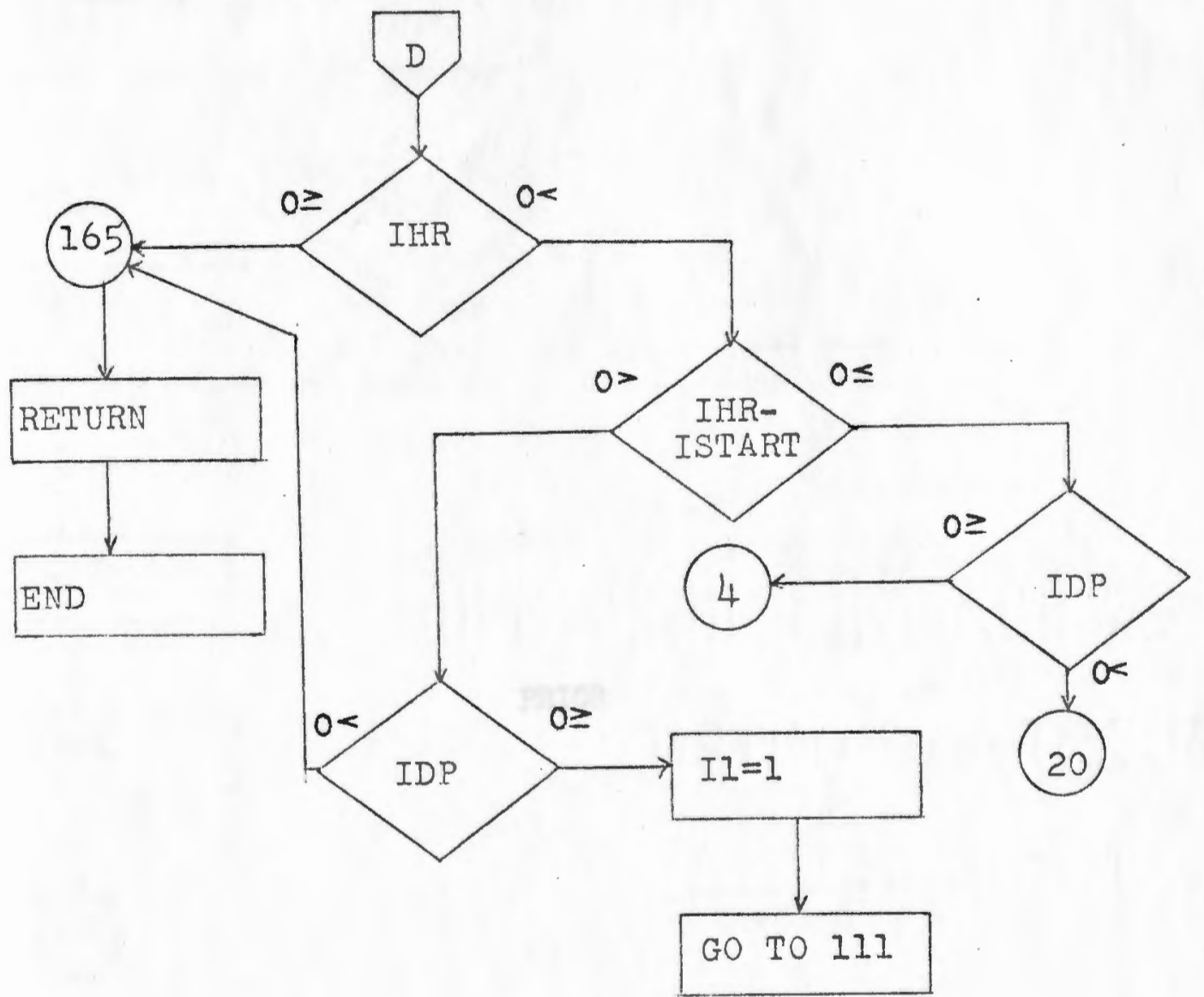




\section{PRIOR}




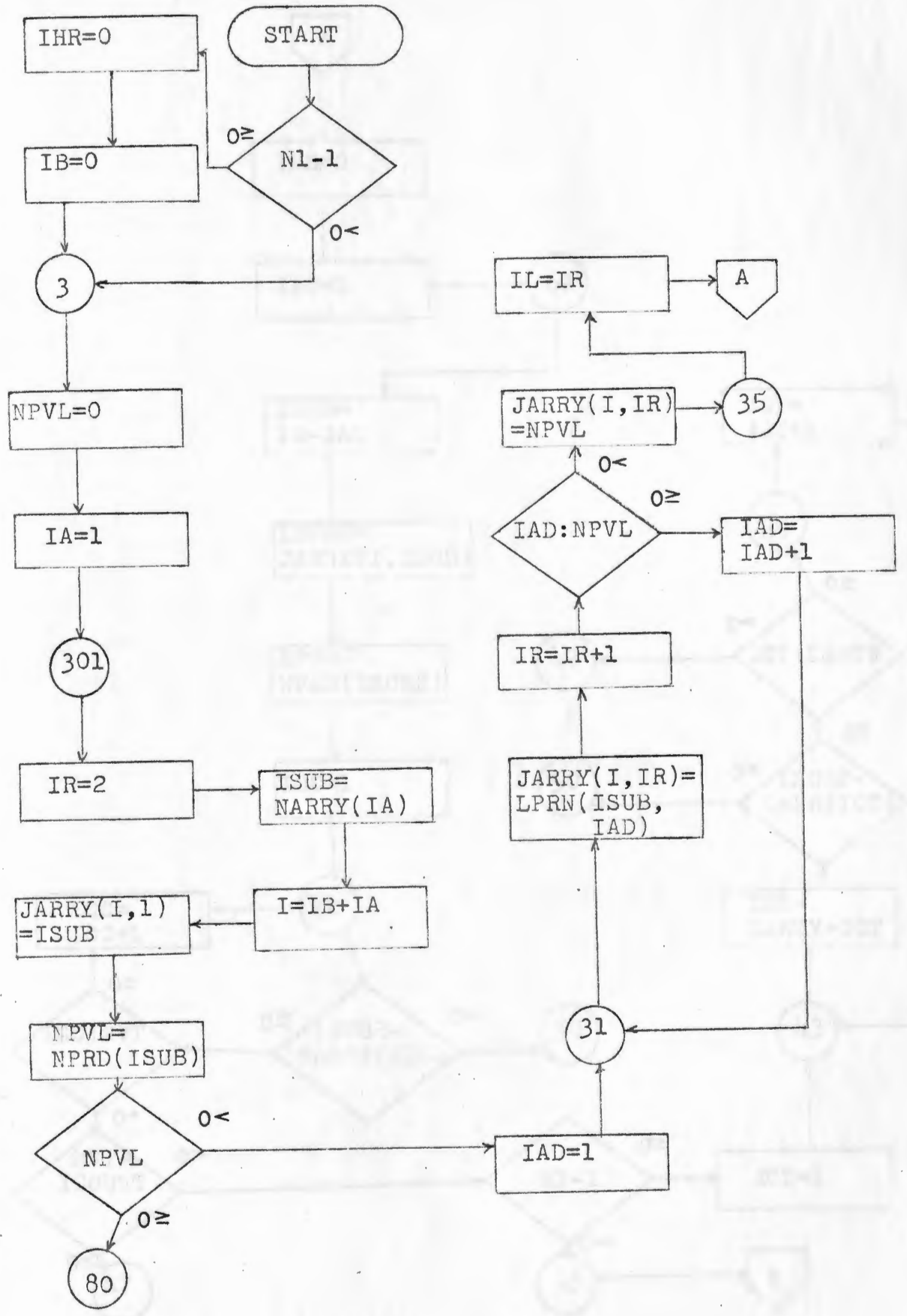




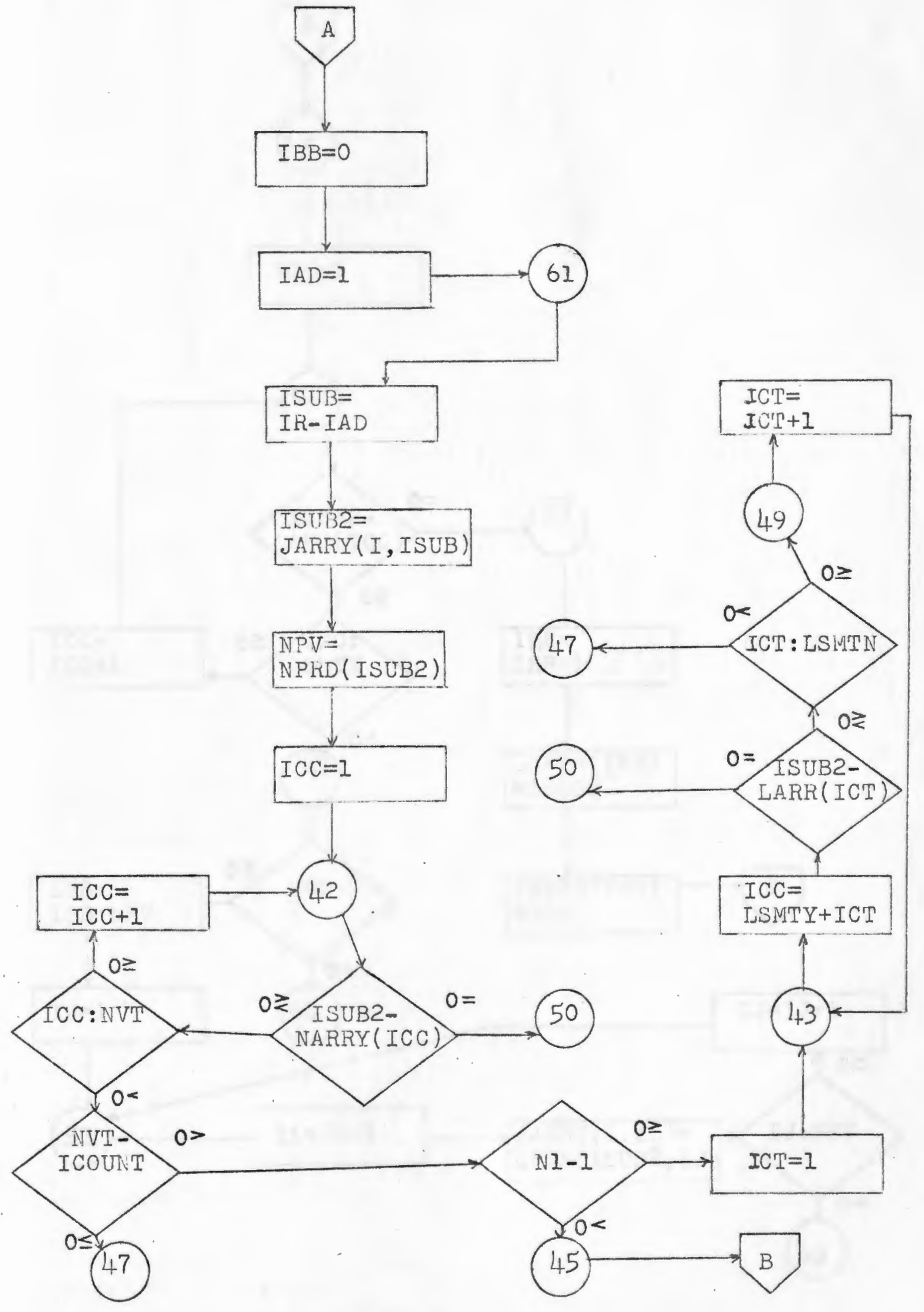




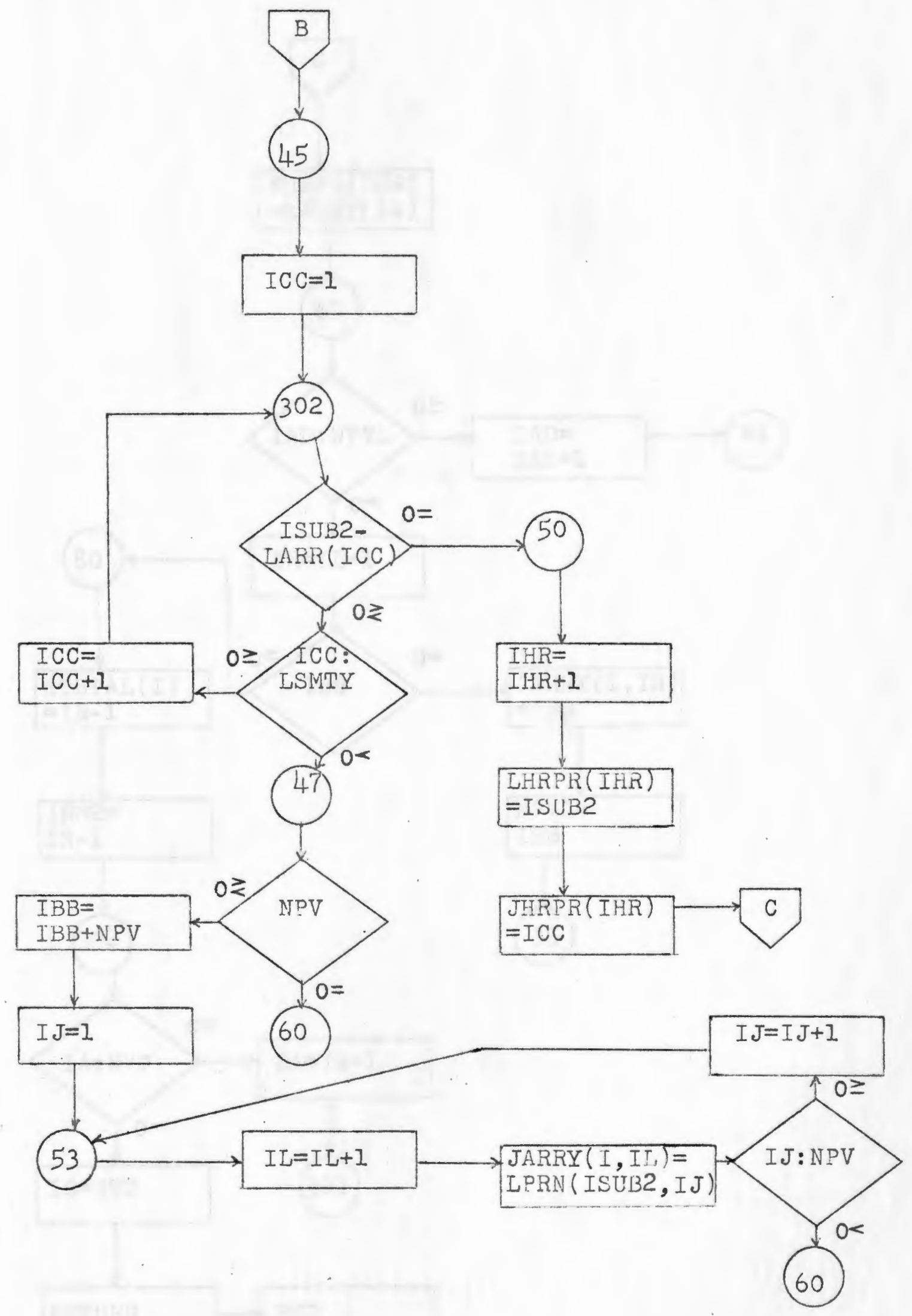




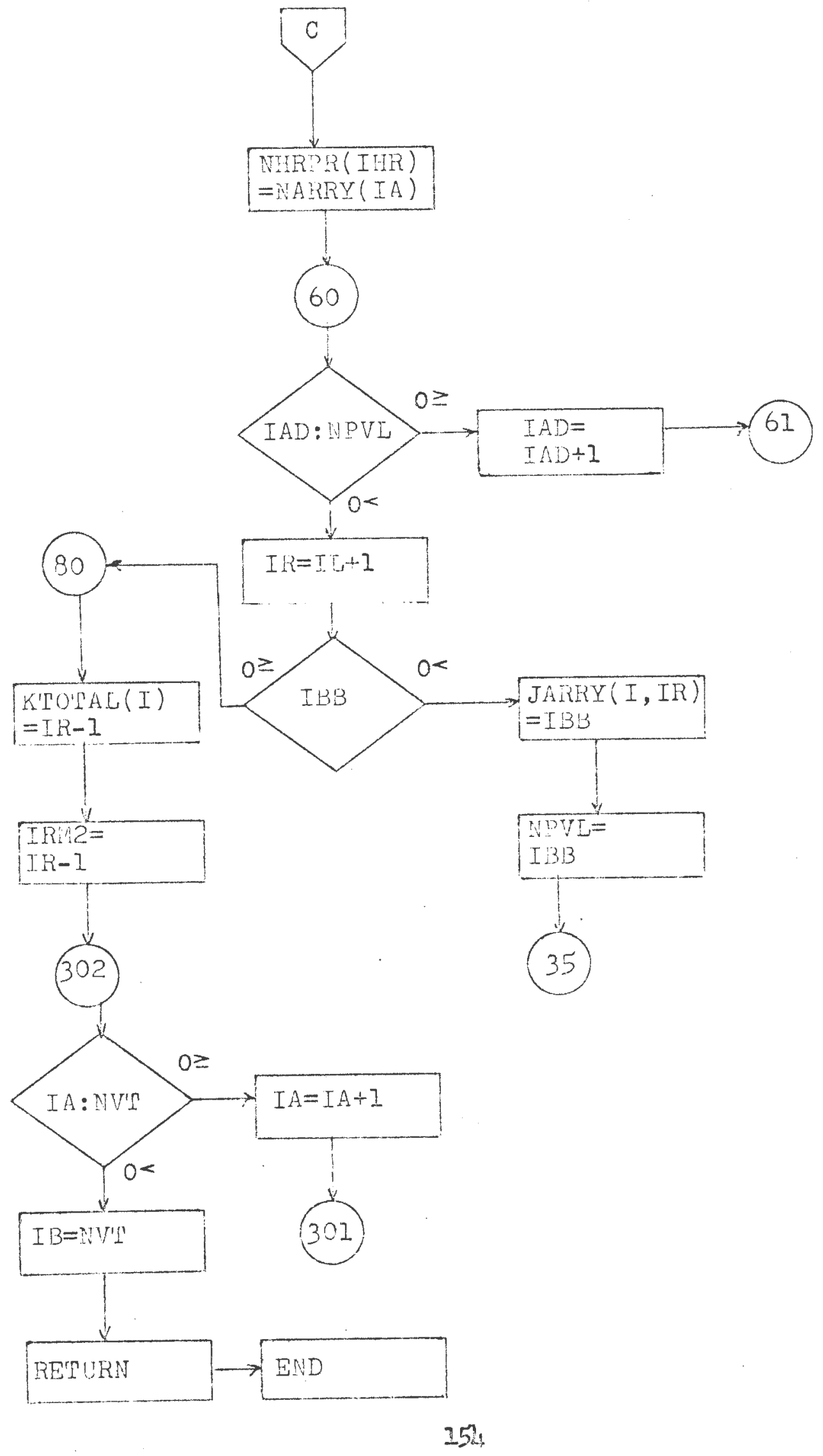


OUTPUT 


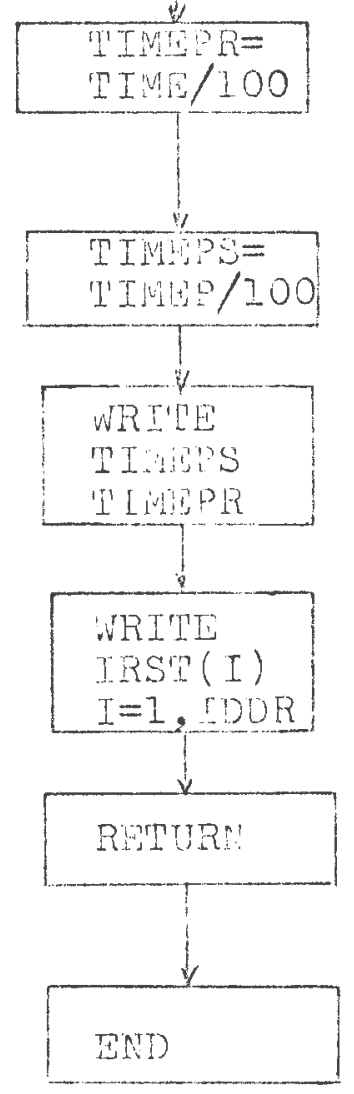




\section{BIBLIOGRA PHY}

Bennett, Carl and Franklin, Noman. Statistical Analysis $\frac{\text { in chemistry and the Chemical Industry. New York: }}{\text { John wiley and Sons, } 1967 \text {. }}$

Burling, Temple; Lenta, Edith; and Wilson, Robert. The Give and Take in Hosoitals. Now York: G. D. Putnam's Sons, 1956.

Burr, Trving, $N$. Engineoring, Stetistics and Quality Control. New York: McGraw-1iLI Book Co., 1953.

Crane, K. Centralized Patient Transportation and Orderly

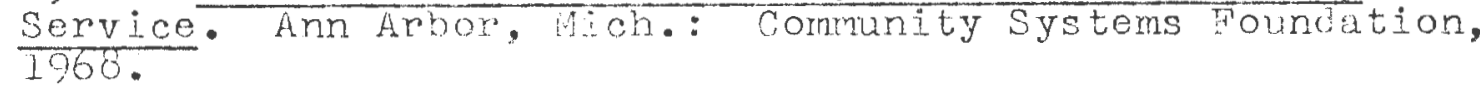

Giancola, D. Recommendations for the Improvement of Messenger Service. Ann Arbor, Mich.: Community Systems Foundetion,

Giancola, D。 Analysis Recuired to Create a Messenger Service. Arn Arbor, Mich.: Community Systems Foundation, 1.968.

Jupiter, Robert. "Patient Iransport Service Saves Valuable Nursing Hours". Hosoitals, Vol. / 2, No. 6. (Narch 16, 1968), pp. $53-57$.

Mactachern, Malcolm T.; Mospital Organization and Management. Chicago: Physician's Record Co., 1957.

Macleod, V. Messenger Service. Ann Arbor, Mich.: Community Systems Foundation, 1968.

Smalley, Harold E. and Freeman, John R. Hospital Industrial. Engineering. New York: Reinhold PubIishing Corp., 1966. 